\title{
Structure and diversity of the dry woodland savanna of northern Namibia
}

\author{
Dissertation
}

zur Erlangung des Doktorgrades an der Fakultät für Forstwissenschaften und Waldökologie der Georg-August-Universität Göttingen

vorgelegt von

Friedrich Patrick Graz

geboren in Northeim (Deutschland)

Göttingen, im Oktober 2004 
D7

1. Berichterstatter: Prof. Dr. K. von Gadow

2. Berichterstatter: Prof. Dr. R. Mitlhöner

3. Berichterstatter: Prof. Dr. J. Saborowski

Tag der mündlichen Prfung: Freitag der 04. Februar 2005

Diese Arbeit wurde durch die Niedersächsische Staats- und Universitätsbibliothek, SUB Göttingen, unter folgender Internetadresse veröffentlicht:

http://webdoc.sub.gwdg.de/diss/2005/graz/ 
Das walte Gott

Vater, Sohn und Heiliger Geist

— Dr. Martin Luther 



\section{Summary}

This dissertation is constituted of five scientific publications dealing with population structures and the spatial differentiation of trees within woodland savanna in northern Namibia. The dissertation emphasizes the importance of the ecological setting in which the species are found to support the management of the species in their natural circumstances.

The publications feed into the following two sections:

The first section deals with the ecological setting of the dry woodlands savanna, highlighting the interconnectedness of various determinant and modifying factors that affect vegetation development. This is dealt with in the following publications:

Graz, F. P. 2003. An HTML-based concept model of the dry savanna woodland ecosystem, for teaching and learning. Conservation Ecology 7(1): 9.

URL: http://www. consecol.org/vol7/iss1/art9.

Graz, F. P. submitted. Determinants of vegetation patterns in the dry woodland savanna of northeastern Namibia.

These are supported by the following four publications that deal with specific species found in the woodlands, but are of lesser significance.

Graz, F. P. 2004. Description and Ecology of Pterocarpus angolensis in Namibia. Dinteria 29:27-39.

Graz, F. P. 2002. Description and Ecology of Schinziphyton rautanenii (Schinz) Radcl.-Sm. In Namibia. Dinteria 27:1935.

Graz, F. P.. 2003. Fire damage to Schinziphyton rautanenii (Schinz) trees in North-Eastern Namibia. Dinteria 28:39-43. 
Graz, F. P. 2003. The growth of Schinziphyton rautanenii seedlings under different shade conditions. Dinteria 28:4446.

The second section deals with two different aspects of woodland structure in three subsections. Population structures of two prominent woodland species are described and analysed in relation to the ecological background. Based upon these descriptions and interpretations a yield regulation system is proposed for use in northern Namibia in the absence of growth data. The system considers the natural mortality rates of the woodland species as well as desired quantities of timber in a specific final size class. This is dealt with in the following publication:

Graz, F. P. \& von Gadow, K. submitted. Application of a Stem Number Guide Curve for sustainable harvest control in the dry woodland savanna of northern Namibia.

Finally, the importance of the spatial aspects of woodland structure is considered. A simulation model was developed and used to investigate the behaviour of the mingling index, Msp, that was subsequently used to quantify aspects of spatial structure. This is dealt with in the two publications below:

Graz, F. P. 2004. The behaviour of the species mingling index $M_{s p}$ in relation to species dominance and dispersal. European Journal of Forest Research 1:87-92.

Graz, F. P. in press. Assessing the spatial diversity of a dry savanna woodland stand in Northern Namibia using neighbourhood-based measures. Biodiversity and Conservation. 


\section{Zusammenfassung}

Die regen-grünen Trockenwälder Namibias erstrecken sich über eine Fläche von ca. $160.000 \mathrm{~km}^{2}$ im Nordosten des Landes in den Regionen Caprivi, Kavango und Otjozondjupa (nach Giess, 1998). Dieses stellt ungefähr $20 \%$ der gesamten Landfläche von Namibia dar. In den benachbarten Ländern Botswana und Sambia sowie in Zimbabwe gehen die Trockenwälder in die bekannten Miombo-Wälder über. Diese Region wird durch einen Wechsel von Regen- und Trockenperioden geprägt. Die Trockenwälder werden ausschliesslich auf sandigen Böden gefunden, die relativ arm an Nährstoffen sind.

Die Trockenwälder sind für die lokale als auch regionale Ökonomie dadurch von grosser Wichtigkeit, dass sie eine Vielzahl Rohstoffe für Nahrungsmittel, Baumaterial, Brennmaterial und verschiedene weitere Zwecke liefern. In Namibia sind 50-60\% der Landbevölkerung direkt oder indirekt und in verschiedenem Masse von diesen Rohstoffen abhängig; 1996 wurde der Gesamtwert der jährlich verbrauchten Rohstoffe auf ca. N\$1060mio geschätzt (NFSP, 1996).

Auf die Vegetation wirkt eine Reihe von Systemfaktoren ein, die in zwei Gruppen eingeteilt werden können (Graz, submitted). Auf der einen Seite stehen die „Determinanten“, d.h. diejenigen Faktoren die die potentielle Vegetation bestimmen. Dieses sind in erster Linie jene Faktoren, die den Wasserhaushalt der Böden bestimmen. In der Hauptsache handelt es sich hier also um Niederschlag und Verdunstung sowie die Zusammensetzung der Böden (Graz, submitted).

Demgegenüber stehen die „Modifizierenden Faktoren“, die auf die bestehende Vegetation einwirken, um strukturelle Veränderungen zu bewirken. Diese sind in erster Linie menschliche Einflüsse wie Bodennutzung, Weidewirtschaft, Holzeinschlag und das Sammeln von Feldfrüchten. Als weiterer und sehr wichtiger Faktor steht die Einwirkung von Feuer.

Feuer hat verschiedene Einflüsse, die entweder direkt oder indirekt auf die Vegetation einwirken. Hier steht in erster Linie die Hitze-Einwirkung 
auf einzelne Pflanzenteile. Einerseits werden Stämme direkt verbrannt oder nur das Kambium an einzelnen Stellen beschädigt. Andererseits werden Blätter und Blüten von denjenigen Baumarten versengt, die vor dem Ende der Trockensaison ausschlagen (Graz, submitted).

Indirekte Einflüsse sind diejenigen, die nach einem Brand wirken, z.B. erhöhte Schwankungen der Bodentemperatur und Bodenfeuchtigkeit sowie eine Änderung der inter- und intraspezifischen Konkurrenz um die im Boden gebundene Feuchtigkeit.

Die Pflanzenarten, die in den Trockenwäldern vorkommen, sind zu mehr oder minderem Masse an die verschiedenen Systemfaktoren angepasst, so dass die Zusammensetzung eines Bestandes je nach Intensität oder Frequenz einer Einwirkung schwanken kann.

Es ist auffallend, wie viele Anpassungen an die Einwirkung von Feuer beobachtet werden können. Neben der Keimung von Arten wie Pterocarpus angolensis, die durch Feuer stimuliert wird (van Daalen, 1991), kann bei Arten, die in geringerem Masse Feuer-anfällig sind, auch eine dickere Rinde festgestellt werden, die das Kambium gegen die direkte Hitzeeinwirkung schützt. Die meisten holzartigen Pflanzen schlagen ausserdem wieder neu aus, sollte der obere Teil der Pflanze ganz von einem Brand abgetötet bzw. abgeholzt worden sein (Graz, submitted).

In Abhängigkeit der Feuerfrequenz und -saison werden verschiedene Arten unterschiedlich bevorteilt. $P$. angolensis und Burkea africana beispielsweise werden mit zunehmender Feuerfrequenz häufiger angetroffen. Baikiaea plurijuga dagegen gedeiht nur wenn die Bestände vor Feuer geschützt werden (Graz, in press).

So können zum Beispiel anhand von verschiedenen Datensätzen Unterschiede in Populationsstrukturen von $P$. angolensis gezeigt werden, die vor allem auf unterschiedliche Feuerfrequenzen zurückzuführen sind. Auf den kommerziellen Farmen nahe der Trockenwälder ist das Brennen ganz eingestellt worden, was eine fast vollkommene Unterbindung der Etablierung von Jungpflanzen zur Folge hatte (Graz and von Gadow, submitted).

Im Gegensatz dazu brennt der Unterwuchs ein paar Kilometer entfernt jedes oder jedes zweite Jahr. Hier gibt es ausreichenden Jungwuchs, der die absterbenden Bäume ablösen bzw. ersetzen kann.

Diese Unterschiede werden dadurch hervorgerufen, daß die hohe Feuerfrequenz verschiedene Arten benachteiligt oder deren Entwicklung behindert, wodurch die Konkurrenz für die Jungpflanzen von Arten wie $P$. 
angolensis verringert wird.

Wenn also die natürlichen Prozesse und Störungen weiterhin auf die Bestände einwirken, ist es möglich, eine relativ gesunde Populationstruktur zu erhalten. Das heisst, es ist möglich einen Teil der Bäume zu entfernen, ohne dass die Baumpopulation dadurch gefährdet wird.

Um festzulegen wie viele Bäume von den verschiedenen Durchmesserklassen einem Bestand entnommen werden können, wird in dieser Arbeit mittels negativer Exponentialfunktion eine Plenterwaldkurve erzeugt, die eine stabile, nachhaltig nutzbare Populationsstruktur vorschlägt (Graz and von Gadow, submitted). Die Funktion baut sich auf die natürliche Mortalitätsrate der einzelnen Arten oder eines Gesamtbestandes auf, sowie auch auf eine gewünschte Bestandesgrundfläche oder Stammzahl. Anhand der Funktion wird eine Mindestanzahl von Bäumen in den einzelnen Durchmesserklassen berechnet, die benötigt werden, um die Population unter den herrschenden Bedingungen fortbestehen zu lassen.

Die Anwendung der Kurve wurde anhand verschiedener Datensätze erprobt. Es muss unterstrichen werden, daß die einzelnen Parameter der Funktion nicht nur als mathematische Grössen sondern auch als biologische Eigenschaften ausgewertet werden müssen (Graz and von Gadow, submitted).

Es ist möglich, daß durch die Störungen gleichzeitig eine räumliche Differenzierung von Baumarten sowie auch deren Durchmesserverteilungen entstehen kann. Die Feueranfälligkeit sowie auch andere systemgerichtete Anpassungen einzelner Arten lassen Bestände entstehen, die von wenigen Arten stark dominiert werden können (Graz, in press).

Die räumliche Differenzierung einzelner Arten lässt sich anhand des artenspezifischen Durchmischungsindex $M_{s p}$ quantifizieren. Es erwies sich jedoch als nötig, das Verhalten des Index gegenüber verschiedener Bestandesstrukturen zu beschreiben (Graz, 2004a). Hier wurde anhand einer Reihe von Simulationen festgestellt, daß $M_{s p}$ von der Artenzusammensetzung eines Bestandes sowie deren Durchmischung beeinflusst wird (Graz, 2004a). Es wird daher eine Normgrösse vorgeschlagen, mit der die gemessene Grösse verglichen werden kann, um eine Aussage über die eigentliche Durchmischung zu ermöglichen.

Die praktische Anwendung des Index und dessen Aussagekraft wurde in einem Bestand untersucht und bestätigt (Graz, in press). 



\section{Contents}

Summary $v$

Zusammenfassung vii

$\begin{array}{ll}\text { 1. Introduction } & 1\end{array}$

2. Ecological and Socio-Economic Background 7

2.1. Determinants ...................... 9

2.1.1. Terrain and Soil Factors . . . . . . . . . . . 9

2.1.2. Precipitation .............. . . . 10

2.2. Modifiers ................... 11

2.2.1. Direct Human Impact . . . . . . . . . . . . . . . . . 11

2.2.2. Grazing . . . . . . . . . . . . . . 12

2.2.3. Fire . . . . . . . . . . . . . 13

2.2.3.1. Fire Frequency . . . . . . . . . . . . 14

2.2.3.2. Fire Season . . . . . . . . . . . . 15

2.2.4. Plant Responses . . . . . . . . . . . . . 16

3. Aspects of Structure 19

3.1. Population Structures . . . . . . . . . . . . . 19

3.2. Yield Regulation in Namibian Woodlands . . . . . . . . 23

3.3. Spatial Diversity . . . . . . . . . . . . . . . . . 32

3.3.1. Determining Diversity . . . . . . . . . . . 32

3.3.2. Spatial Diversity . . . . . . . . . . . 34

4. Conclusion 45 
A. An HTML-based concept model of the dry savanna woodland ecosystem, for teaching and learning

A.1. Introduction . . . . . . . . . . . . . . . 50

A.2. HTML Modelling vs. Diagrams . . . . . . . . . . . . 52

A.3. Implementation Of The HTML Documents . . . . . . . 57

A.4. Discussion And Conclusions . . . . . . . . . . . . . 59

A.5. References . . . . . . . . . . . . . . 60

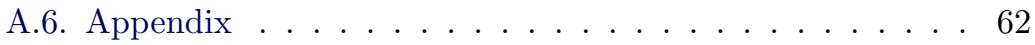

B. The behaviour of the species mingling index $M_{s p}$ in relation to species dominance and dispersal

B.1. Introduction . . . . . . . . . . . . . . . . . . . 64

B.2. Species Mingling . . . . . . . . . . . . 66

B.3. Description of the model . . . . . . . . . . . . . . 69

B.4. Results . . . . . . . . . . . . . . 70

B.5. Discussion . . . . . . . . . . . . 73

B.6. Conclusion . . . . . . . . . . . . . . . 74

B.7. Acknowledgements . . . . . . . . . . . . 75

B.8. References . . . . . . . . . . . . . . 75

C. Assessing the spatial diversity of a dry savanna woodland stand in Northern Namibia using neighbourhood-based measures $\mathbf{7 7}$

C.1. Introduction and Background . . . . . . . . . . 78

C.2. Spatial diversity and woodland structure. . . . . . . . 79

C.3. Description of the Study Area . . . . . . . . . . . . . . . 82

C.4. Material and Methods . . . . . . . . . . . . . . 83

C.4.1. The Interspersion of Tree Attributes . . . . . . . . 83

C.4.2. Uniform Angle Index . . . . . . . . . . . . . . . . 86

C.4.3. Sampling . . . . . . . . . . . . 87

C.5. Results and Discussion . . . . . . . . . . . . . . 88

C.6. Conclusions . . . . . . . . . . . . . . . . . . 94

C.7. Acknowledgement. . . . . . . . . . . . . . . . 94

C.8. References . . . . . . . . . . . . . . . . . 95

D. Determinants of vegetation patterns in the dry woodland sa$\begin{array}{ll}\text { vanna of northeastern Namibia } & 99\end{array}$

D.1. Introduction . . . . . . . . . . . . . . . . . . 99

D.2. Determinants, Modifiers and Species Responses . . . . . 101 
D.2.1. Determinants . . . . . . . . . . . . . . 101

D.2.1.1. Terrain and Soil Factors . . . . . . . . . 101

D.2.1.2. Precipitation . . . . . . . . . . . . . 104

D.2.1.3. Vegetation Responses . . . . . . . . . . 105

D.2.2. Modifiers . . . . . . . . . . . . . . 107

D.2.2.1. Direct Human Impact . . . . . . . . . 107

D.2.2.2. Grazing . . . . . . . . . . . . . . . 108

D.2.2.3. Fire . . . . . . . . . . . . . 110

D.3. Discussion and Conclusion . . . . . . . . . . . 116

D.4. Acknowledgements . . . . . . . . . . . . . . 117

D.5. References . . . . . . . . . . . . . . 117

E. Application of a Stem Number Guide Curve for sustainable harvest control in the dry woodland savanna of northern Namibia

E.1. Introduction . . . . . . . . . . . . . . . . . . . . 124

E.2. The Inverse Exponential Function . . . . . . . . . . 127

E.3. Application and Interpretation . . . . . . . . . . . . . . 133

E.4. Implementation of the curve . . . . . . . . . . . . . . . 134

E.5. Conclusion . . . . . . . . . . . . . . 137

E.6. Acknowledgements . . . . . . . . . . . . . 137

E.7. References . . . . . . . . . . . . . . . . . 137

$\begin{array}{ll}\text { Bibliography } & 141\end{array}$

$\begin{array}{ll}\text { Acknowledgements } & 151\end{array}$

$\begin{array}{ll}\text { Eidesstattliche Erklärung } & 153\end{array}$

$\begin{array}{ll}\text { Lebenslauf } & 155\end{array}$ 



\section{List of Figures}

1.1. Extent of the Dry Woodland Savanna in Namibia (after Giess, 1998) . . . . . . . . . . . . . . 2

1.2. Terrain features in the Kavango region (after Graz, 1999) 4

1.3. The soils that coincide with the savanna woodland vegetation (after Coetzee, 2001). The source of the data is at a scale of 1:1,000,000. Small-scale variations are therefore not visible. . . . . . . . . . . . . . . . 5

1.4. Fire frequency observed in parts of the woodland savanna from 1996 to 2000, compiled by J. le Roux and S. Trigg of the Etoscha Ecological Institute. . . . . . . . . . . 6

2.1. The identification of two distinct soil layers after the twolayer model of Walter (1971) . . . . . . . . . . . 8

2.2. Mean annual rainfall as given by the NAMSOETR data base $($ Coetzee, 2001) . . . . . . . . . . . . . 11

3.1. Diameter distributions of $P$. angolensis from Kanovlei (a) and farm Rooidag (b). The line graph in (a) is the negative exponential growth curve (after Graz and von Gadow, submitted). . . . . . . . . . . . . . 21

3.2. The dbh-class distribution of two hypothetical stands, with (a) $q=1.3(r=0.769)$; and (b) $q=1.4(r=0.714)$. In each case $N_{1}$ was 50 trees. . . . . . . . . . . 26

3.3. Dbh-class distribution based on a basal area of $B=20 \mathrm{~m}^{2}$, using $D=45 \mathrm{~cm}, h=5 \mathrm{~cm}$ and $q=1.6$, resulting in a total stocking rate of 1382 stems. . . . . . . . . . . . . 29 
3.4. Diameter class distributions modelled with equation 3.8 , using $q=1.6$ and: (a) $D=45$ with changing $B$, and (b) $B=20 \mathrm{~m}^{2}$, with changing $D \ldots \ldots \ldots \ldots \ldots$

3.5. The mingling of black, grey and white points within an area (after Graz, 2004a). . . . . . . . . . . . . 35

3.6. The relationship between the mingling complement, $1-$ $M_{B}$, for a species $B$, and the proportion $P(B)$ of trees that the species contributes to a stand, in which it is randomly interspersed with all other trees. . . . . . . . 38

3.7. The distribution of $M_{i}$ values of (a) beech and (b) ash in the Bovenden forest of Lower Saxony in Germany (with permission K. von Gadow). . . . . . . . . . . . . . . 40

3.8. The distribution of $M_{i}$ values for B. plurijuga (bars) and the expected hypergeometric distribution using equation 3.11. $M=0.298$. . . . . . . . . . . . . . . 4

3.9. The mingling of $B$. plurijuga, $P$. angolensis and $B$. africana with bars depicting the observed distribution of the $M_{i}$ values, and lines showing the expected distribution as determined using equation 3.12 . . . . . . . .

3.10. The aggregation of dead trees around the sample trees. Note the high degree of aggregation in the area dominated by $B$. plurijuga. The graph shows the mingling of dead trees in the area. $M=0.438 \ldots \ldots$. . . . . . . . 44

A.1. Schematic presentation of the factors that affect mortality of adult trees in the dry savanna woodlands . . . . . . . .

A.2. Schematic presentation of the factors that affect seedling establishment in the dry savanna woodlands . . . . . . . .

A.3. A causal loop type diagram that combines the mortality of trees in figure A.1 and the establishment of seedlings in figure A.2. The '+' and '-' signs indicate a positive and negative relationship between factors respectively . . . . .

A.4. Factors that affect woody plant mortality in the woodland system, with links indicating where the various factors influence one another . . . . . . . . . . . . .

B.1. The mingling of black, grey and white tree species within an area (after Gadow, 1999). . . . . . . . . . . . 
B.2. Hypergeometric probability distribution of $M_{i}$ values for species $A$ based on relatively high and low proportions of species $A$ in a stand respectively . . . . . . . . . 68

B.3. Species mingling of beech and ash in the Bovenden forest in Lower Saxony, Germany (with kind permission from Prof. K. v. Gadow) . . . . . . . . . . . . . . . . 69

B.4. The relationship between the probability with which species $B$ is assigned, $P_{(B)}$, in a single patch, and the complement of the mean mingling index $M_{B}\left(=1-M_{B}\right)$ for patches covering $100 \%, 75 \%, 50 \%$ and $25 \%$ of a stand. 71

B.5. The relationship between $M_{B}$ and the number of patches within which species $B$ may occur, with $P(B)=0.5$. . . 72

C.1. The mingling of black, grey and white 'trees' within two square stands (after Gadow 1999). . . . . . . . . . . . . 81

C.2. The dispersion of Baikiaea plurijuga, Pterocarpus angolensis and Burkea africa, within the study area. High values of $M_{i}$ are shown in large circles and vice versa. The graphs depict the observed relative distribution of $M_{i}$ values (bars), and the theoretical hypergeometric distribution (lines) of the values that would indicate a completely random interspersion of the species. . . . . . . . . . . 92

C.3. The aggregation of dead trees within the stand. The degree of interspersion is reflected by the size of the points, with a high degree of aggregation shown by larger points. $M=0.438 \ldots \ldots \ldots \ldots \ldots \ldots$

D.1. Section of an aerial photograph of the Kavango region, northern Namibia. The wide strips represent the dunes, while pans are visible as almost black patches within the streets as are cultivated fields. (DSM 1996) . . . . . . . . 101

D.2. A section through the dune and street complex after Graz (1996). Mixed vegetation (referred to as 'broken dune' vegetation by Graz (1999)) is a mixture of typical dune and street vegetation, and is found on very shallow dunes. 102

D.3. The separation of dune and street vegetation on individual farms (DSM 1996). . . . . . . . . . . . . . . 109 
E.1. The graphs show the hypothetical dbh-class distribution of two stands, with (a) $q=1.2$; and (b) $q=1.3 \ldots 129$

E.2. The distribution of trees in 10 dbh-classes that represent a sustainable population given the maximum diameter size, the number of diameter classes and the annual rate of reduction. . . . . . . . . . . . . . . 130

E.3. Guide curves for a tree species using $B=21 \mathrm{~m}^{2}$ with $D=50 \mathrm{~cm}$, and $B=13 \mathrm{~m}^{2}$ with $D=35 \mathrm{~cm}$. The value of $q=1.8$ remained constant. . . . . . . . . . . . . . 132

E.4. Diameter-class distribution of woody plants in a woodland stand near Kanovlei, Namibia (bars), and the hypothetical distribution with $N_{1}=10$, and $q=1.63 \ldots . .133$

E.5. The dbh-class distributions (bars) and the best fitting negative exponential curves of (a) Burkea africana, with $q=1.55(p=0.006)$; and (b) Pterocarpus angolensis, with $q=1.31(p=0.749)$ ignoring the poor fit of classes two and three in each case. . . . . . . . . . . . . . . 134

E.6. Diameter class distribution of non-timber trees in Kanovlei and the stem-number guide curve based on $q=2.5$ and $B=3 \ldots \ldots \ldots \ldots \ldots$ 


\section{List of Tables}

3.1. The calculation of $k_{3}$ with $D=40 \mathrm{~cm}$ and $h=5 \mathrm{~cm}$, (after Cancino and von Gadow, 2002). . . . . . . . . . 28

3.2. Values for $k_{3}$ for different values of $D$ and $q$ with $h=5 \mathrm{~cm} .28$

3.3. Two hypothetical woodland stands comprised of 1000 trees and five species. . . . . . . . . . . . . . 33

3.4. Shannon and Simpson indexes describing the stands shown in Table 3.3. Note that as the Simpson Index approaches 1, the index shows lower diversity. . . . . . . . 34

3.5. The Shannon and Simpson indexes for the two squares shown in Figure 3.5. . . . . . . . . . . . . . . . . 35

C.1. Mean of the various indicators for each of the identified species. $P(S p)$ denotes the proportion that a species contributes to the stand as a whole. The species specific indicators are: $W_{S p}=$ mean UAI, $D_{S p}=$ mean mortality, $M_{S p}=$ mean mingling, $T_{S p}=$ mean diameter dominance, and $H_{S p}=$ mean height dominance. The overall values for each indicator was calculated using the entire data set. 90

C.2. Comparing the proportion $P(S p)$ that a species contributes to the population with $\left(1-M_{S p}\right)$. ${ }^{*}$ Note that the value of $D_{S p}$ is used here (the mean proportion of dead neighbours), rather than the mingling index. . . . . 91

D.1. Tree species typically found on dunes and in the streets, after de Sousa Correira \& Bredekamp (1987), Giess (1998) and Burke (2002). . . . . . . . . . . . . 102 



\section{Introduction}

The dry woodland savanna in Namibia is found in the northeastern part of the country, extending through the Omaheke, Otjozondjupa, Kavango and Caprivi regions of the country (Figure 1.1) into Angola, Botswana, Zambia and Zimbabwe. The vegetation was first described by W. Giess in 1971, but later revised by the same author (Giess, 1998). Within Namibia the vegetation covers an area of roughly $160,000 \mathrm{~km}^{2}$ as part of a broader category classed as Baikiaea-vegetation by Werger and Coetzee (1978).

The woodlands constitute an important supply of essential resources for the local communities. Wood is extracted for a variety of purposes including building, fencing and as firewood, but also for saw-timber or to support the local carving industry. Non-timber products include food, medicine, thatch grass and grazing. In 1992 alone the wood and nonwood products that were extracted by the informal sector were valued at almost $\mathrm{N} \$ 1060$ million (NFSP, 1996).

The soils that support the woodlands are dominated by unconsolidated aeolian material, generally referred to as Kalahari Sand (de Pauw and Coetzee, 1999).

The sand covers a layer of calcrete to form a terrain of sandy plains or a system of east-west orientated linear dunes (Graz, 1999) as shown in Figure 1.2. Satellite data from the Directorate of Forestry and aerial photos of the Otjozondjupa region show that these features continue into the Caprivi and Botswana. In the interdunal zones (locally termed 'streets') the calcretous soils may be exposed.

The region is traversed by few perennial rivers such as the Okavango and Kwando/Linyanti and by omuramba (vegetated dry river beds) of unconsolidated fluvial sands (de Pauw and Coetzee, 1999). The street and omuramba soils are shallower than the dunes, have a heavier texture (Anon, 1971), and are generally considered more productive than the dunes.

The different soil types (Figure 1.3) give rise to noticeably different 


\section{Introduction}

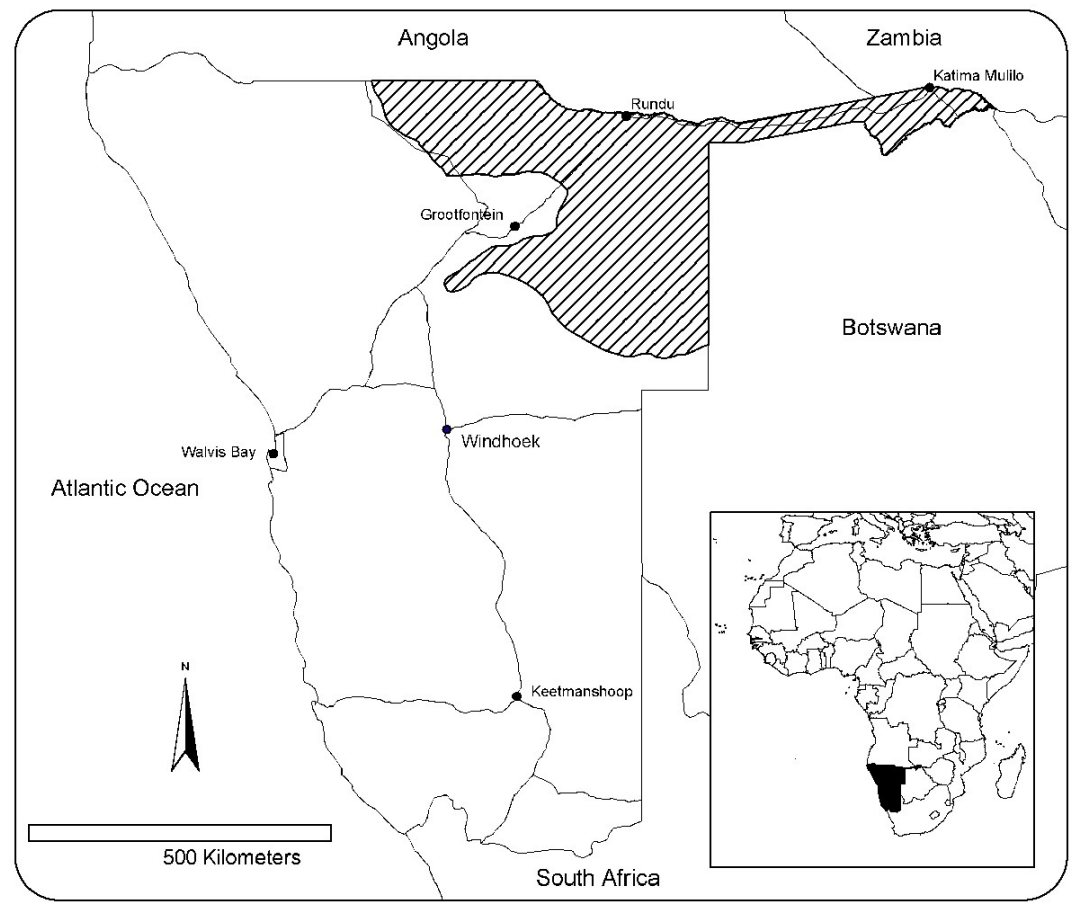

Figure 1.1.: Extent of the Dry Woodland Savanna in Namibia (after Giess, 1998)

species composition. Broadleaved trees such as Pterocarpus angolensis, Schinziophyton rautanenii, Guibourtia coleosperma, Baikiaea plurijuga or Burkea africana are found on the deep sands while various species of Acacia, Ziziphus mucronata and Dichrostachys cinerea dominate in the omuramba and streets (Giess, 1998; Burke, 2002). This differentiation of vegetation may be attributed to differences in soil moisture holding capacity.

The actions and interactions of various abiotic and biotic factors (including human influences) dictate the structure of the woodlands or modify it to result in an irregular patchwork of species composition, growth forms and population structure of the component species (von 
Breitenbach, 1968; Chakanga, 1995; de Sousa Correira and Bredenkamp, 1987; Graz, 1996; Burke, 2002). Some of these will be described in more detail later.

The vegetation is frequently affected by wildfires, mostly of anthropogenic origin (Goldammer, 1998). This is probably the single most important factor that modifies the structure and spatial diversity of the woodland vegetation, apart from the direct influence of human activities.

This is not a recent development as fire has influenced savanna type vegetation for several thousand years. Each year vast tracts of land are burnt in southern Africa. Trigg (1998) estimated that approximately $67 \%$ and $75 \%$ of the Caprivi region were burnt respectively in 1996 and 1997. Figure 1.4 shows the frequency of fire recorded over a large part of the woodland areas in the five-year period 1996 to 2000. The fire frequency recorded in the figure reflects a patchwork of different fire histories that is reflected to some degree in woodland composition.

The timing and frequency of burning plays an important ecological role. On the one hand the germination of the seed of some species is improved (see van Daalen, 1991), while the regeneration and adult trees of other species may be killed (Graz, 2003b). Because of its significant ecological importance, fire is dealt with in more detail in the following sections.

The purpose of this study is to identify and evaluate a number of structural characteristics of the dry woodland savanna. To assist the understanding of the structural development this thesis provides a brief summary of the ecological and socio-economic setting of the vegetation in Namibia. Subsequent sections then highlight specific structural traits and evaluate these in terms of causes and their implications for future vegetation development and management. 


\section{Introduction}

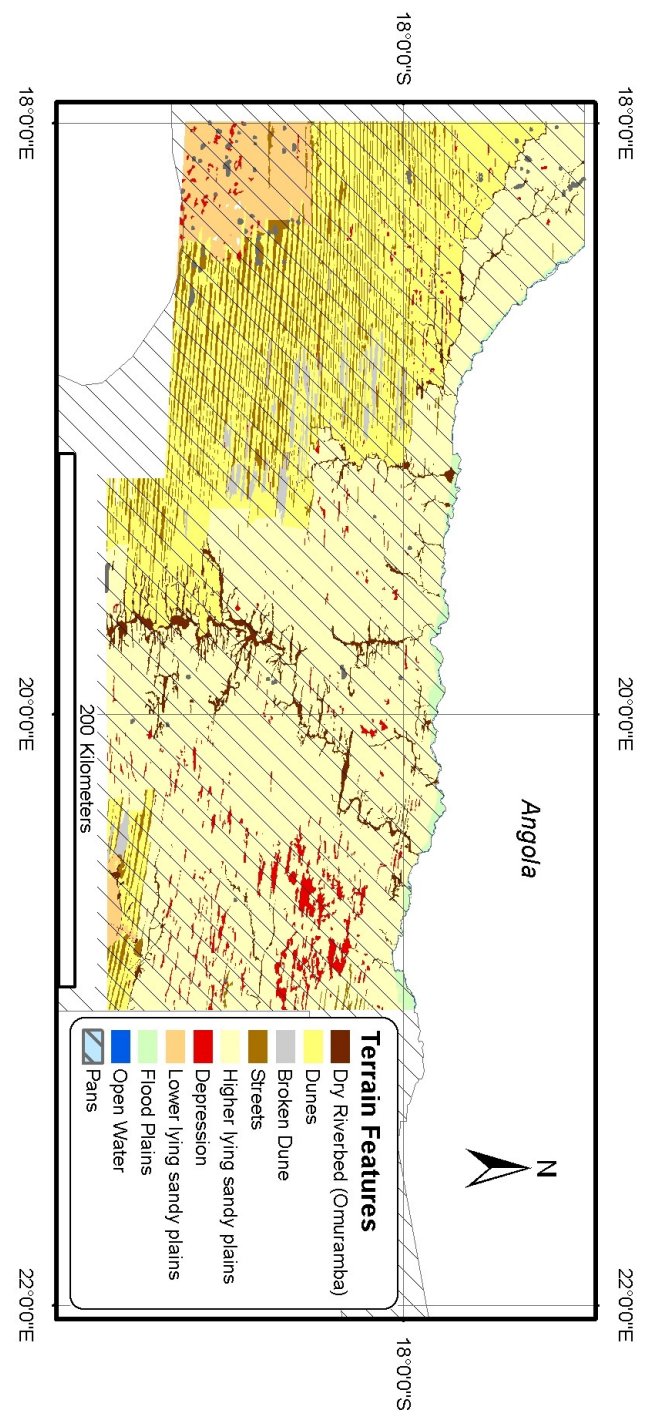

Figure 1.2.: Terrain features in the Kavango region (after Graz, 1999) 


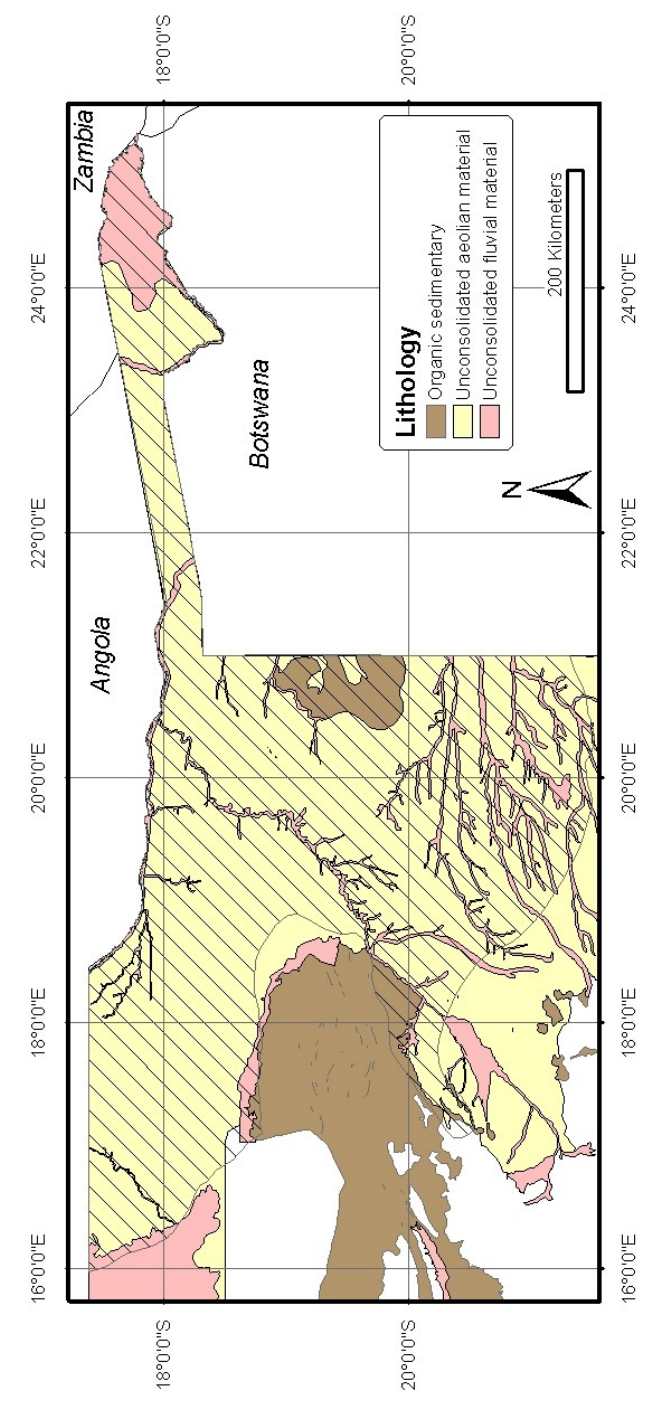

Figure 1.3.: The soils that coincide with the savanna woodland vegetation (after Coetzee, 2001). The source of the data is at a scale of $1: 1,000,000$. Small-scale variations are therefore not visible. 


\section{Introduction}

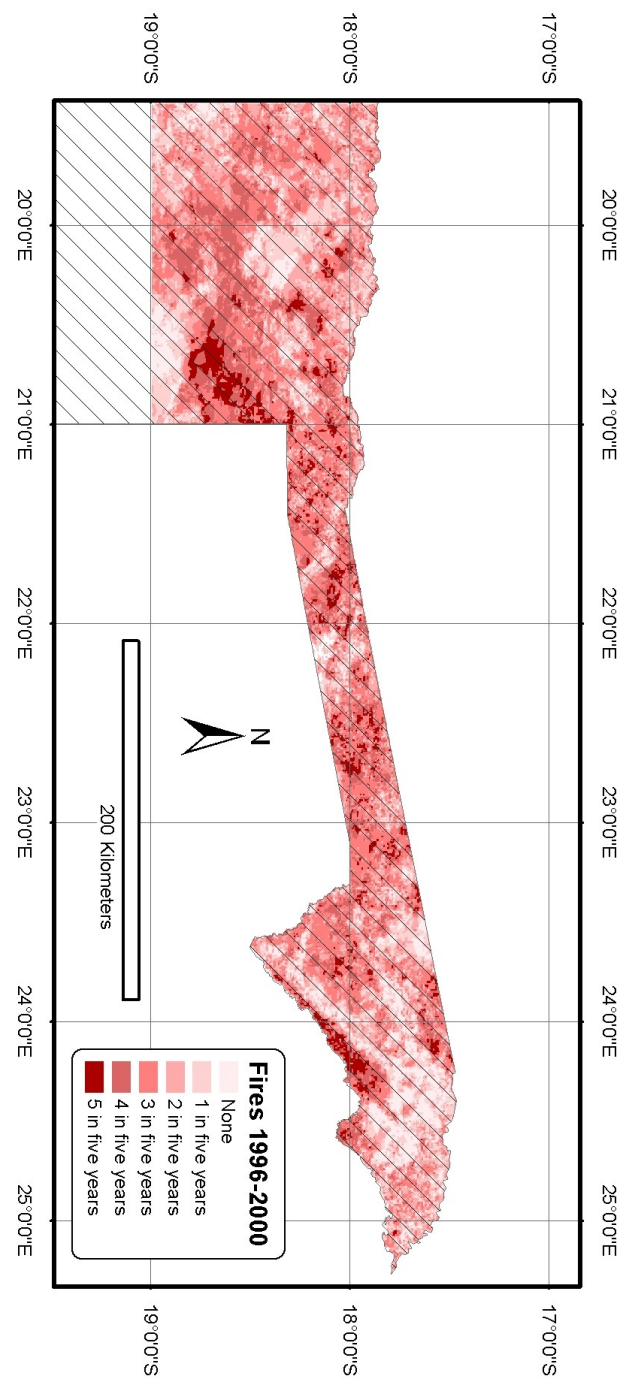

Figure 1.4.: Fire frequency observed in parts of the woodland savanna from 1996 to 2000 , compiled by J. le Roux and S. Trigg of the Etoscha Ecological Institute. 


\section{Ecological and Socio-Economic Background}

Research carried out in woodland type vegetation in the past assumed the validity of the two-layer model originally proposed by Walter (1971) and later elaborated upon by Walker and Noi-Meir (1982). The model divides the vegetation into a herbaceous and woody plant component that access soil water at different soil-depths, as illustrated in Figure 2.1 .

In accordance with the theory, the fine adventitious roots of grass plants, the main constituents of the herbaceous vegetation, would primarily colonize the topsoil while those of the woody components are concentrated in the sub-soil. Water infiltrating the soil after an effective rainfall event would initially be available to the herbaceous vegetation. Once the requirements of this vegetation component is met or exceeded the surplus water would percolate into the lower lying soil layer to be available to the woody plants.

Although the rooting strategies of the herbaceous and woody components did not adhere as strictly to the model, Knoop (1982) concluded in her study that the two-layer model was nevertheless applicable to the Burkea-savanna of the Nylsvlei Reserve in South Africa. The species composition and soils in parts of this reserve are comparable to those of Namibia's woodland areas.

The relationship between woody and herbaceous vegetation is not entirely one-way. The herbaceous plants are outcompeted for light when the woody vegetation develops sufficient canopy cover (Graz, 2003b).

The model implies that any factor acting on one part of the vegetation may ultimately affect the water balance and therefore the system functioning as a whole. For instance, heavy grazing may affect a reduction in the herbaceous cover, and subsequently the herbaceous plant fuel. This would eventually result in a less intense or even delayed burn with direct benefit to the woody plant component. 


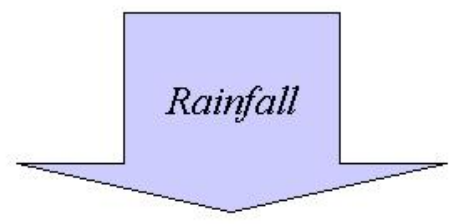

Water infiltration

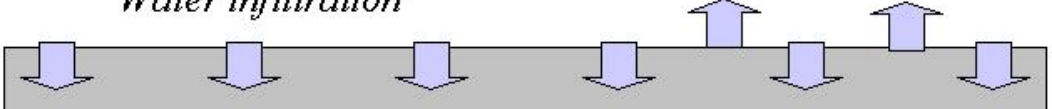

Uptake of water by herbaceous vegetation
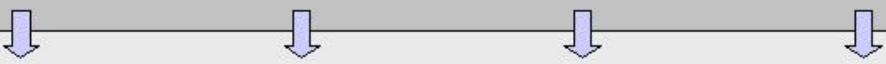

\section{Evaporation}

Root zone for woody vegetation

Figure 2.1.: The identification of two distinct soil layers after the two-layer model of Walter (1971)

On the other hand, a fire may simply reduce the amount of fuel in the woodlands without significantly affecting the woody plants. However, this would in turn affect the amount of grazing available. Should the grazing be too little for the demands made by game and domestic animals, the grasses may be severely overgrazed benefiting the woody plants.

In order to provide a systematic approach for describing or modelling the interactions of the various factors that enact on the vegetation. Graz (2003b) proposed an HTML model of the savanna processes. The approach is particularly effective in modelling feedback-loops that are otherwise difficult to follow.

Since the presentation of the two layer model Scholes and Walker (1993) have proposed an alternative temporal separation model supporting a division of resource use in time rather than space, and briefly discuss the potential implications. No further research seems to have been carried out to support this model, although there is a substantial amount of corroborating evidence. This will not be dealt with here, and 
interpretation of ecological events will be in terms of the more widely accepted model.

The factors that govern the dry woodland savanna, as discussed in the following sections, may be divided into two groups (Graz, 1996, submitted). The potential vegetation structure is controlled by the determining factors, represented by those factors that influence the available soil moisture; primarily soil characteristics, rainfall and evaporation (Scholes and Walker, 1993).

The modifying factors, on the other hand, alter the environment or the effect of the determining factors to favour one group of species or growth form over another, or affect individual species or growth forms directly. These factors are generally of anthropogenic origin in the form of grazing, resource extraction ${ }^{1}$ and fire.

What follows is a short introduction to the determining and modifying factors to facilitate a better understanding of their importance.

\subsection{Determinants}

\subsubsection{Terrain and Soil Factors}

Individual studies of dune type soils by Helgren (1982) and Mitlöhner (1997) as well as unpublished data from different parts of the woodland savanna report sand and fine sand components of 90-96\% (see also Coetzee, 1999). This texture has important implications for the soil moisture balance by influencing the water holding capacity and hydraulic conductivity of the soil.

The texture affects the amount of moisture that the soil may retain as cohesion and adhesion water. Sand grains have a much smaller surface to volume ratio when compared to smaller soil particles so that there is a lower surface area to which water may adhere (Foth, 1990).

Although the presence of organic material would generally increase the water holding capacity, the environmental conditions present in the area are not conducive to organic matter build-up. The highly variable soil moisture, particularly in the top-soil, severely retards decay, while periodic fires reduce the matter that may nonetheless have accumulated (Malaisse et al., 1975).

\footnotetext{
${ }^{1}$ Land clearing for cultivation is here regarded as part of resource extraction
} 
Since the pore spaces between the individual soil particles in sand are notably larger than in heavier soils it would be expected that drainage through sand is also much faster. This is true for water-saturated soils, but the hydraulic conductivity decreases with decreasing soil moisture (Foth, 1990, p.62). Water infiltration into very dry soils is therefore relatively slow. On very hot days, after a dry period, water drops may be observed to remain on the soil surface for up to a few minutes before entering the ground or evaporating. Runoff is nevertheless extremely limited on the dune soils, although on the heavier soils between the dunes some water may accumulate in scattered pans (Graz, submitted).

In addition, Helgren (1982) and Coetzee (2001) report a low nutrient status for these soils. Helgren (1982) considers that most nutrients are stored in the plants rather than in the soil. This implies that the periodic fires would result in an overall reduction of the available nutrients in the root zone of the woodland plants, although this could not be confirmed.

\subsubsection{Precipitation}

The sub-region in which the woodland savanna occurs is characterized by a distinct cycle of wet and dry periods. The wet season in Namibia extends from the end of September to around mid March, with the remainder of the year dry. Long term observations have shown a distinct moisture gradient from the south-western parts of the woodland areas towards the north-east of the region (see Figure 2.2). Average rainfall ranges from $400 \mathrm{~mm}$ in the south-west to over $700 \mathrm{~mm}$ in the far eastern parts of the Caprivi strip (Amakali, 1992; Coetzee, 2001).

Significant annual variations in both the amount and timing of precipitation occur, making rainfall highly unpredictable. Individual rainfall events often occur as thunderstorms (Graz, 1996), that may sometimes cover extensive areas but frequently are localized. At a smaller scale therefore, significant spatial variation exists in the timing and amount of rain (Graz, submitted).

The effectiveness of rainfall events is modified by interception from the vegetation. Although some intercepted water will evaporate from the vegetation, a proportion will reach the soil as through-fall and stemflow. The latter, stem-flow, represents a concentrated application of water around the base of a tree that results in a zone of increased soil moisture around the tree (de Villiers and de Jager, 1981). 


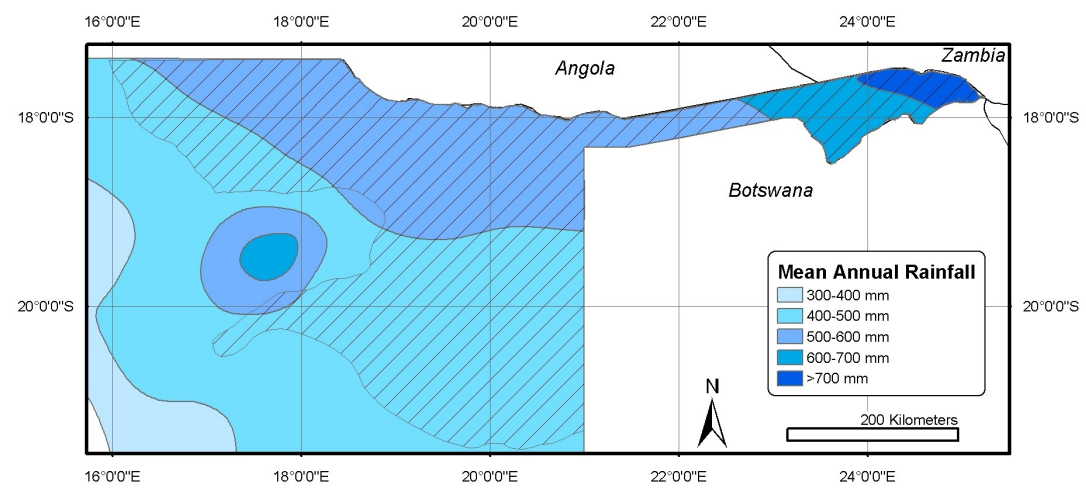

Figure 2.2.: Mean annual rainfall as given by the NAMSOETR data base (Coetzee, 2001)

Evapotranspiration over the savanna woodland area in Namibia is estimated at between $2600 \mathrm{~mm}$ and $2800 \mathrm{~mm}$ per annum Crerar and Church (1988) also increasing from the south-west to north-east. Based on the resulting moisture deficit, and combined with temperature requirements for active growth, de Pauw and Coetzee (1999) estimated a growing period of between 91 and 135 days for the woodland areas.

\subsection{Modifiers}

\subsubsection{Direct Human Impact}

While the woodland savannas cover around $20 \%$ of Namibia's land area the same area supports between 50 and $60 \%$ of the country's population (Mendelsohn et al., 2002) who extract a wide variety of resources from the woodland to support their day-to-day lives, as indicated previously (see Le Roux, 1971; van Rooyen, 2001). Most of the area is used for subsistence farming under communal management.

The total amounts of resources that are used annually and the number of plant species involved are quite substantial, and the selective pressure on some species or size classes may cause a change in woodland composition. This has not been documented in Namibia, but is reflected in 
the number of different tree species now used by the carving industry. This represents a change from previous, casual observations in 1993/94 when most carvings were made from $P$. angolensis.

In his study in South Africa Columba (2003) also observed that the number of tree species in his study area declined when human influence increased, especially at the edges of the woodland areas.

Changes in vegetation structure are not limited to changes in species composition but also affect tree population structures. For example, Shackleton (1993) had observed in South Africa that specific size classes of trees were targeted for firewood, depending on how easily the wood could be handled. While this has also not been recorded as such in Namibia, the diameter distributions presented by Graz and von Gadow (submitted) suggest that the same is true here.

\subsubsection{Grazing}

Since the majority of the woodland area is not suitable for cultivation due to the poor moisture and nutrient holding capacity of the soils, land use practices concentrate on livestock farming.

A volume of literature that deals with grazing practices and the effects of grazing on grass plants is available but will not be reviewed here (see Tainton, 1999, for a comprehensive discussion of grazing and grazing practices in Southern Africa). It is necessary, however, to highlight two of the issues that affect general vegetation development.

Generally, the effect of grazing must be considered in terms of the frequency, i.e. the time between grazing events, and intensity, i.e. the amount of material that is removed over a given period of time.

With the establishment of commercial farms in the southwestern sections of the woodlands permanent water points were established in areas previously without permanent surface water. This permitted farmers to retain cattle on the farms throughout the year. While a system of rotational grazing/rotational resting is generally implemented on these farms, the resulting grazing patterns are different to those of the unmanaged wildlife populations that occurred in the area prior to the establishment of farms (see Savory and Butterfield, 1999).

Commercial farming practices have been implemented over the last 40 years in the northeastern parts of the Grootfontein magisterial district. Differences in fire regimes and grazing management practices be- 
tween the communal and commercial farming areas have resulted in clear differences in vegetation development (Graz, 1996). Water points are currently under development in many communal areas and it must be expected that the surrounding vegetation will be affected as well.

\subsubsection{Fire}

As already indicated, the woodland areas of Namibia are frequently subject to fires. While some fires are started by natural causes (Siegfried, 1981) the majority of fires are now a result of human action (Goldammer, 1998).

The effect of fire may be considered in two ways. On the one hand is the direct damage to various plant parts caused by heat. Late season burns (see later) may damage newly formed leaves and flowers of those species that sprout before the onset of the rains (Graz, submitted).

Less evident are the indirect effects of a burn. The soils in the denuded areas are not only exposed to wind erosion but also to stronger variations in temperature and moisture contents. This affects a number of processes such as decomposition as well as the establishment of young seedlings.

In the past, fire was an important traditional management tool in the woodland areas of Namibia, primarily to manage grazing. Traditional authorities had implemented strict control systems to regulate burning of the veld (Kotze, 1968). If a person had wanted to burn to remove the grass of the previous year, shortly before the next rain season, he would have to obtain the permission of the Chief (Wandres, 1909, p.676). Now, however, most of these systems have degenerated or been abolished altogether as the power of some traditional courts was eroded (Tuomasjukka et al., 1998). Goldammer (1998) also highlights the decline in nomadic habits of the indigenous people. The latter, together with the growing population of Namibia, has caused an increased demand on the woodlands. Not only is the demand for firewood increasing, but there is also an increase in the incidence of fire in the woodland areas.

The effect of fire on the vegetation is significantly affected by timing and frequency of burning (Graz, 2003b) due to the influence of these two factors on the intensity of fire and subsequent damage. 


\subsubsection{Fire Frequency}

The frequency of fire refers to the number of fires that occur over a given period of time. Important is not so much the number of fires that occur, but the period between two successive burns. This period represents the time that is available for plants to recover from the effects of one fire (Trollope, 1982), and for young plants to outgrow a stage where they might be severely damaged or killed by the next.

The interval also represents the time available for a fuel load to accumulate prior to the next burn. When time intervals are short, the fuel load consists primarily of leaf litter and grasses. As the length of the period is extended twigs, branches and eventually whole trees will be added. This accumulated fuel load significantly affects the potential damage caused by the next burn as the amount and flammability of the herbaceous and woody fuels influence the intensity of the burn.

When the general development of the vegetation is considered it becomes evident that the future influences on the vegetation and the severity of the impact of these influences are a function of the current condition of the vegetation. The current condition again is a function of past influences. During his simulation study, Peterson (2002) determined that an area might show an ecological memory. In his study Petersen determined that the probability of a fire in an area would increase if the area had previously been burnt.

In general terms the ecological memory implies that the probability with which an event occurs is affected by (similar) disturbances in the past, since the event or disturbance changes the condition of the vegetation, which in turn changes the probability that a similar event or disturbance is repeated. The concept is supported by the earlier findings of $\mathrm{Li}$ et al. (1999) that an area's susceptibility to fire is determined by its condition. The condition in turn is a function of the fire history ${ }^{2}$.

The findings of Peterson (2002) are also in line with other observations from the field. Scholes and Walker (1993, p.224) maintain, for instance, that a grass-dominated vegetation will be maintained by recurrent fires. The smaller sized grass fuels in turn increase the likelihood

\footnotetext{
${ }^{2}$ Such ecological memory may also be displayed in relation to other factors. Light grazing, for instance, indirectly results in the rejuvenation of grass plants, with the younger material being more palatable to grazing animals (after Wolfson, 1999; Wolfson and Tainton, 1999). Other such cycles are not as clearly apparent.
} 
of fire (Heikkila et al., 1993).

\subsubsection{Fire Season}

The term fire season is somewhat misleading, since fires are generally confined to the dry season, from around late April to the end of September. The effect of fire and the response of the vegetation change with the timing of a burn within the dry season. As the dry season progresses the fuel becomes increasingly dry, particularly the small fuels. This increases its flammability, and allows it to burn at a higher intensity later in the season ${ }^{3}$. It is in this context and due to the physiological status of the woodland plants that the fire season is divided into an early season, i.e. early in the dry season, and a late season.

At the beginning of the fire season, when fuel is still comparatively moist fires are less intense, and it is possible that not all fuel is consumed. At the same time most of the deciduous woody plants have reached physiological dormancy (Lawton, 1978), although species such as $B$. plurijuga and $B$. africana may continue to grow longer into the dry season. Dormancy of the woody plants and a lower fire intensity result in less damage to woody plants than a fire later in the season (Rutherford, 1981). In the long run, therefore, early burning favours the woody plant component of the woodlands.

At the same time, the perennial grasses have also reached dormancy but a burn may stimulate the grasses to flush ('out of season flushing'). Due to a lack of water the above ground parts of the grasses will eventually die off, however. At the onset of the next growing season the grasses will not sprout as vigorously (Tainton, 1999), thus weakening the herbaceous layer, and delaying the accumulation of the herbaceous fuels.

On the other hand, a fire that occurs towards the end of the dry season may result in considerably more damage to the woody vegetation, as plants start to break dormancy. This may then result in damage to leaves, flowers or immature fruit of those plants/species that flush before the onset of the first rains ${ }^{4}$.

\footnotetext{
${ }^{3}$ The rate of combustion reflects the intensity of a burn, i.e. the energy released per unit time, which in turn influences the effect of the fire.

${ }^{4} \mathrm{~A}$ number of species produce flowers and leaves before the onset of the rains. These include $P$. angolensis, T. sericea, S. rautanenii and others.
} 
Clumps of woody plants may develop due to incomplete burns and start to shade out much of the herbaceous growth, with a concomitant reduction in the herbaceous fuel load and likelihood of fire. Consequently in order to promote the formation of closed woodlands, management burns would need to be carried out early in the dry season (Trapnell, 1959; Geldenhuys, 1977a; Chidomayo, 1988).

\subsubsection{Plant Responses}

The responses of the vegetation and its component species to the external factors form an independent group of variables, although it may be argued that current species adaptations and species requirements are also a form of response to the long-term environmental conditions. Below is a brief, though by no means exhaustive summary of the adaptations of woodland species.

Many of the adaptations that were documented enable the trees to cope with fire. A number of woodland species exhibit cryptogeal germination (the plumule is buried in the soil during the development of the root crown.) The buds on the root crown are therefore protected from fire (Walker et al., 1986) therefore enabling the plant to coppice from below ground if the aerial parts are removed.

The suffrutex behaviour documented for P. angolensis by Vermeulen (1990) permits a young plant to develop a root system to a size that will support a large, permanent trunk. S. rautanenii and B. africana follow a similar strategy, although this has not been described as such in the literature.

The thick bark developed by some species provides further protection against fire. Hare (1965) had determined that the time required by fire to kill the cambium of a tree is dependent on the thickness and thermal conductivity of the bark. Wilson and Witkowski (2003) suggested that $B$. africana trees with a dbh of less than around $13 \mathrm{~cm}$ were killed by fire, as the bark was not yet thick enough to protect the cambium. The authors assume that trees outgrow their susceptibility since bark thickness of the species increased with tree diameter. Vermeulen (1990) reported a similar relationship between bark thickness and diameter for P. angolensis.

When the bark of adult trees is damaged physically, the tree will become more susceptible to fire damage. This was reported by Yeaton 
(1988) for B. africana, and by Shackleton (2002) for P. angolensis. Further observations in the field and those reported by Graz (2003a) show that growth stresses are also able to cause a breach of the bark of $S$. rautanenii and $P$. angolensis.

When trees are damaged at the base or extracted most are able to coppice, noticeably again $P$. angolensis (Vermeulen, 1990) but also Terminalia sericea (Teague and Killilea, 1990), Ochna pulchra (Walker et al., 1986), S. rautanenii and Guibourtia coleosperma. The coppicing ability is not limited to the woodland trees, but is frequently observed for shrubs, like Grewia flava, G. flevescens, Baphia massaiensis and Bauhinia petersiana. 
2. Ecological and Socio-Economic Background 


\section{Aspects of Structure}

Vegetation structure may be considered as the organization of individuals that form a stand, vegetation type or plant association (Edwards, 1983). In his text Edwards limited the primary elements of structure to growth form, stratification and coverage. Von Gadow (1999) extended the concept to include the distribution of any tree characteristic within a forest or stand. It is therefore not only possible to describe stand structure in terms of species, tree size (through diameter, height, crown dimensions or other quantity), sex, stress symptoms or mortality, but also in terms of the spatial distribution of these characteristics within an area and in relation to each other.

\subsection{Population Structures}

Traditionally, forest inventory practices have concentrated on those structural characteristics that are important for timber management, i.e. age or size class distributions (see von Gadow and Breedenkamp, 1992, p.30). The presence of trees of certain ages or sizes, i.e. the size structure of the tree population, not only indicates the allowable cut for a given period but also facilitates prediction of future states of the forest, therefore indicating if sufficient raw materials of different sizes will be available (von Gadow, 1988).

Inventories in Europe and north America now also consider the naturalness of forests, often linked to their diversity (Zenner, 1998). The author considers diversity primarily in terms of species composition. However, when a forest stand is considered its diversity should be assessed in terms of other structural components as well:

When dealing with plantation forests, such as those established in South Africa, Australia or Brazil, individual stands are segregated on the basis of species and planting date. Since genetically similar material is used the trees within the stands are generally of similar size unless 
there is sufficient variation in growing conditions. Such stands therefore show little diversity in terms of species, age, tree size or even genetic composition.

The woodlands of northern Namibia are by nature closer towards the other end of the structural scale, i.e. the continuous cover forest scenario described by Seydack (2001); trees of different species, size and age are found within a single forest stand. Unlike it is the case under plantation conditions, natural regeneration replaces those trees that are removed from a stand either through exploitation or natural causes. Since the trees in the stands are of different ages, the harvesting of trees of a particular dimension does not need to result in the clearing of whole areas $^{1}$.

Disturbance or manipulations of stands may, however, be required to maintain the multi-age structure since competition may suppress the regeneration and cause an even sized stand to develop. This is not only the case in temperate forests, as described by Guldin (2001), but also under woodland conditions in Namibia.

Diameter distributions from different parts of the country indicate that periodic disturbances, and particularly fire, are necessary to rejuvenate at least some of the woodland species. In this context consider the dbh-class distributions of two P. angolensis provided in Figure 3.1. The species occurs throughout much of the woodland areas and is of significant socio-economic importance (Graz, 2004b).

Figure 3.1(a) reflects the dbh-structure of of a stand in a communal area near Kanovlei as opposed to that on a commercial farm $40 \mathrm{~km}$ east of the Kanovlei stand Figure 3.1(b).

The differences between the two distributions are very distinct. The Kanovlei data (a) follows the inverse-J diameter distribution (Graz and von Gadow, submitted) characterised by a large number of plants in the smallest size class. The number of plants in the subsequent size classes show a high degree of mortality. Mortality then decreases and the number of plants stabilizes.

It is clear that the number of trees in the third size class, i.e. between 5 and $15 \mathrm{~cm}$ in diameter (white bars), are considerably fewer than suggested by the negative exponential growth curve superimposed on

${ }^{1}$ Under some conditions a near-clearfelling may actually result, as described by von Breitenbach (1968). See also later in text. 


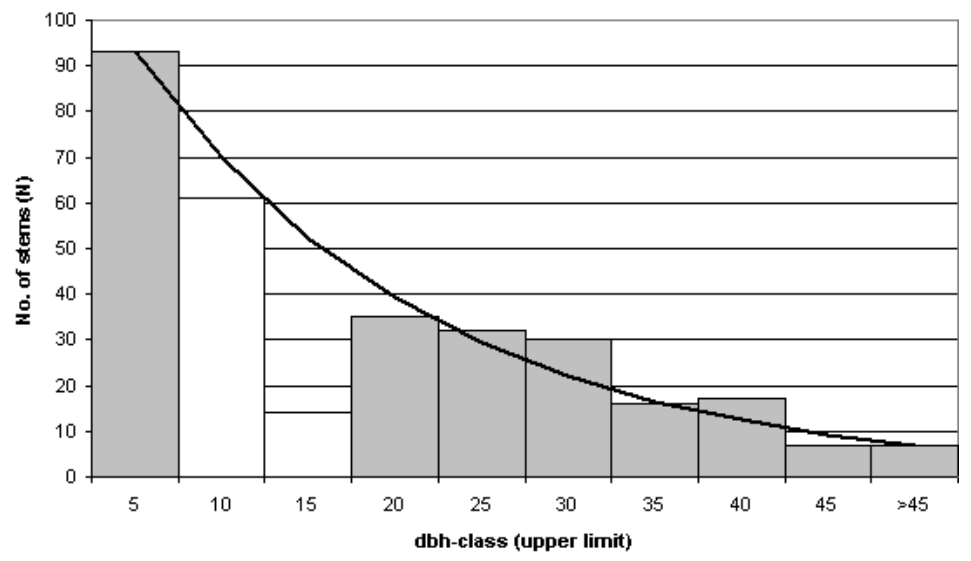

(a)

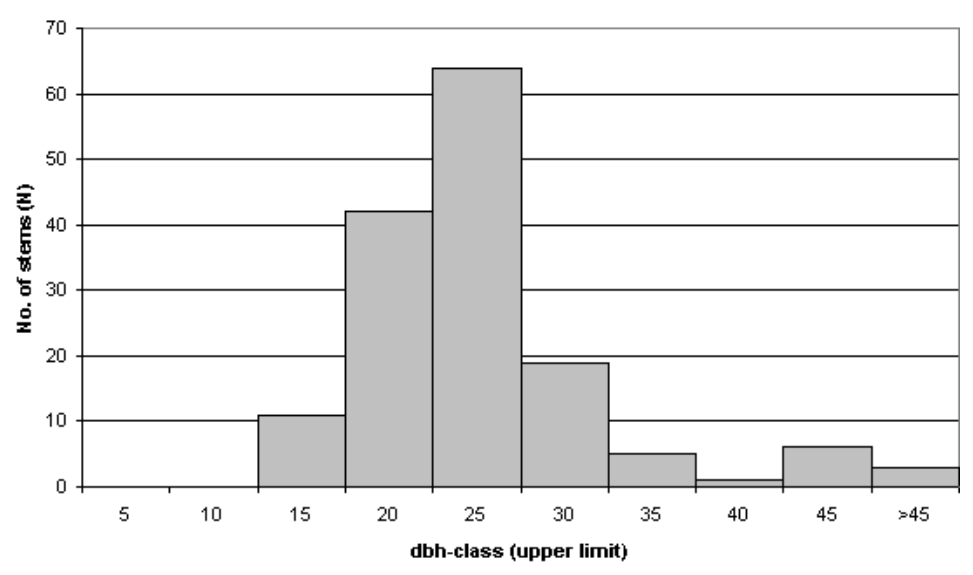

(b)

Figure 3.1.: Diameter distributions of $P$. angolensis from Kanovlei (a) and farm Rooidag (b). The line graph in (a) is the negative exponential growth curve (after Graz and von Gadow, submitted). 
the diameter distribution. This may be a result of selective harvesting by a nearby community. The third size class in particular is used in the construction of housing. No records of actual removal were kept, however.

In contrast, the data from farm Rooidag (Figure 3.1(b)) follows a positively-skewed distribution as might be generated using the Weibull function. No trees are recorded with a dbh smaller than $10 \mathrm{~cm}$, implying that there has been no regeneration for some time. The comparatively low number of plants in the third and fourth size classes indicate that the decline in regeneration may have been gradual rather than sudden.

The cause of these different population structures is probably a result of the difference in general vegetation management. Consider that the farm had been established about thirty years prior to the assessment.

The farm was subject to a relatively constant grazing pressure over the years, while government policy discouraged the use of fire as a rangeland management tool. Combined, these factors, i.e. the elimination of fire and the consistent grazing pressure, had resulted in divergent development of the vegetation in general (Graz, 1996), with more undergrowth found on the farms.

This had various effects on the $P$. angolensis regeneration. For instance, the germination of the specie's seed is significantly improved by fire (van Daalen, 1991), so that the implementation of the no-burn policy effectively reduced germination success. The lack of fire also permitted the establishment of denser woody undergrowth that suppressed any seedlings that had been able to become established.

Constant grazing also reduced the competition between the herbaceous and woody vegetation components in general, further favouring the development of the woody undergrowth - in terms of the two-layer theory.

The two scenarios depicted by the two diameter distributions are not unique to Namibia. Shackleton (2002) found a dbh-structure following the inverse-J pattern at Bushbuckridge, South Africa. According to that author the area is burnt annually or biannually. Schwartz et al. (2002) on the other hand found the structures in Rukwa, Tanzania, to be similar to that on farm Rooidag. The authors stated that the area burnt repeatedly, but did not indicate fire frequency, and had interpreted the lack of regeneration to be caused by direct damage by grazing animals. Under present circumstances the inverse-J population structure must be 
considered the healthier and more sustainable.

\subsection{Yield Regulation in Namibian Woodlands}

A large scale inventory was conducted (see Korhonen et al., 1997a,b) to provide a general overview of the tree resources rather than to obtain detailed data for the development of a yield regulation system or even management plans (Korhonen pers com.). As such, Namibia is significantly lacking in growth data to assist in yield regulation (Hangula, 1999). This deficit of information seems to be a problem throughout Southern Africa for some of the woodland species (Shackleton, 2002).

Due to the different ages of trees and varying degrees of inter-tree competition within a stand, site index values and single tree growth models are not readily implemented, making yield regulation considerably more complex than for single species or even-aged stands. Recall that the diameter increment of a tree is affected by stand density, or rather the degree of competition between a tree and the remainder of the stand. Growth models would therefore not only have to consider site quality but changes in the degree of competition (such as in terms of stand density) as well. The task is complicated further by the relationship between growth and rainfall, such as reported by Stahle et al. (1999) for P. angolensis.

Considering a general lack of available manpower, information and general resources in Namibia any yield regulation system would need to be simple to implement without being simplistic. Since some areas are managed by unschooled people guidelines should be provided in terms of stem numbers rather than timber volumes. Here it is useful to develop a guide curve that would define a desirable population structure in terms of numbers of trees in a particular dbh-class for a given area.

In order to establish guidelines for yield regulation Schwartz et al. (2002) had modelled a P. angolensis population with a dbh-structure that followed the inverse-J distribution using a Markov type model (see also Suzuki, 1983). The stable state distribution obtained through their model followed a similar dbh-class distribution. The technique facilitates relatively simple calculations of future dbh-structures with the transition from one diameter class to the next, completely independent of transitions between other size classes. However, the construction of 
a Markov model requires a significant amount of data to determine the elements of the transition matrix. Also, Stahle et al. (1999) had found that diameter growth rates would change due to changes in environmental conditions, so the transition between size classes is not readily predictable.

Childes (1984) used a similar approach to model the progression of Baikiaea plurijuga through a series of developmental stages rather than size classes but was unable to obtain appropriate transition probabilities.

Graz and von Gadow (submitted) show on the other hand that the diameter distribution of some woodland trees may be described using the negative exponential growth curve. Since the mathematical manipulations of the exponential equation are relatively simple, and its implementation requires significantly less data than the matrix model approach, the negative exponential curve may serve to assist yield regulation under certain circumstances. In general terms the function is used to determine a sustainable population structure that considers the desired stocking of a stand, and a specific maximum diameter, while the stand is subject to a given, constant mortality rate. The negative exponential function has the general formula:

$$
N_{i}=k_{0} \cdot e^{-k_{1} \cdot d_{i}}
$$

where $N_{i}$ is the number of trees in size class $i$, while $k_{0}$ and $k_{i}$ are factors that control the shape of the curve. Here $k_{0}$ represents the intercept of the graph with the y-axis, while $k_{i}$ affects the rate of change from one diameter class to the next larger, and with $d_{i}$ representing the diameter class midpoint of class $i$.

The negative exponential function implies that the number of plants will decline at a constant rate, $r$, from any dbh-class, $j$, to the next larger class, $j+1$. In demographic terms the value of $r$ therefore denotes the mortality rate from one size class to the next, and is obtained through:

$$
r=\frac{N_{j+1}}{N_{j}}
$$

In order to develop the growth curve, for a specific target tree-size it is necessary to define a quantity $q$, that is the exact inverse of $r$ :

$$
q=r^{-1} \quad \text { or } \quad q=\frac{N_{i+1}}{N_{i}}
$$


where $N_{i}$ is the number of stems in diameter class $i$, and $N_{i+1}$ the number of stems in the next smaller diameter class (Cancino and von Gadow, 2002).

The quantities $r$ and $q$ are interpreted as follows. For instance, a value of $r=0.80$ indicates that $80 \%$ of trees advance from a dbh-class to the next larger diameter class. Values of $r=1$ or $r=0$ imply that all or no trees would advance to the class respectively. Similarly, $q=1$ means that there is no change in tree numbers between two successive classes, while a value of $q<1$ results in an increase from one class to the next smaller dbh-class. Values of $q$ smaller than 1 should not be obtained.

Further manipulation of the equation 3.3 leads to equation 3.4:

$$
N_{i}=N_{1} \cdot q^{i-1}
$$

where $N_{1}$ is the number of trees in the largest diameter class. This permits the calculation of a required number of trees in all other dbhclasses given a specific value for $r$ and subsequently $q$, and a number of trees in the largest diameter class.

The dbh-class distributions presented in Figure 3.2, were generated using equation 3.4 , with $N_{1}=50$ trees, to show the sensitivity of the distribution to the value of $q$. Note that the stands differ in their total growing stock of 879 and 1193 stems in Figures 3.2(a) and 3.2(b) respectively.

It must be kept in mind, that the number of diameter classes that comprise the distribution are an important variable; equation 3.4 had shown that the number of stems in a dbh-class is calculated using the number of classes rather than the diameters themselves.

The number of classes, $n$, would be determined by specifying a maximum permissible tree diameter, $D$, beyond which trees should not grow, as well as a suitable class width, $h$, and calculating:

$$
n=\frac{D}{h}
$$

Although it is mathematically possible to use non-integer values of $n$ in further calculations the value of $h$ should rather be chosen in such a way that $n$ is an integer value to ease interpretation.

When evaluating the number of classes or the class width it is essential to note that a change in the number of classes would result in a different 


\section{Aspects of Structure}

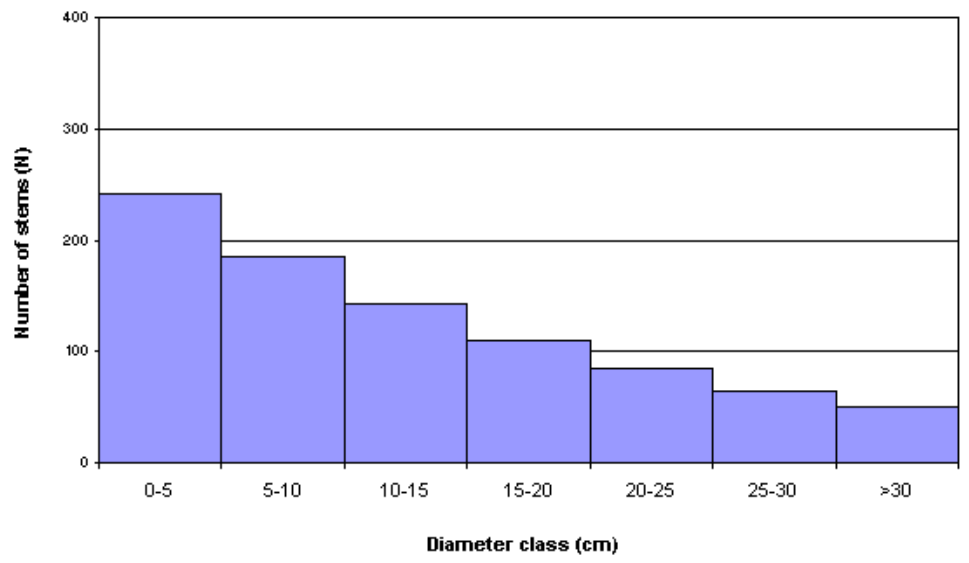

(a)

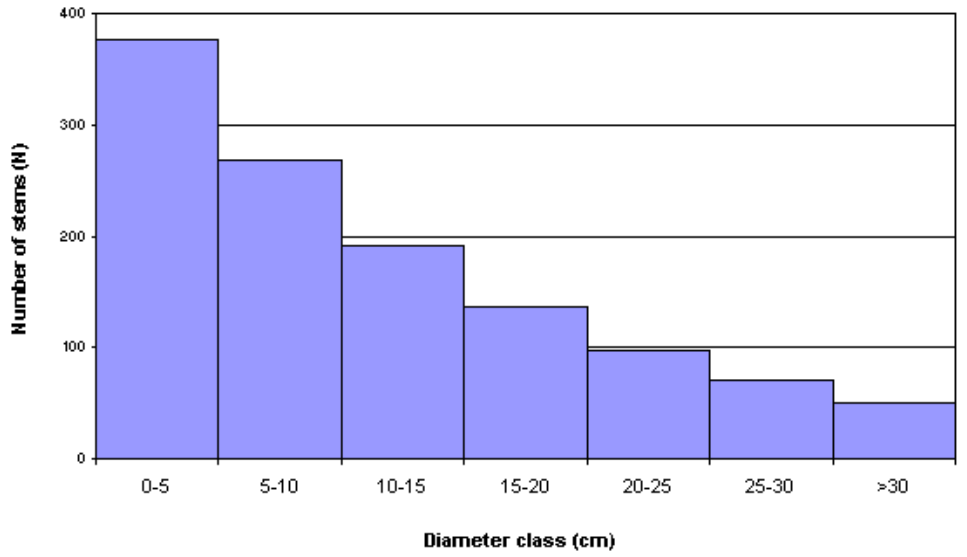

(b)

Figure 3.2.: The dbh-class distribution of two hypothetical stands, with (a) $q=$ $1.3(r=0.769)$; and (b) $q=1.4(r=0.714)$. In each case $N_{1}$ was 50 trees. 
stocking rate if the value of $q$ is not adjusted as well. To maintain a specific stocking rate for a specific stand or area it is therefore necessary to manipulate the two values together such that:

$$
q=e^{k_{1} \cdot h}
$$

For a full derivation of equation 3.6 refer to Cancino and von Gadow (2002).

When $q$ is estimated using actual stand data it is possible to use this value to generate a guide curve that recommends a minimum number of trees for each diameter class. The tree population could be harvested sustainably only if the trees in excess of this residual minimum number within each dbh-class were removed.

Since the value of $N_{1}$ forms the basis from which the remainder of the guide curve is derived, its value must be established with care. Apart from setting $N_{1}$ arbitrarily it is possible to calculate a value based on a specified total stocking rate, $G$, or total basal area, $B$, given specific values of $q$. The methods are presented respectively in equation 3.7 and equation 3.8. Cancino and von Gadow (2002) provide the derivation for these equations:

$$
N_{1}=\frac{G}{\sum q^{i-1}}
$$

and

$$
N_{1}=\frac{B}{k_{2} \cdot \sum q^{(i-1)} \cdot d_{i}^{2}}
$$

where $k_{2}=\pi / 40000$. The factor $k_{2}$ is used to convert the dbh-class midpoint, given in centimetres, to an equivalent basal area in square meters.

It must again be emphasized that the denominator of equation 3.8 needs to be calculated separately, based on the values of $q$, and the number of diameter classes (Graz and von Gadow, submitted).

$$
k_{3}=k_{2} \cdot \sum q^{(i-1)} \cdot d_{i}^{2}
$$

Table 3.1 and Table 3.2, provide examles of the calculation of $k_{3}$, for different values of $D$ and $q$. Table 3.1 illustrates the steps used to compile $k_{3}$, while Table 3.2 provides values of $k_{3}$ for different values of $D$ and $q$. 


\begin{tabular}{|c|c|c|c|c|}
\hline & & & \multicolumn{2}{|c|}{$q$} \\
\hline Dbh-Class (cm) & $d_{i}(\mathrm{~cm})$ & $\mathbf{i}$ & 1.2 & 1.4 \\
\hline $0-5$ & 2.5 & 8 & 0.002 & 0.005 \\
\hline $5-10$ & 7.5 & 7 & 0.013 & 0.033 \\
\hline $10-15$ & 12.5 & 6 & 0.031 & 0.066 \\
\hline $15-20$ & 17.5 & 5 & 0.050 & 0.092 \\
\hline $20-25$ & 22.5 & 4 & 0.069 & 0.109 \\
\hline $25-30$ & 27.5 & 3 & 0.086 & 0.116 \\
\hline $30-35$ & 32.5 & 2 & 0.100 & 0.116 \\
\hline $35-40$ & 37.5 & 1 & 0.110 & 0.110 \\
\hline \multicolumn{3}{|c|}{$k_{3}$} & 0.460 & 6.49 \\
\hline
\end{tabular}

Table 3.1.: The calculation of $k_{3}$ with $D=40 \mathrm{~cm}$ and $h=5 \mathrm{~cm}$, (after Cancino and von Gadow, 2002).

\begin{tabular}{|c|c|c|c|c|c|}
\hline \multirow{2}{*}{$\begin{array}{l}\text { Maximum } \\
\text { dbh (cm) }\end{array}$} & \multirow[b]{2}{*}{$\begin{array}{l}\text { No. of } \\
\text { classes }\end{array}$} & \multicolumn{4}{|c|}{$q$} \\
\hline & & 1.2 & 1.4 & 1.6 & 1.8 \\
\hline 20 & 4 & 0.046 & 0.051 & 0.057 & 0.063 \\
\hline 25 & 5 & 0.095 & 0.112 & 0.131 & 0.154 \\
\hline 30 & 6 & 0.173 & 0.216 & 0.269 & 0.336 \\
\hline 35 & 7 & 0.291 & 0.385 & 0.513 & 0.688 \\
\hline 40 & 8 & 0.460 & 0.649 & 0.932 & 1.349 \\
\hline 45 & 9 & 0.693 & 1.050 & 1.633 & 2.570 \\
\hline 50 & 10 & 1.009 & 1.648 & 2.789 & 4.803 \\
\hline
\end{tabular}

Table 3.2.: Values for $k_{3}$ for different values of $D$ and $q$ with $h=5 \mathrm{~cm}$. 


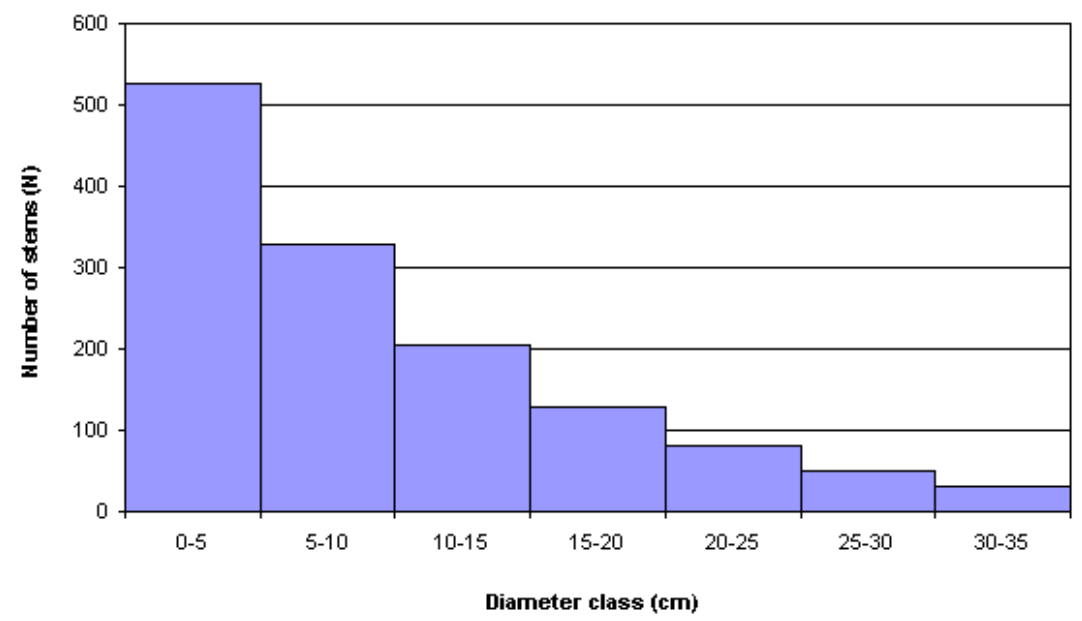

Figure 3.3.: Dbh-class distribution based on a basal area of $B=20 \mathrm{~m}^{2}$, using $D=45 \mathrm{~cm}, h=5 \mathrm{~cm}$ and $q=1.6$, resulting in a total stocking rate of 1382 stems.

Given a total basal area per hectare of $B=20 \mathrm{~m}^{2}$ for a stand, a maximum dbh of $D=45 \mathrm{~cm}$, a diameter class width of $5 \mathrm{~cm}$ and a value of $q=1.6$ would result in the diameter distribution provided in Figure 3.3 .

Specifically, equation 3.9 yields a value of $k_{3}=1.633$, while equation 3.8 is used to determine the number of trees in the largest diameter class, $N_{1}=12$. The remainder of the dbh-class distribution is obtained using equation 3.4 .

When dbh-class distributions are determined on the basis of a desired basal area, but using different values of $h$ with the appropriate value for $q$, it is important to note, that the total stocking rates will also change. Note that the basal area in each dbh-class is based solely on the class midpoint, thus ignoring any diameter variations within the class.

Using the above methods to develop a guide curve it is tempting to manipulate the value of $q$ to obtain a distribution reflecting desirable maximum tree dimensions and numbers of trees that could be exploited in the larger size classes. It is important, that the biological interpreta- 
tion of $q$ is borne in mind, however. The value of $q$ is directly linked to the natural mortality rates affecting the tree population. While raising the value would reflect a poorer survival, a lowering of $q$ would imply improved survival, which cannot be guaranteed under the circumstances.

To obtain a desirable stocking rate it is therefore more appropriate to manipulate the values of $B$ and/or $D$. This is illustrated in Figure 3.4(a) and Figure 3.4(b) that reflect the changes in the two parameters. In order to facilitate comparison between the two graphs, note that the curve marked $B=20 \mathrm{~m}^{2}$ in Figure 3.4(a) is the same as that marked $D=45$ in Figure 3.4(b).

While it is possible to determine a single guide curve for a whole stand to encompass all species at the same time, it must be borne in mind that not all species would be extracted. Graz and von Gadow (submitted) therefore suggested that the trees in a stand be allocated to the following three classes:

\section{Class I: Principal timber species}

The reproductive stages of species harvested for timber, including seedlings, suffrutex or coppice, saplings, immature and mature trees.

Class II: Non-timber trees

All stages of tree species that provide non-timber products.

\section{Class III: Dead trees}

Dead trees that are also unable to coppice.

Given the limited knowledge of the growth and development of the individual species within a class it may be more practical to develop combined guide curves for a class as a whole. This should be an interim measure until more knowledge of the demography of the individual species is available. It would of course be more desirable to establish guide-curves for individual species, since not all trees will be used within the same diameter classes and have different survival values. For instance, P. angolensis is usually harvested when it exceeds a diameter of about $45 \mathrm{~cm}$, while $B$. africana is exploited from the smaller size classes.

There may be some uncertainty with the classification of some species. G. coleospermum and S. rautanenii, for instance, produce fruit but are also exploited by the carving industry. In such cases it is necessary 


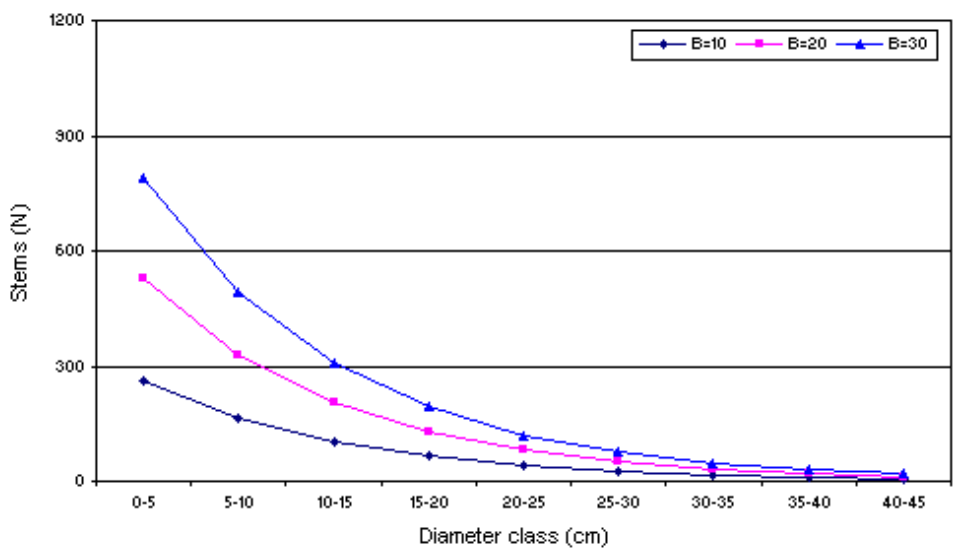

(a)

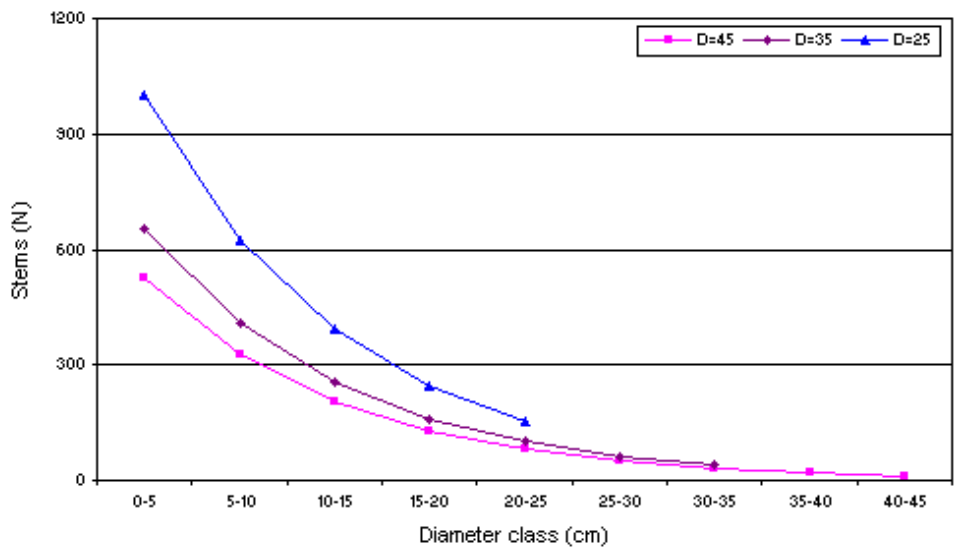

(b)

Figure 3.4.: Diameter class distributions modelled with equation 3.8, using $q=$ 1.6 and: (a) $D=45$ with changing $B$, and (b) $B=20 \mathrm{~m}^{2}$, with changing $D$. 
to determine the primary resource that a tree provides in an area and classify the species accordingly.

\subsection{Spatial Diversity}

When the occurrence of a particular species or vegetation is studied, the scale at which this is done must be taken into account (Levin, 1992; Turner et al., 2001). To illustrate this, consider the following example:

On a global or continental scale the species Schinziophyton rautanenii occurs in a very limited area, in a belt across the southern African subregion (Peters, 1987). Within this region the species occur in patches, depending on the spatial distribution of growth factors, such as the availability of deep aeolian sands (Helgren, 1982). At a local scale - that is, within a stand - a species might show an aggregated, random or regular (sometimes referred to as overdispersed) distribution pattern such as described by Begon et al. (1986). Measures such as the nearest neighbour or the uniform angle index can be used to quantify such distribution patterns.

In view of interspecific interactions, however, the distribution of a species should not be considered in isolation, but needs to be regarded in relation to other species. At global level this may be done by comparing the region of occurrence of different species. Where such regions overlap closer investigation may evaluate the patches in relation to each other using landscape metrics (see McGarigall et al., 2002). Should such patches overlap, however, the diversity of overlapping areas and the intermingling of species becomes relevant.

\subsubsection{Determining Diversity}

Diversity has in the past often been equated with the number of species that comprise a stand, i.e. the species richness of the stand. This approach has two basic shortcomings, however. The first is the need for a decision regarding the species to be included in the species list. Should birds, reptiles and woody plants be included? Should trees and grasses be included? Trees and insects?

In his review Roche (2001) suggests that those organisms be included that are at a given level of interest Taxonomic groups, such as trees 


\begin{tabular}{|l|r|r|}
\hline Species & Stand A & Stand B \\
\hline \hline Schinziophyton rautanenii & 200 & 960 \\
\hline Pterocarpus angolensis & 200 & 10 \\
\hline Burkea africana & 200 & 10 \\
\hline Terminalia sericea & 200 & 10 \\
\hline Combretum collinum & 200 & 10 \\
\hline Number of Trees & $\mathbf{1 0 0 0}$ & $\mathbf{1 0 0 0}$ \\
\hline Species richness & $\mathbf{5}$ & $\mathbf{5}$ \\
\hline
\end{tabular}

Table 3.3.: Two hypothetical woodland stands comprised of 1000 trees and five species.

and mammals, or individual growth forms, could be used to identify or delineate such levels.

The second problem with equating species diversity with richness is that all species are included on an equal footing irrespective of the number of individuals a species may contribute. The problem may be illustrated using the example provided in Table 3.3, adapted from Zar (1999) and Magurran (1988).

Each of the two stands in the table is comprised of 1000 trees, belonging to five different species. While the different species in Stand A are represented equally with two-hundred individuals each, Stand $B$ is severely dominated by one species (S. rautanenii). Although the two stands are clearly different in composition, the diversity expressed as species richness would classify them as being equal.

Popular diversity indexes such as the Shannon, Brillouin or Simpson indexes therefore consider the contribution of a class (species) towards the diversity of a stand as a function of the proportion or the number of individuals contributed by each class (see Magurran, 1988).

According to Zar (1999) the Shannon index is sensitive not only to the distribution of the species counts, but also to the number of species identified. The index is therefore often augmented by a measure of evenness that compares the calculated index with the maximum possible diversity for the number of species included in the index ${ }^{2}$.

${ }^{2}$ An equivalent evenness index may also be calculated for the Brillouin index. The index and evenness could not be conputed due to insufficient computing power, 


\begin{tabular}{|l|c|c|}
\hline Index & Stand A & Stand B \\
\hline \hline Shannon & 1.609 & 0.223 \\
\hline Simpson & 0.199 & 0.922 \\
\hline Shannon Evenness & 1.000 & 0.139 \\
\hline
\end{tabular}

Table 3.4.: Shannon and Simpson indexes describing the stands shown in Table 3.3. Note that as the Simpson Index approaches 1, the index shows lower diversity.

Table 3.4, provides the Shannon and Shannon based evenness indexes for the two stands shown in Table 3.3.

Here, Stand $A$ is regarded as more diverse than Stand B, and with the species much more evenly represented in Stand $A$ as well. In view of the composition of the two stands this result is intuitively more acceptable.

\subsubsection{Spatial Diversity}

The diversity indexes identified above provide a summary statistic for a stand in general only, as they are based solely on the numbers of trees of each contributing species. While this is important in itself, the description does not indicate if different species are isolated in distinct parts of a stand or if they are part of a mix of species in the stand as a whole, i.e. their spatial dispersion.

Consider the two diagrams provided in Figure 3.5. Each of the two squares contains thirty-six points comprised of 12 points of each black, grey and white. The difference between the two diagrams is purely the degree to which these points are interspersed or mingled.

Although it is evident that the two squares in Figure 3.5 are dissimilar no difference would be reported between the two when using the Shannon or Simpson indexes (see Table 3.5).

Now consider that all black points are removed from both diagrams in Figure 3.5. Where mingling is low, a large portion of the square would now be empty. Where mingling is high the same size area would be bare, but it would be comprised of many smaller patches.

given the sample size. 


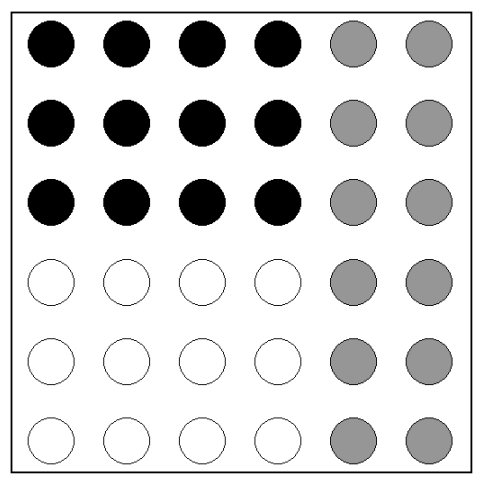

(a) Low Mingling

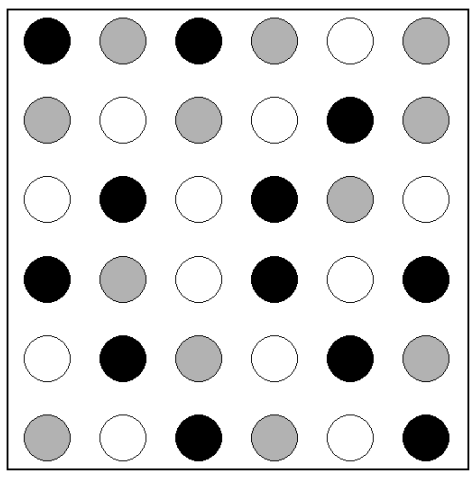

(b) High Mingling

Figure 3.5.: The mingling of black, grey and white points within an area (after Graz, 2004a).

\begin{tabular}{|l|c|c|}
\hline Index & Stand A & Stand B \\
\hline \hline Shannon & 1.099 & 1.099 \\
\hline Simpson & 0.314 & 0.314 \\
\hline Shannon Evenness & 1.000 & 1.000 \\
\hline
\end{tabular}

Table 3.5.: The Shannon and Simpson indexes for the two squares shown in Figure 3.5 . 
The implications are the same when the concept is transferred to trees of different species in a woodland stand. The desirability of the smaller or larger clearing is open to interpretation. While larger areas are more subject to wind erosion they would also be more suitable for the regeneration of $P$. angolensis (after Vermeulen, 1990).

It is therefore necessary to augment the usually used diversity indexes by quantifying mingling separately. Considering the above, the mingling of a particular plant trait, such as species, may be defined as the degree to which a tree with the particular trait is surrounded by trees of the same or different traits. For instance, the mingling of species would reflect the degree to which a tree of species $X$ is surrounded by trees of any other species except $X{ }^{3}$ The degree of mingling of a trait will fall between the two extremes introduced in Figure 3.5.

Interest in quantifying the spatial relationship between plants within a community is not new. Braun-Blanquet (1932), for instance, describes five classes of sociability as follows:

Soc.1: growing on in a place/singly.

Soc.2: grouped or tufted.

Soc.3: in troops, small patches or cushions.

Soc.4: in small colonies, in extensive patches or forming carpets.

Soc.5: in great crowds (pure populations).

The allocation of plant groups to these classes is, however, dependent on the interpretation and experience of the observer, and is therefore rather subjective.

Pretzsch (2001) provided a brief review of the index of segregation developed by Pielou to provide a measure of association in a two-species system. The same method may, however, not be implemented when more than two species need to be considered.

Lewandowski and Pommerening (1997) evaluate a more objective measure of interspersion, the species-mingling index, $M_{s p}$. In accordance with the previously presented definition of mingling the index reflects the degree to which a tree is surrounded by those of other species. The

${ }^{3}$ The mingling of tree size may also be determined in this way only if size-classes are defined prior to an enumeration and the trees occurring in the different size classes are evaluated. 
index is therefore determined for an individual tree by comparing it with its $n$ closest neighbours. The tree specific index $M_{i}$ is then determined as:

$$
M_{i}=\frac{1}{n} \sum_{i=1}^{n} m_{i j}
$$

where

$$
m_{i j}= \begin{cases}1, & \text { if the tree is of another species } \\ 0, & \text { if the tree is of the same species }\end{cases}
$$

When four neighbours are evaluated $M_{i}$ may acquire one of five possible values:

$M_{i}=0 / 4 \quad$ none of the neighbours are of a different species,

$M_{i}=1 / 4 \quad$ one of the neighbours is of a different species,

$M_{i}=2 / 4 \quad$ two of the neighbours are of a different species,

$M_{i}=3 / 4 \quad$ three of the neighbours are of a different species; and

$M_{i}=4 / 4 \quad$ all of the neighbours are of a different species.

The arithmetic mean $\left(M_{s p}\right)$ of the observed values of $M_{i}$ for a species, $s p$, then provides an estimate of the degree of mingling of the particular species within the stand that was assessed. Since the index is based on the five possible values of $M_{i}$, it may only attain values between 0 and 1 . Values of $M_{s p}$ close to 0 imply that trees of the species occur in groups reflecting a low level of species mingling (a high degree of aggregation). High values of $M_{s p}$, close to 1, on the other hand, indicate that trees of the species occur in isolation of other trees of the same species, therefore implying a high level of species mingling.

Using a simulation model Graz (2004a) showed that if a species is dispersed randomly within a stand the mingling complement, $1-M_{s p}$, is equal to the proportion of individuals that the species contributes to the stand ${ }^{4}$. In other words, if a species is interspersed randomly then the proportion that a species contributes to a stand equals the proportion $P(s p)$ that the species contributes to the stand. This is shown in Figure 3.6 .

The relationship may be intuitively understood if each value of $M_{i}$ is considered to represent a sample of the stand, to assess the proportion

\footnotetext{
${ }^{4}$ The value $1-M_{s p}$ may be considered as an indicator of aggregation for that species
} 


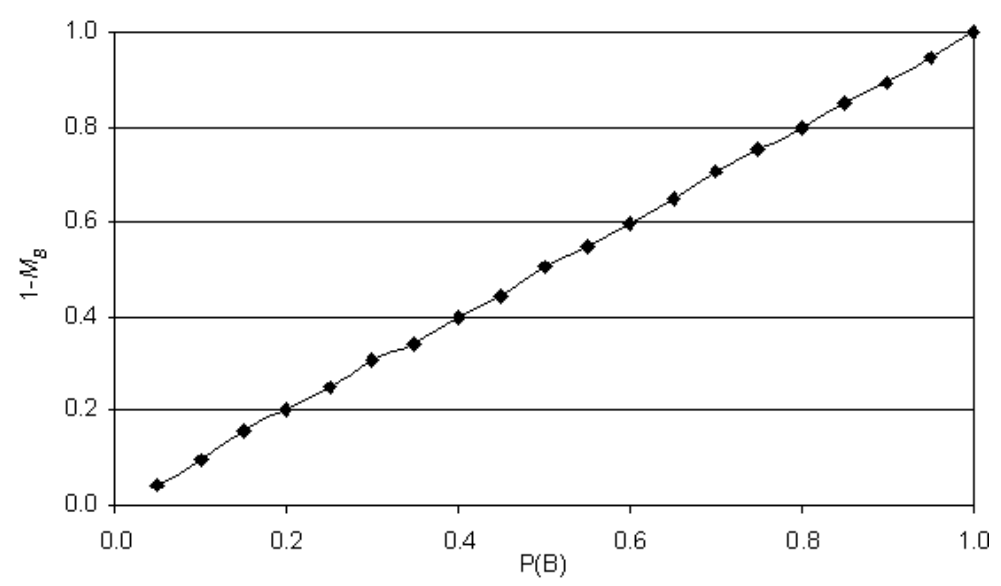

Figure 3.6.: The relationship between the mingling complement, $1-M_{B}$, for a species $B$, and the proportion $P(B)$ of trees that the species contributes to a stand, in which it is randomly interspersed with all other trees.

that the species contributes to the stand. The mean of these samples would then provide an estimate of the overall proportion that the species contributes to the stand. As the degree of clumping increases, reflected by a lower value of $M_{s p}$, then the value of $\left(1-M_{s p}\right)$ increases, becoming larger than $P(s p)$.

Due to its dependency on the species composition of a stand, Graz (2004a) proposed the use of an index $M$ defined as:

$$
M=\frac{1-P(s p)}{M_{s p}}
$$

The quantity $M$ may generally take values larger than zero but smaller than 1 . A value of $M=1$ implies that the trees are randomly interspersed within the stand. As $M$ decreases towards zero it indicates increased aggregation. Values of $M$ larger than 1 may be found if the species is overdispersed.

Rather than considering only the mean mingling value, the distribution of $M_{i}$ values may provide further insight into the spatial structure 
of a stand. Figure 3.7 shows the distribution of $M_{i}$ values for the forest Bovenden, Lower Saxony, after von Gadow and Hui $(2002)^{5}$. The distributions indicate that beech is more often than not found in groups while ash is generally more of a solitary tree.

When a species $s p$ is interspersed randomly within a forest the expected distribution of $M_{i}$ values may be estimated using the hypergeometric distribution (Lewandowski and Pommerening, 1997).

This distribution determines the probability, $P$, that $x$ trees of a particular species occur in a sample of size $n$ taken from a population of $N$ trees of which $k$ individuals are not of species $s p$. Equation 3.12 provides the notation of the hypergeometric distribution as provided by Newmark (1997):

$$
\begin{aligned}
P= & \frac{\frac{k !}{x !(k-x) !} \cdot \frac{(N-k) !}{(n-x) !(N-k-(n-x)) !}}{\frac{N !}{n !(N-n) !}} \\
& \text { for } \quad x=0,1,2, \ldots n
\end{aligned}
$$

The expected number of $M_{i}$ values for $s p$ is obtained when $P$ is multiplied by the number of trees that were sampled. Observed and expected distributions can then be compared using standard statistical methods to assess randomness. It is important to note, however, that the approach requires knowledge of the actual composition of the stand. To illustrate the potential of the method, consider Figure 3.8.

The figure shows the distribution of $M_{i}$ values for the species Baikiaea plurijuga (bars) observed by Graz (in press) and the theoretical hypergeometric distribution of these values. The hypergeometric distribution was calculated using the number of individuals that the species contributed to the sample trees, and using the total number of sample trees as $N$. Given the low number of $B$. plurijuga as sample trees $(116 / 1120)$ a very high frequency of $M_{i}=4 / 4$ would be expected if the species were interspersed randomly. A comparison between the actual and expected distributions using the chi-square test showed a highly significant difference between the two $(p \ll 0.001)$.

To investigate if the index reflected conditions in the field a woodland stand of approximately 70ha was assessed as reported in Graz (in press).

${ }^{5}$ Note that the values of $M_{i}$ are bbased on the comparison of the sample tree with only three neighbours, rather than four as suggested here. 


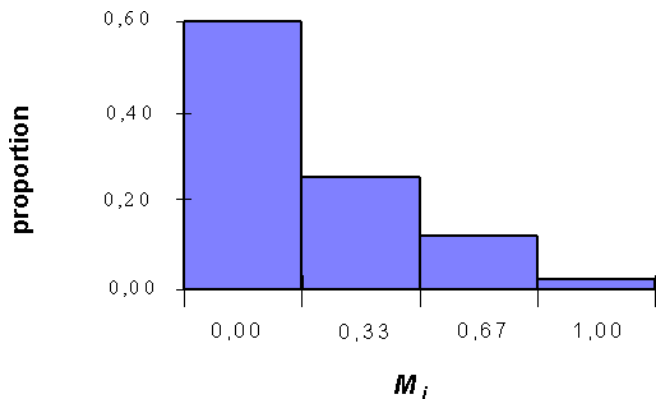

(a) Beech

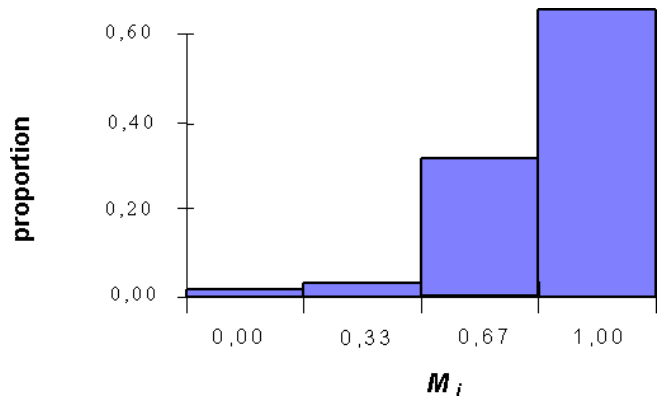

(b) Ash

Figure 3.7.: The distribution of $M_{i}$ values of (a) beech and ( $\mathrm{b}$ ) ash in the Bovenden forest of Lower Saxony in Germany (with permission K. von Gadow). 


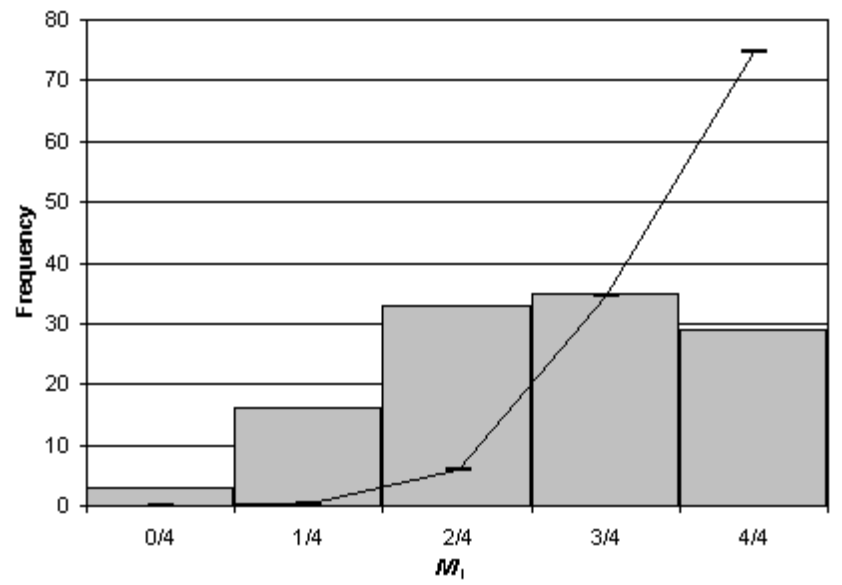

Figure 3.8.: The distribution of $M_{i}$ values for $B$. plurijuga (bars) and the expected hypergeometric distribution using equation 3.11. $M=0.298$.

The stand was initially inspected visually to facilitate comparison between the situation reported by the index and the actual conditions in the field.

A total of 1121 sample trees were identified on a regular grid of one geographic second ${ }^{6}$, with the resulting distribution of $M_{i}$ values for $B$. plurijuga, $P$. angolensis and B. africana provided in Figure 3.9 obtained from 1121 sample trees.

The species specific maps of the stand also given in Figure 3.9 clearly show the spatial distribution of the sample trees as well as the numbers of dissimilar neighbours. The accompanying graphs show the distribution of $M_{i}$ values associated with the individual species. Each diagram is accompanied by the value of $M$ as determined using equation 3.11.

From the diagram in Figure 3.9(a) it is evident that B. plurijuga is concentrated in one area. This is very much reflected by the large discrepancy between the actual and expected distributions of $M_{i}$ values

\footnotetext{
${ }^{6}$ At the latitude of the study area this is the equivalent distance of about $30 \mathrm{~m}$, which had been found to be just in excess of the maximum distance between the larger trees in the stand.
} 
as well as the low value of the indicator $M$.

P. angolensis, Figure 3.9(b), on the other hand occurs almost throughout the stand and seems to show a high degree of mingling in most areas. This is supported by the relatively good fit between the actual and hypothetical distribution of $M_{i}$ values, as well as the value of $M$.

The third species, B. africana, depicted in Figure 3.9(c), reflects a scenario that falls between the two extremes represented by $P$. angolensis and B. plurijuga. The species occurs throughout most of the stand though it is noticeably absent from the area dominated by B. plurijuga. In the areas where the species does occur it shows a moderate to high degree of mingling. The value of $M$ reflects this adequately.

Due to a high prevalence of dead trees a surrogate species of dead was introduced to determine the interspersion of mortality within the stand. The aggregation and mingling of the dead trees is shown in Figure 3.10. The map shows the aggregation of dead trees, rather than their mingling, since this is more intuitive in aiding interpretation. The graph and value of $M$ are, however, based on the mingling index. From the figure it is evident, that the aggregation of dead trees is associated with the occurrence of B. plurijuga in the stand.

Graz (in press) suggested that the patch of B. plurijuga forms the remnant of a larger stand. This was based on findings by von Breitenbach (1968) who argued that frequent fires encourage a shift from almost pure B. plurijuga stands in the Caprivi region towards mixed stands, as well as by Geldenhuys (1977b).

The distribution of $P$. angolensis may be due to the regeneration requirements of the species. Vermeulen (1990) reported that the species requires conditions of low competition to regenerate successfully. It is therefore likely that the condition of the vegetation permitted the establishment of this species in the past with other species encroaching later.

B. africana is much less subject to competition, with seedlings able to establish under some canopy (Yeaton, 1988). For this species it is not documented if young trees will remain in a suffrutex-like form until a gap in the canopy opens and light conditions improve. It may be observed in the field, however, that the young plants are able to survive frequent fires (see also Wilson and Witkowski, 2003). 

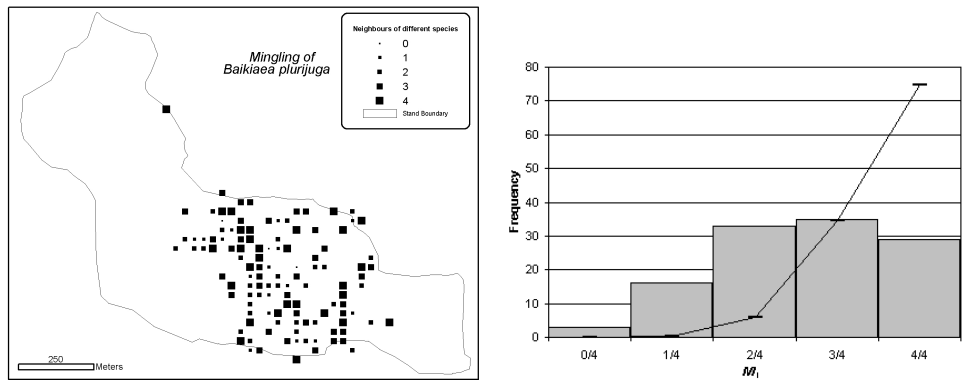

(a) $M=0.298$
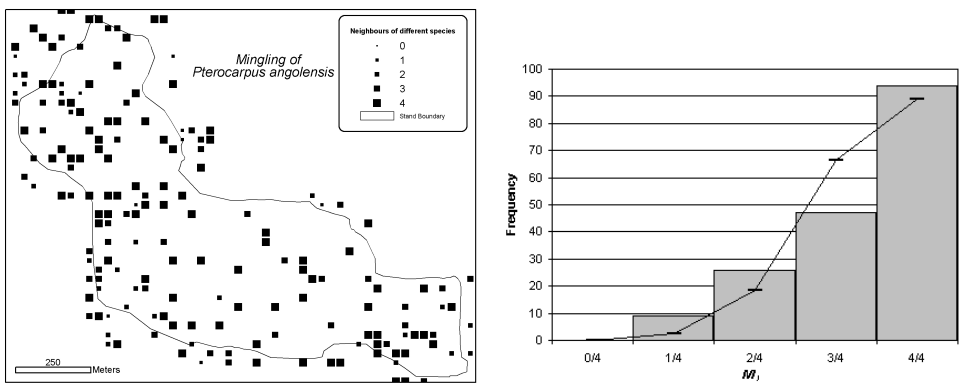

(b) $M=0.877$
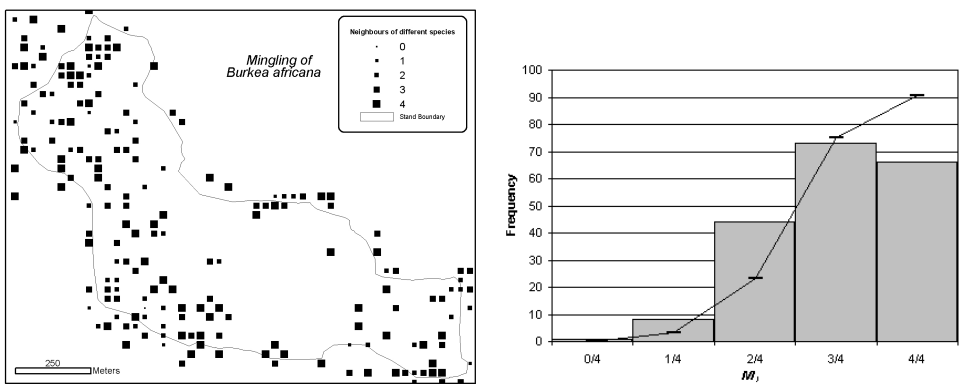

(c) $M=0.696$

Figure 3.9.: The mingling of $B$. plurijuga, $P$. angolensis and $B$. africana with bars depicting the observed distribution of the $M_{i}$ values, and lines showing the expected distribution as determined using equation 3.12. 

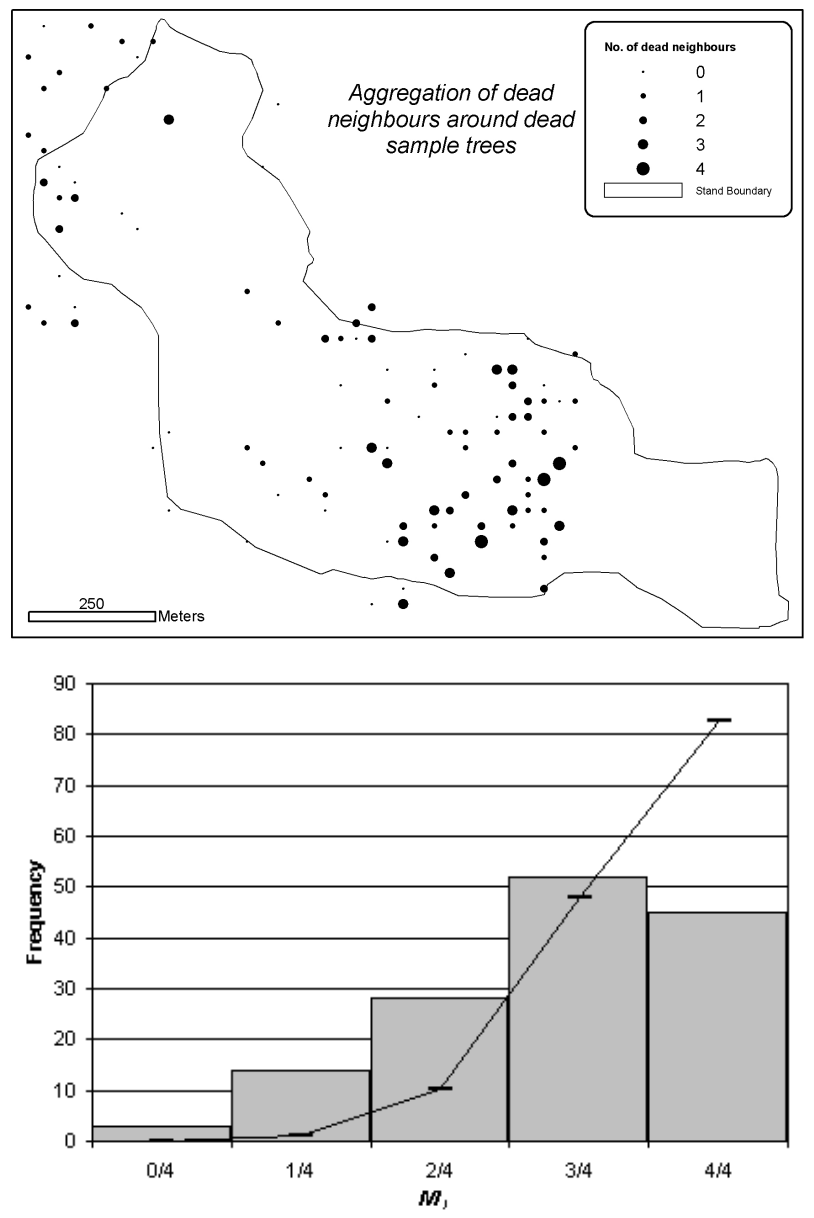

Figure 3.10.: The aggregation of dead trees around the sample trees. Note the high degree of aggregation in the area dominated by $B$. plurijuga. The graph shows the mingling of dead trees in the area. $M=0.438$ 


\section{Conclusion}

The dry woodland savanna in northern Namibia is affected by an array of factors. This results in significant structural and spatial diversity, both within stands, and over a wider area. The influencing factors do not only affect the development of the vegetation directly, but may modify the effect of the others. Grazing will, for instance, not only impact the grass plants directly but will at the same time reduce the amount of grass fuel for a subsequent fire. These interactions were effectively addressed using a HTML based modeling approach. The approach facilitated the designation of feedback loops that are otherwise difficult to track.

The influence that the different factors have on the vegetation depends on the frequency and intensity of their influence. Changes in one or both of these aspects will therefore modify the development of the vegetation or parts of the vegetation. An increase in the fire frequency will, for instance, encourage development away from $B$. plurijuga dominated vegetation to one dominated by $P$. angolensis or $B$. africana. While the processes are often understood in general their effect on many species is significantly less clear.

In order to establish management strategies, it is necessary to assess the structure of the woodland stands, as well as any structural changes that may take place. This is particularly important when dealing with timber harvesting, given the current levels of resource extraction. As yet there are not growth models available for Namibia that could assist in the prediction of woodland development or timber yield. This is in part due to a lack of data, although growth models are very difficult to develop for multi-aged stands, and particularly in the complex ecological and socio-economic setting of the woodlands.

While adaptive management is therefore necessary, it is equally important to develop interim guidelines for timber extraction. Here, the negative exponential function should be considered as a relatively simple method that models a sustainable tree population structure. The approach not only takes cognizance of desired timber yields but also the 
natural mortality rates that affect the tree population.

The exploitation of timber must, however, not only be considered in terms of the volume that is removed, but also in terms of the spatial structure of the population that is harvested. Size specific harvesting of $P$. angolensis might for instance, result in the partial removal of the species from a particular area. It is therefore necessary to establish the spatial differentiation of a particular species or size class within stands. While the mingling or aggregation of a species may be quantified using the species mingling index $M_{s p}$, derivatives of the measure may be used to establish the degree of segregation of tree size.

The methods that are presented here are simple to implement in the field while providing much of the necessary information for ecologically sound management. This is necessary for the maintenance of sustainability and diversity of the woodlands while these are under continuous human pressure. 


\section{Appendixes}

The Appendixes provide copies of the articles comprising this thesis in order of their publication date. 
4. Conclusion 


\section{A. An HTML-based concept model of the dry savanna woodland ecosystem, for teaching and learning}

Graz, F.P. 2003. An HTML-based concept model of the dry savanna woodland ecosystem, for teaching and learning. Conservation Ecology 7(1): 9. [online] URL: http://www . consecol. org/vol7/iss1/art9

The above publication was printed with the permission of the author.

\section{Abstract}

This article introduces a web-based conceptual model of the vegetation to facilitate easy understanding of the processes that govern the development of the woodlands. The model is based on a simple table structure that can be interpreted by most web-browsers, making it easily accessible. This latter consideration is important due to a weak telecommunication link to most of the outlying areas in Namibia.

The model may be accessed by community based natural resource managers to provide an overview of the complexity of the savanna woodland system.

Keywords HTML model, Dry Savanna Woodlands, Namibia, Ecology 


\section{A. An HTML-based concept model of the dry savanna woodland ecosystem, for teaching and learning}

\section{A.1. Introduction}

The dry savanna woodlands of northern Namibia provide a number of different resources to the rural communities, ranging from construction material and a source of energy to food and tools. In 1992 Ollikainen estimated that a total of 1.5 million cubic meter of wood was used for firewood alone (Ollikainen 1992). In 1996 the National Planning Commission determined a GDP (agricultural production) of $\mathrm{N} \$ 2.6$ billion, though ignoring the informal sector. During the same year the total woodland resources that were used by the informal sector amounted to an equivalent value of almost $\mathrm{N} \$ 1060$ million per annum (NFSP 1996, p. 3).

Despite the dependence by rural people on the woodland resources little management besides law enforcement is currently implemented. This is partly due to the limited financial and human resources available, but also due to limited knowledge of the woodlands and their ecology, slowing the implementation of management actions that support sustainable utilization.

Models of the woodland areas may assist in directing data collection, and identifying and testing management options before they are implemented (Starfield \& Bleloch 1991, p. 3).

A variety of models have been developed in the past to look at the savanna system (Starfield et al. 1993, Milton \& Hoffman 1994, Jeltsch et al. 1996, Joubert \& Rothauge 2001). Starfield et al. (1993) developed a frame-based model of woodlands in Zimbabwe, to investigate the interaction between various vegetation components. Graz (1996) simulated some known ecological processes with a simple systems model of the dry savanna woodlands in northern Namibia. Jeltsch et al. (1996) developed a spatial model to investigate the woody component in the Negev.

The state and transition models proposed by Milton \& Hoffman (1994) and Joubert \& Rothauge (2001) are descriptive and static in nature. The authors describe the different states that the vegetation may assume under various environmental conditions. Changes in these conditions or the intensity of different factors may cause a transition of the vegetation to another state.

The two state and transition models provide diagrams to depict the interaction of ecological and management processes. Accompanying de- 
scriptions provide details about the different sections of these diagrams and the nature of interactions.

While such illustrations are very useful tools to obtain a good overview of the savanna woodland system, Graz (1996) experienced problems with developing all the necessary links, especially feedback loops, despite the limited complexity of the model.

In order to cope with complexity a top down approach may be used together with step-wise refinement. This technique that has been used in computer programming to break down a problem into components that could be worked on individually (Sterling \& Shapiro 1997, p. 67) or broken down into further sub-units.

Analogous to this approach a number of sub-models may be developed, to be referenced by a parent diagram. Each of these sub-models may be maintained or updated independently.

Alternative approaches to cope with complexity are described by du Toit et al. (1995, p.64) for the development of mind maps, and Novak (undated) for concept maps. These methods identify a core thought to which influencing factors or more specific concepts are linked by a series of lines. Links are not only extended towards the core, but also between the influencing factors thus potentially forming complex networks.

The model presented in Appendix 1 consolidates existing information on the dry savanna ecosystem into a conceptual model using an approach that combines step-wise refinement and the method to create mindmaps. The literature for the model is cited in the reference section of Appendix 1.

The various factors that determine and modify the structure of the dry savanna woodlands are presented, and the interactions between the different factors are identified and described. Unlike the models referred to above, this model is developed using the Hypertext Markup Language (HTML), which is used in the development of Internet web pages.

HTML, click-able diagrams, Java and JavaScripts may be used to develop an interlinked / cross-linked hierarchy of text and figures as described in Graham (1997) and Kidder \& Harris (1997). In this way, step-wise refinement may be implemented almost boundlessly, while retaining simple diagrammatic presentation.

A further advantage of this approach is, that the model may be accessed using standard Internet web browsers, making it a useful teaching tool. Students, managers and community leaders may browse through 


\section{A. An HTML-based concept model of the dry savanna woodland ecosystem, for teaching and learning}

different components and levels of complexity on their own, backtracking to previous screens as desired. Additionally, the various components of the model may be revised and updated individually, at a central point.

The structure used in compiling the model was chosen primarily to maintain easy access to the model. Parts of Namibia are served by slow communication lines, with substantial downloading times. A more sophisticated approach would make the model less accessible in these areas simply because of communication. Images, while very useful for the illustration of various aspects, were excluded for similar reasons.

\section{A.2. HTML Modelling vs. Diagrams}

Diagrams, such as those provided by Joubert \& Rothauge (2001) or Graz (1996) are used to show the relationship between different components of a system. Flow diagrams may easily be developed with standard office software such as Microsoft Powerpoint, while more sophisticated applications such as Vensim (Ventana Systems Inc.) provide a tool to develop causal loop diagrams that may be expanded into dynamic systems models.

A further, popular method of showing relationships between factors is through the implementation of mind maps (du Toit et al. 1995, p.64) or concept maps (Novak undated). These techniques identify influencing factors and components that affect a specific concept.

These techniques display information schematically, but without the addition of descriptive text. As detail and scope increase, however, it becomes increasingly difficult to depict a model on paper, particularly if the number of feedback-loops increases, and text is added.

To illustrate the problem consider the two sections of a woodland model in Figures A.1 and A.2. Figure A.1 depicts the factors that affect the mortality of adult trees in the woodlands.

Tree mortality is affected by the severity of damage by fire, human and animal impact, the availability of soil water, the vigor of the plants and the effects of pests \& diseases. Each of these factors is affected by others. For instance, the degree of fire damage is a function of the fire frequency, fire intensity and fire season.

Figure A.2 shows the factors that govern the establishment of seedlings. Here, the core component, seedling establishment, is affected ger- 


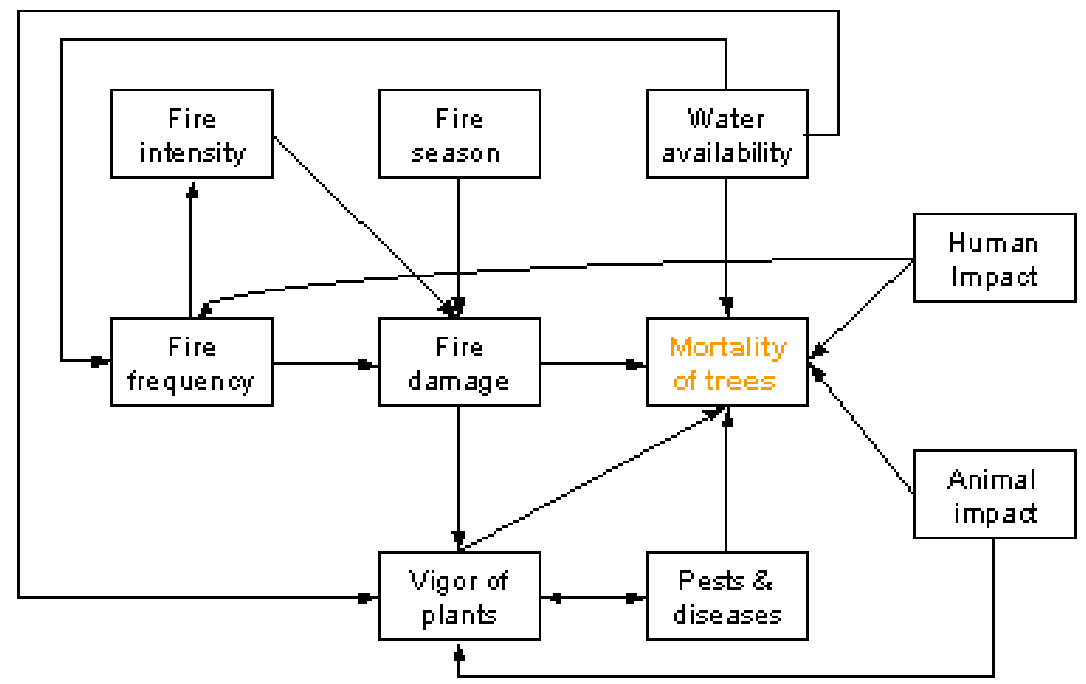

Figure A.1.: Schematic presentation of the factors that affect mortality of adult trees in the dry savanna woodlands

mination, soil water availability and fire damage. The figure shows that the components not only affect the establishment of seedlings, but also have an effect on each other, though indirectly.

Both sections are relatively simple and easy to understand as links may be followed between the core components and the factors that affect them. Additionally, each section only includes the factors relevant to the topic at hand, i.e. mortality of trees (Figure A.1) and the establishment of seedlings (Figure A.2). The reader is therefore less likely to digress from the topic.

As the factors are relatively few in each of the two diagrams, they may be loosely spaced on paper, thus improving readability.

Since both sections reference water availability, fire damage and the vigor of trees they could also be combined to form a single diagram, linked through these three factors. This is done in Figure A.3, in a causal loop type diagram using Vensim (Ventana Systems Inc.). While the combination of the two diagrams provides a more complete picture 


\section{A. An HTML-based concept model of the dry savanna woodland ecosystem, for teaching and learning}

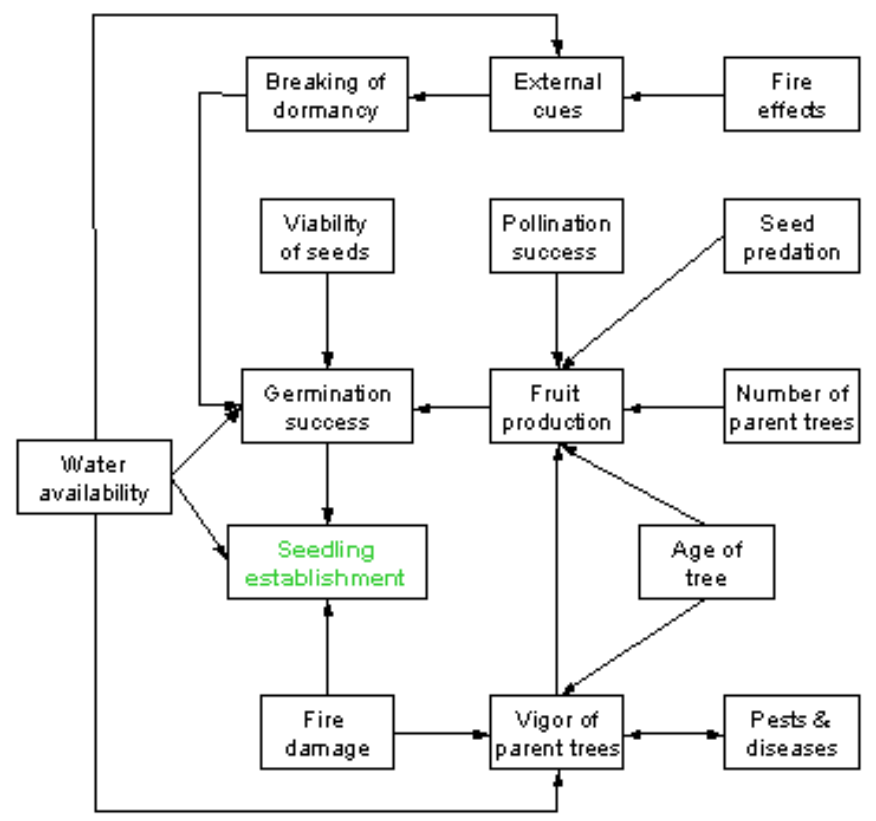

Figure A.2.: Schematic presentation of the factors that affect seedling establishment in the dry savanna woodlands

it also becomes increasingly complex, and more difficult to read. In order, therefore, to ease comparison with the previous diagrams the core components of figures A.1 \& A.2 have been highlighted using different colors.

In order to maintain readability the factors might be spaced more widely on paper. This would result in a drawn out diagram. On the other hand, the figure could be restricted in size thus making some sections appear very busy. Consider for instance, "vigor of parent trees" and its influencing factors in Figure A.3. While the vigor of the parent trees is an important aspect, the number of uni- and bi-directional links seems to emphasize the significance of the factor above others, subsequently causing bias in the interpretation of the diagram.

It must be noted that the complexity of figures A.2, A.2 and A.3 


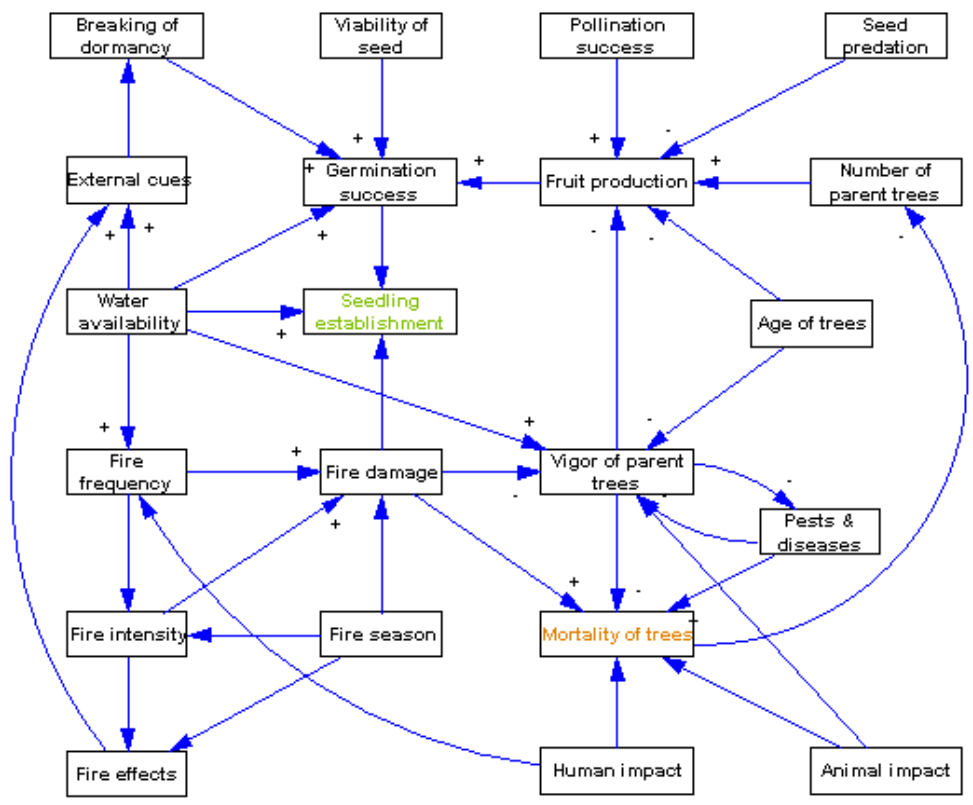

Figure A.3.: A causal loop type diagram that combines the mortality of trees in figure A.1 and the establishment of seedlings in figure A.2. The '+' and '-' signs indicate a positive and negative relationship between factors respectively

has been restricted by summarizing factors. Water availability is, for instance, influenced by soil conditions, rainfall and competition with other woodland plants. The factors 'soil condition' and 'competition with other woodland' plants could again be subdivided. The expansion of the factors would, however, make the figure less readable and the reader would be more likely to digress because of an information overload.

While the diagrams in figures A.1 \& A.2 show the various factors that affect one another, they do not provide information on the type of association. The causal loop type diagram in Figure A.3 attempts resolve this by indicating a positive relationship between factors (indicated by a ' + ') or a negative relationship (indicated by a '-') between the factors. 


\section{A. An HTML-based concept model of the dry savanna woodland ecosystem, for teaching and learning}

Here, a positive relationship implies that an increase in one factor would result in an increase in the other, while a negative relationship indicates that an increase in a factor would cause a decrease in the other. Since the nature of the links are only known in a general way they cannot be quantified using constants or equations.

However, not all relationships could be labelled in this way. For instance, the effect of fire may initially increase germination, but as fires become more intense, seed is damaged. Van Daalen (1991) found, for instance that a higher percentage of Pterocarpus angolensis seed germinated in response to medium intensity fires as compared to very high or very low intensity fires.

To compound the problem, the nature of the links from one factor to the others may differ. For instance, water availability affecting seedling establishment refers to the amount of soil water, whereas fire frequency is indirectly affected by the development of the herbaceous vegetation as a result of water, and the breaking of dormancy considers the amount of water that may remove inhibitory chemicals.

Milton \& Hoffman (1994) and Joubert \& Rothauge (2001) attempted to overcome this problem by numbering the individual states and transitions, and providing descriptive text separately. A disadvantage of this system is that a reader is required to cross-reference the diagram and text on different pages.

The problem would not be solved by, say, using a larger sheet of paper. The user of the model would be required to view the model from a greater distance to see it in its entirety, in which case the writing would become increasingly less readable.

A further alternative would be to combine space and color coding, i.e. allocating different colors to different sub-modules of the model. However, as the number of sub-modules increases, different shades of the same color become increasingly difficult to distinguish. This problem is similar to the allocation of colors when preparing maps (ESRI 1994). Also, this approach would require decisions on where such color-coded sub-models would begin or end.

The technique described here presents a simple tool to break down a complex model into sub-units that can be displayed separately or in groups. The various sections of the model are stored in separate HTML documents that are linked to a parent document using uniform resource locators (URL) (Graham, 1997). Each of the sub-documents in turn 
may act as parent document for further refinement.

Similar to the implementation of hyperlinks on the Internet, many documents may point to one parent, while conversely; a single document may point to many parent or child documents. The various child documents may also cross-reference one another.

This characteristic has important implications for model development. Once a section has been developed, it may be referenced by multiple higher-level models. For instance, a sub-section that deals with the development of soil moisture is important for seedling development, plant vigor and growth. The sub-section can therefore be referenced by all three. Similarly, the vigor of adult trees not only effects tree survival and their seed production, but also the plants' susceptibility to attacks by pests and diseases.

An important advantage of the use of URLs is the ease with which feedback loops may be dealt with. For instance, reduced light intensity on the woodland floor due to shading by woody plants results in a weaker herbaceous layer. This in turn eases the establishment of woody seedlings and the subsequent development of the woody layer.

\section{A.3. Implementation of The HTML Documents}

To facilitate easy access and navigation through the model and its component descriptions, the browser window is divided into three horizontal sections using frames; with the implementation of frames the individual sections of the screen may be changed independently.

The upper-most frame (model frame) permits the reader to navigate through the individual sub-models, while the central frame (description frame) is used to display the descriptive text requested by the reader.

The last frame contains a menu that provides navigation aids and access to a list of the literature referenced by the model. The menu could be extended to solicit feedback from the readers.

The html documents that contain the sub-models use a simple table structure to present the individual factors or elements and the linkages between them in a systematic way. Figure A.4 provides an example, showing the factors that influence woody plant mortality. The factors 


\section{A. An HTML-based concept model of the dry savanna woodland ecosystem, for teaching and learning}

are entered as text into the table, while leader lines to other components are displayed using images of arrows.

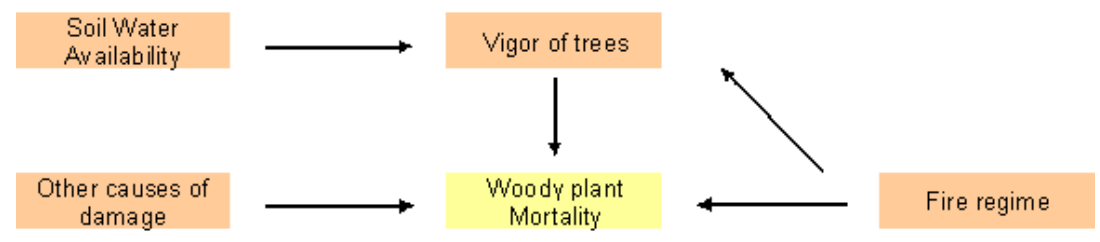

Figure A.4.: Factors that affect woody plant mortality in the woodland system, with links indicating where the various factors influence one another

Any element of a sub-model that is subdivided further provides a hyperlink to the next level of refinement. For instance, following the hyperlink attached to the factor 'Fire regime' would show a sub-model dealing with fire frequency, season and intensity.

Descriptions of model components may be called up from the model frame, to be displayed in the description frame underneath. This permits the reader to access more than one relevant description for a sub-model while still viewing the sub-model.

To distinguish between hyperlinks to sub-models and those to descriptions the links to descriptions are enclosed in parenthesis, and are provided below the name of the factor.

Explanatory text is also provided for some leader lines between individual elements within a sub-model. Following a hyperlink attached to such a leader line will also cause text to be displayed in the description frame. For example, the effect that fuel load development has on fire frequency is linked to a leader line, while detailed information on the development of fuel loads and fire frequency are provided by descriptions of the factors themselves.

Images that offer a hyperlink are by default displayed with a box. Further consideration suggested, however, that the box distracted the reader by drawing attention to the leader line rather than to the submodel as a whole. Hyperlinked leader lines are therefore blue, as opposed to the normal black. 


\section{A.4. Discussion And Conclusions}

The conceptual model described here organises knowledge in the form of text thereby making it freely readable to the user, and functioning as an important primer to more detailed mathematical models or even expert systems.

HTML is inappropriate for the development of mathematical modelling, and very inefficient in the development of an expert system type approach. Both techniques would be more effectively implemented with Java, such as the Mandarax expert system shell.

In view of the simplicity of the approach access to the knowledge base is facilitated through a web browser, rather than through sophisticated software. This is important in a society where people are computer literate, but have only limited numerical skills.

Simplicity is also important from the technological side. Browsers differ in their ability to recognise or interpret some HTML mark-up tags, although standards have been recommended by the W3 consortium (Münz 2001). The simple table structure, the placement of images within tables and hyperlinks are, however, a standard implementation. The structure of the HTML documents therefore makes the model more widely and consistently accessible. At the same time, the simple documents result in small files that require relatively short downloading times.

HTML permits the extension of a conceptual model almost indefinitely, while providing a simple method for the incorporation of feedback loops. The simplicity, however, also entices to modeller to expand in one particular area of interest while neglecting others. It is therefore important to keep in mind the purpose for the model and monitor its development to ensure that it does not digress in one direction, and neglecting others.

This problem is shown in the model in Appendix 1. Since there is much conceptual information available on the effect of fire on the savanna woodland system, the sub-models concerning fire are considerably more detailed than other sections. Any necessary extensions, such as speciesspecific considerations, could be appended to or incorporated into the model, as they are required.

The construction of an HTML model may be simplified by defining a document template that provides the basic table structure. Such a tem- 


\section{A. An HTML-based concept model of the dry savanna woodland ecosystem, for teaching and learning}

plate will have the added advantage by supporting layout consistency. Development of a central style sheet that defines text and general display attributes may promote consistency further.

In order for the model to adhere to its original objective, to provide an overview of the ecological interactions and not to become too detailed as to become widely applicable, the information has been limited, although numerous examples are provided in the text.

More detailed information on the various factors has been documented in the past. The impact of fire on the savanna woodlands has been dealt with by von Breitenbach (1968), Jankowitz (1983) and Rutherford (1981). Grazing is discussed in more detail by Tainton (1999) and Savory \& Butterfield (1999).

HTML provides an effective method for storing information that can not be structured into a tabular format as hyperlinks may be maintained between different parts of the data, permitting feedback loops. Where communication technology and browser software permit HTML, JavaScript, Java and XML may provide additional tools in structuring knowledge and making it readily accessible to a wide variety of users.

\section{A.5. References}

Du Toit, P., M. Heese, \& M. Orr. 1995. Practical Guide to Reading, Thinking and Writing Skills. Southern Book Publishers. Johannesburg, South Africa. p305.

ESRI. 1994. Advanced ARC/INFO - Version 7; Cartographic Production. Training material provided by: Environmental Systems Research Institute, Redlands, California.

Foth, H.D. 1990. Fundamentals of Soil Science (8th ed). John Wiley \& Sons.

Graham, I.S. 1997. HTML Sourcebook (3rd ed). John Wiley \& Sons. Graz, F.P. 1996. Management of a Pterocarpus angolensis population under the influence of fire and land use. M.Sc. Thesis, University of Stellenbosch, Stellenbosch, South Africa.

Jankowitz, W.J. 1983. Die Plantekologie van die Waterberg Platopark. Ph.D. Thesis, University of the Orange Free State. Bloemfontein, South Africa. 
Jeltsch, F., S.J. Milton, W.R.J. Dean, \& N. Van Rooyen. 1996. Tree spacing and coexistence in semiarid savannas. Journal of Ecology 84:583-595.

Joubert, D.F., \& A. Rothauge. 2001. A preliminary state-and-transition model for managers of semi-arid rangeland in central Namibia. Poster presented at the 36th Congress of the Grassland Society of Southern Africa, 22-25 January 2001. Aventura, South Africa.

Kidder, G., \& S. Harris. 1997. Official HTML Publishing for Netscape (2nd ed). Ventana Commuications Group. Research Triangle Park, North Carolina.

Knoop W.T. 1982. Interactions of Herbaceous and Woody Vegetation in Two Savanna Communities at Nylsvley. M.Sc. Thesis, University of the Witwatersrand. Johannesburg, South Africa.

Milton, S.J., \& M.T. Hoffman. 1994. The application of state-andtransition models to rangeland research and management in arid succulent and semi-arid grassy Karoo, South Africa. African Journal of Range and Forage Science 11:18-26.

Münz, S. 2001. SelfHTML 8.0. URL: http://selfhtml.teamone.de Novak, J.D. undated. The Theory Underlying Concept Maps and How To Construct Them. URL: http://cmap.coginst.uwf .edu/info/

NFSP. 1996. Namibia Forestry Strategic Plan. Directorate of Forestry, Windhoek, Namibia.

Ollikainen, T. 1992. Study on Wood Consumption in Namibia. Directorate of Forestry, Windhoek.

Rutherford, M.C. 1981. Survival, regeneration and Leaf biomass changes in woody plants following spring burns in Burkea africana - Ochna pulchra Savanna. Bothalia 13:531-552

Savory, A., \& J. Butterfield. 1999. Holistic Management (2nd Ed). Island Press.

Starfield, A.M., \& A.L. Bleloch. 1991. Building Models for Conservation and Wildlife Management. Burgess International Group (inc). Minneapolis, Minnesota.

Starfield, A.M., D.H.M. Cumming, R.D. Taylor, \& M.S. Quadling., 1993. A frame-based paradigm for dynamic ecosystem models. AI Applications 7:1-13

Sterling, L., \& E. Shapiro. 1997. The Art of Prolog: advanced programming techniques (ED 2). MIT Press. 
A. An HTML-based concept model of the dry savanna woodland ecosystem, for teaching and learning

Tainton, N. 1999. Veld Management in South Africa. University of Natal Press, Pietermaritzburg.

Van Daalen, C.J. 1991. Gemination of Pterocarpus angolensis seed. South African Journal of Forestry 158:33-36

Vensim, Ventana Systems Inc. http://www.vensim.com/ accessed November 2001

Von Breitenbach, F. 1968. Long-Term Plan of Forestry Development in the Eastern Caprivi Zipfel. Department of Forestry, Saasveld, South Africa.

Walker, B.H., \& I. Noy-Meir. 1982. Aspects of the Stability and Resilience of Savanna Ecosystems. In Huntley B.J and Walker B.H. (Eds) 'Ecology of Tropical Savannas'; Springer Verlag, Berlin.

\section{A.6. Appendix}

The full model is provided at:

http://www.consecol.org/vol7/iss1/art9 


\section{B. The behaviour of the species mingling index $M_{s p}$ in relation to species dominance and dispersal}

Graz, F.P. 2004. The behaviour of the species mingling index $M_{s p}$ in relation to species dominance and dispersal. European Journal of Forest Research 1:87-92.

\section{Abstract}

Ecosystem conservation plays an increasingly important role in forest management. The value for such conservation has been directly linked to high diversity of species and structure within systems. In the past, forestry inventory practices have concentrated on aspects that were primarily required for timber management. Now, however, much interest has arisen in measures that will indicate higher or lower diversity. The interspersion of trees of different species reflects diversity at a very local level, and may serve as an important indicator for the simplification of a forest or woodland system. The article shows that the mingling index $M_{s p}$ is robust towards the spatial dispersal of plants, and provides some guidelines as to its interpretation.

Keywords: Spatial diversity, aggregation, mingling, simulation 


\section{B. The behaviour of the species mingling index $M_{s p}$ in relation to species dominance and dispersal}

\section{Zusammenfassung}

Schutz und nachhaltige Nutzung von Okosystemen spielt eine immer bedeutendere Rolle in der Plannung und im Management der Wälder. Der Wert solcher Nachhaltigkeit wird oft mit hoher Artenvielfallt und Vielfältiger Struktur verbunden. Bisher hat sich die Inventur in der Hauptsache auf solche Aspekte konzentriert, die sich primär auf das Management von Holzvorkommen bezogen. Nun waechst jedoch das Interesse an Maßen mit denen strukturelle Diversität beschrieben werden koennen. Die Durchmischung von Arten reflektiert die Diversität auf sehr lokaler Ebene, und kann die Vereinfachung von Waldsystemen anzeigen. Dieser Artikel zeigt dass der Index $M_{s p}$ ein robustes Mass für Durchmischung ist, und schlägt Richtlinien zu seinem Gebrauch vor.

Schlüsselwörter: Räumliche Diversität, Aggregation, Durchmischung, Simulation

\section{B.1. Introduction}

In line with the Rio conference, ecosystem conservation plays an increasingly important role in forest management. In Europe and North America forest ecosystems are now also evaluated in terms of their "naturalness" (Zenner 1998), which is directly linked to high diversity of species and structure. Pacala \& Deutschman (1995) also highlighted the importance of diversity for a more stable carbon sink.

In the past, forestry inventory practices concentrated on aspects that were primarily required for timber management (Gadow \& Bredenkamp 1992 , p. 30). As the scope of forestry activities increases or environmental restrictions and guidelines must be adhered to, these traditional measurements may no longer be sufficient. In order to obtain measures of species and structural diversity, and to permit local as well as temporal comparisons of diversity numerous indicators have been developed. McGurren (1988) provides detailed descriptions of a number of these indicators and their behaviour.

Indicators such as the popular Shannon or Simpson indexes, consider the contribution of a species towards diversity as a function of the proportion of individuals it contributes to a stand (McGurren 1988, 
Zar 1999). Neither index, however, will indicate how the members of each species are distributed throughout such a stand or relative to other species.

Such spatial distribution may be measured with an index as the area independent nearest neighbourhood measure provided by Clark \& Evans (1954). Gadow (1999) and Staupendahl (2001) provide the area independent Uniform Angle Index to quantify clumping. Used together with the Shannon index these indexes will provide useful information on spatial structure of a forest stand. However, even such a combination will not indicate if different species may be found in the same patch, or if all are found in isolated, monospecific areas.

The interspersion of trees of different species, i.e. species mingling reflects diversity at a very local level, and may serve as an important indicator for the simplification of a forest or woodland system. Such simplification may be due to harvesting practices that remove a particular species or age class (von Breitenbach 1973) or due to the elimination of sensitive species or size classes by factors such as fire (Graz 1996).

The concept may be expanded to include the intermingling of other characteristics such as dead, or diseased trees in a stand, the sex of dioceous trees, or the interspersion of tall trees as raptor perches. All have important ecological implications.

An index is therefore required that expresses diversity for increasingly small areas. Ultimately, the index would show diversity around a single tree or point. The index of segregation of Pielou reviewed by Pretzsch (2001) provides a measure of association in a two-species system. Once more species need to be considered, however, the index cannot be used as described.

Hui et al. (1998) reported on the measure of surround to describe the spatial mix of tree parameters such as diameter at breast height or tree height. A similar measure that describes species specific mingling, $M_{s p}$, was discussed by Lewandowski \& Pommerening (1997), Gadow (1999) and Gadow \& Hui (2002).

The index is determined by establishing the number of neighbours that are of a different species to that of a particular reference tree or sample point, and expressed as a proportion of the number of neighbours evaluated (Gadow \& Hui 2002).

Hong et al. (2000) report on an aggregation index (AI) to quantify spatial patterns in landscapes. The index is based on the proportion of 


\section{B. The behaviour of the species mingling index $M_{s p}$ in relation to species dominance and dispersal}

neighbouring pixels that are of dissimilar value of the reference pixel in a raster. The total number of neighbours of the same species is then compared to a maximum aggregation level, providing a value between 0 , a low level of aggregation and 1, high level of aggregation.

While Hong et al. (2000) use the method to quantify aggregation of pixels in a raster, it can be modified for the use of point data. A comparison of such a modified AI with $M_{s p}$ using the model described below showed that AI was identical to the inverse of $M_{s p}$. Since both indexes consider the proportion of neighbours of the same species as a reference tree, this is hardly surprising.

Thus far the investigations of $M_{s p}$ have concentrated on random distributions of trees. This is, however, not typical for vegetation such as the dry savanna woodlands of Namibia, as many of the woodland species have a tendency to clump either because of growing conditions, due to dispersal mechanisms or regeneration requirements.

\section{B.2. Species Mingling}

The mingling of species relates to the degree to which trees of a particular species are positioned in relation to the trees of other species. More precisely, the mingling of a species is given by the degree to which a tree is surrounded by trees of other species. This is illustrated in figure B.1 below.

A low degree of mingling implies that trees of a particular species occur with few or no trees of another species in the same area. A high degree of mingling, on the other hand, implies that trees are surrounded by others of different species.

Gadow (1999) establishes species mingling by comparing a sample tree and its four closest neighbours. The mingling index $M_{i}$ is then determined for the sample tree $i$ as:

$$
M_{i}=\frac{1}{n} \sum_{i=1}^{n} m_{i j}
$$

Where

$$
m_{i j}= \begin{cases}1, & \text { if the tree is of another species } \\ 0, & \text { if the tree is of the same species }\end{cases}
$$


Mingling

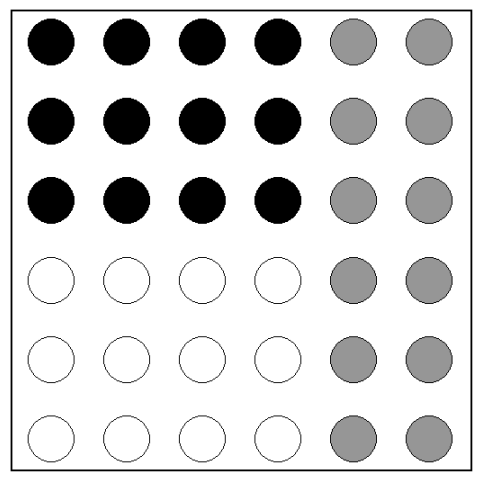

(a) Low

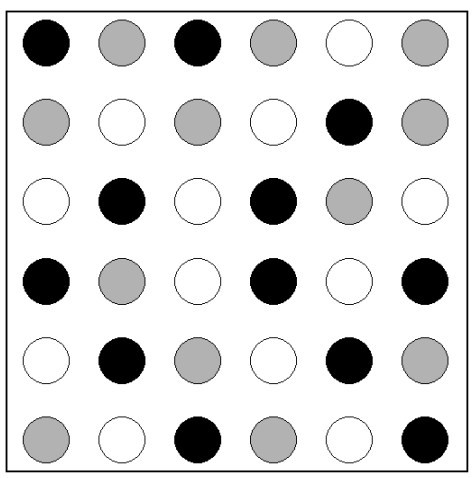

(b) High

Figure B.1.: The mingling of black, grey and white tree species within an area (after Gadow, 1999).

$$
\begin{aligned}
n & =\text { The number of neighbours considered } \\
i & =\text { Sample trees evaluated }
\end{aligned}
$$

When four neighbours are evaluated $M_{i}$ may acquire one of five possible values:

0/4 none of the neighbours are of a different species,

$1 / 4$ one of the neighbours is of a different species,

$2 / 4$ two of the neighbours are of a different species,

$3 / 4$ three of the neighbours are of a different species; and

$4 / 4$ all of the neighbours are of a different species.

The arithmetic mean $\left(M_{s p}\right)$ of the observed values of $M_{i}$ for a species $s p$, is such that $0 \leq M_{s p} \leq 1$. A value of $M_{s p}$ close to 0 implies that trees of the species $s p$ occur in groups therefore indicating a low level of species mingling. High values of $M_{s p}$, close to 1 , on the other hand, indicate that trees of the species occur in isolation of other trees of the same species, therefore implying a high level of species mingling. 


\section{B. The behaviour of the species mingling index $M_{s p}$ in relation to species dominance and dispersal}

The distribution of $M_{i}$ values provided a more detailed insight into the spatial composition of a stand. Gadow \& Hui (2002) provide the distribution for the forest 'Bovenden' in Lower Saxony, Germany, as provided in Figure B.3.
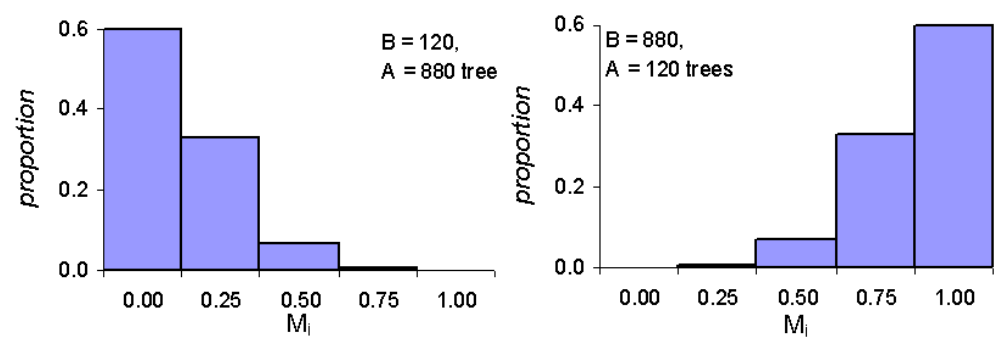

Figure B.2.: Hypergeometric probability distribution of $M_{i}$ values for species $A$ based on relatively high and low proportions of species $A$ in a stand respectively

The two graphs in the figure show that ash is more often a solitary tree than it would occur in groups, while beech occurs in groups.

If a species sp is distributed randomly, however, the spread of $M_{i}$ values can be calculated based on the number of trees that each species contributes to the stand. Lewandowski \& Pommerening (1997) calculated conditional probabilities using the hypergeometric distribution and used Monte Carlo type iterations to establish confidence limits for the distribution.

The two distributions shown in figure B.2 were generated using the hypergeometric distribution for two hypothetical stands. These are comprised of 120 trees and 880 of species $B$ randomly interspersed with 880 and 120 trees of species $A$ respectively.

It is evident that the two hypothetical distributions given in figure B.2 closely follow those of the observed distributions of beech and ash respectively. The similarity between the two distributions implies that ash and beech are randomly dispersed within the stand. This is, however, not always the case, and significant variation may occur in the distribution of $M_{i}$ values.

Should the proportion that species contributes to a stand be known the observed distribution of $M_{i}$ values may be compared with a hy- 


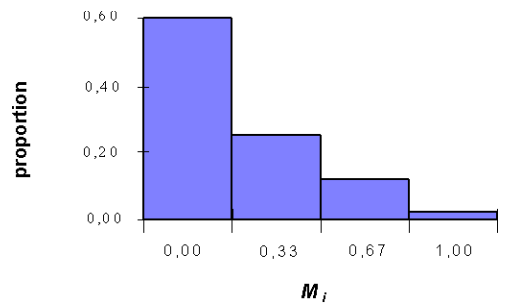

(a) Beech

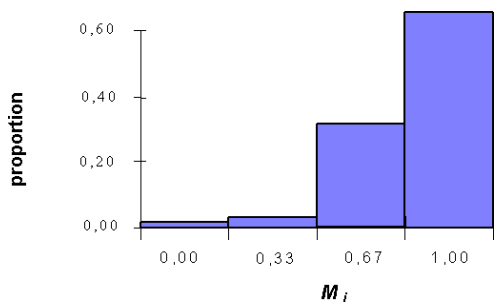

(b) Ash

Figure B.3.: Species mingling of beech and ash in the Bovenden forest in Lower Saxony, Germany (with kind permission from Prof. K. v. Gadow)

pergeometric distribution using the Chi-square test to determine the likelihood of a random distribution.

\section{B.3. Description of the model}

In a simulation study the behaviour of $M_{s p}$ under different spatial dispersal patterns and varying species composition was evaluated.

1000 trees were placed in a square stand of 1 ha and assigned a species to each individual tree with given probability, $P(s p)$. The number of trees and stand area were arbitrarily chosen although some stands within the woodland area have such low density, especially where fire frequency is high, or trees have been eliminated from patches altogether.

However, since $M_{s p}$ does not consider distances to neighbours it is area-independent and tree density should be of lesser importance. This was tested using different sized areas, and found to be true.

Four methods were used to place trees and therefore generate different dispersal patterns.

Method 1: Tree locations were generated randomly within the stand as a whole. Species $B$ was then assigned with probability $P_{(B)}$. Initially species were assigned within a single patch that covered $25 \%$ to $100 \%$ of the total stand area. The method was then modified to method 3 below. Method 2: Tree locations were generated randomly within limited 


\section{B. The behaviour of the species mingling index $M_{s p}$ in relation to species dominance and dispersal}

patches within the stand. The sum of the patch areas amounted to $50 \%$ of the total stand area. The number of patches that were investigated were $1,4,9,16,25$ and 36 . Species $B$ was then assigned with probability $P_{(B)}$ within each patch. This dispersal pattern increased the amount of edge for the stand.

Method 3: Tree locations were generated over the whole area, creating a wholly random dispersal of trees. Species were then assigned randomly within separate patches covering a total of $50 \%$ of the stand area, with a given probability. The number of patches investigated were 1, 4, 9, 16,25 and 36. The dispersal pattern simulated the amount of edge of the areas in which species $B$ occurred and the remainder of the stand. Method 4: The final method used a clumped dispersal of trees using the Matern method described by Stoyan \& Penttinen (2000), and generated with the program Stochastic Geometry, 4.1 (Stg 4.1). Species $B$ was then assigned to all trees in the stand using with a probability $P_{(B)}$.

$P_{(B)}$ was increased from 0.1 to 0.9 , i.e. from a very low presence of the species to a very high presence to simulate the dominance of species $B$ within the stand. One thousand iterations of each combination of dispersal pattern and $P_{(B)}$ were calculated, and the average mingling of species, $M_{s p}$, stored in a text file.

In order to relate $M_{s p}$ to spatial dispersal two measures of the degree of clumping were determined using all trees in the stand as reference trees. The measures were the nearest neighbour of species $B\left(C E_{B}\right)$ after Clark \& Evans (1954) and the tree based Uniform Angle Index $\left(W_{B}\right)$ after Gadow (1996).

Initial results changed the output of the model slightly to replace $M_{B}$ with its complement, i.e. $1-M_{B}$ since this made a number of relationships more easily apparent.

The data was then imported into a spreadsheet for visualization and further analysis.

\section{B.4. Results}

Initially the effect of $P_{(B)}$ on the species mingling index $M_{B}$ was investigated for a totally random dispersion of $B$, generated with method 1 . The four graphs shown in Figure B.4 depict the relationship between the 
complement of $M_{B}, 1-M_{B}$, and $P_{(B)}$ for a single patch in the centre of the stand covering $100 \%, 75 \%, 50 \%$ and $25 \%$ of the stand area.

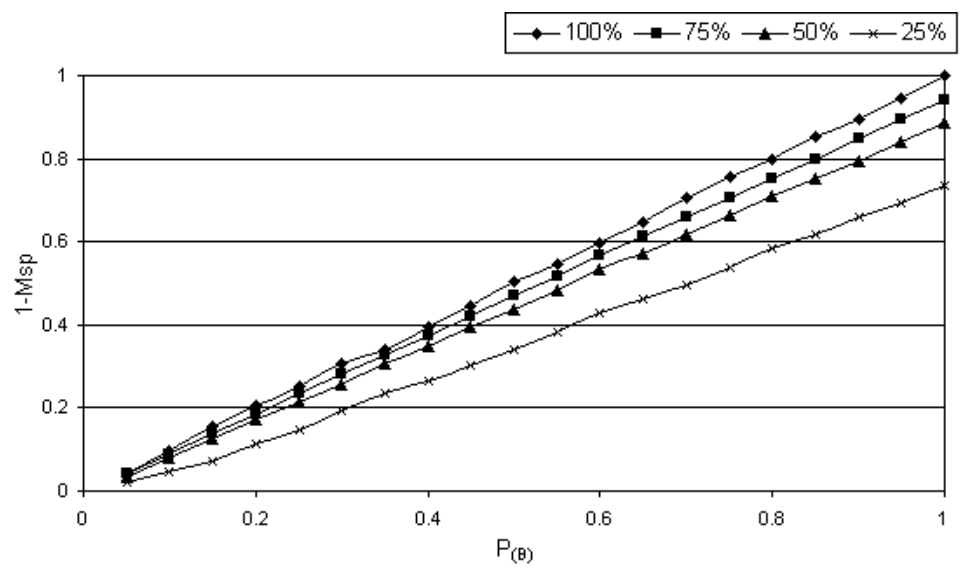

Figure B.4.: The relationship between the probability with which species $B$ is assigned, $P_{(B)}$, in a single patch, and the complement of the mean mingling index $M_{B}\left(=1-M_{B}\right)$ for patches covering $100 \%, 75 \%$, $50 \%$ and $25 \%$ of a stand.

From the figure it is evident that the value of $M_{B}$ is highly dependent on the proportion that species $B$ contributes to the patch in which it occurs. All relationships have a high coefficient of determination of $r^{2}=$ 0.999 or higher. When species $B$ is distributed randomly over the entire stand the mingling complement, $1-M_{B}$, is equal to the proportion $P_{(B)}$ with which the species occurs. As a patch covers decreasing proportions of the stand, the mingling complement deviates more and more from the proportion that the species contributes to the stand.

The deviation of $1-M_{s p}$ from $P_{(B)}$ increases further, as species $B$ is dispersed in larger numbers of patches, i.e. the third form of clumping. Figure B.5 shows the deviation as the number of patches comprising $50 \%$ of the stand is increased, using a consistent $P_{(B)}$ of 0.5 to assign species.

The different relationships between $1-M_{s p}$ and $P_{(B)}$ are a result of the increasing amount of edge between the individual patches and the 


\section{B. The behaviour of the species mingling index $M_{s p}$ in relation to species dominance and dispersal}

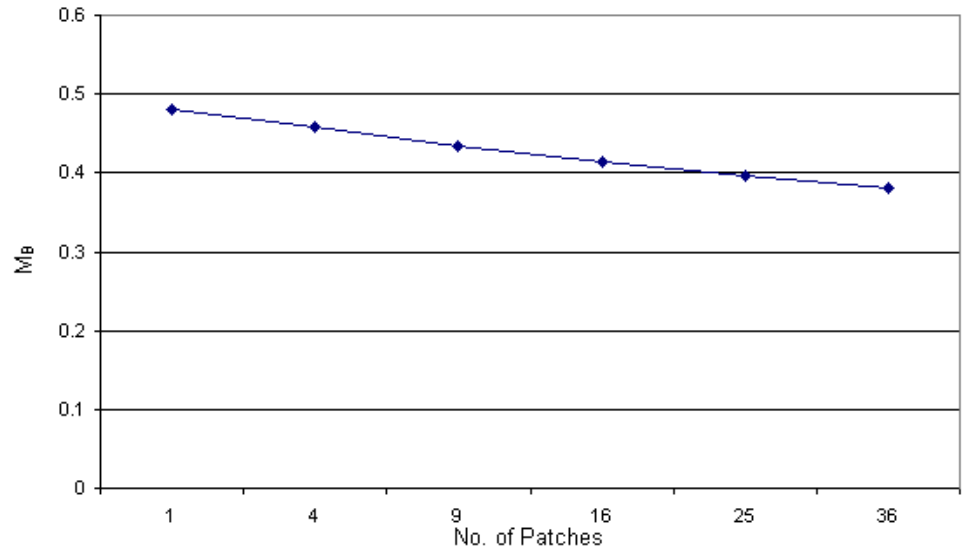

Figure B.5.: The relationship between $M_{B}$ and the number of patches within which species $B$ may occur, with $P(B)=0.5$.

remainder of the stand. Each value of $M_{i}$ is a sample of the composition of the stand. Should trees be dispersed randomly within the stand the mean $M_{i}$ will approach the proportion that each species contributes to the stand.

As a species is limited to an increasing number of patches in the stand using method 3 above, the amount of edge between the patch(es) within which the species occurs and the remainder of the stand increases. The individual values of $M_{i}$ are necessarily higher at the edge of a patch indicating a higher degree of mingling.

The relationship between $M_{s p}$ and $P_{(B)}$ does not change for a clumped dispersal pattern, i.e. the fourth form of clumping, to which species were assigned with probability $P_{(B)}$. Further comparison between $M_{s p}$, the Uniform Angle Index and $C E_{B}$ showed no significant relationship. This implies that $M_{s p}$ is not sensitive to the position of neighbouring trees, only on the proportion that a species contributes to a specific region.

The formula below, formula B.2, may be used to assist in the evaluation of the relationship between $M_{s p}$ and $P_{(s p)}$. 


$$
M=\frac{1-P(s p)}{M_{s p}}
$$

Where $M_{s p}$ is the mean mingling index, and $P_{(s p)}$ is the proportion of species sp within the stand. A low value for $M_{s p}$ together with a low contribution of the species to the stand as a whole indicates a clumping of the species, or its confinement to only part of the sample area. This would be indicated by a low value of $M$, close to 0 . A value of $M$ around 1 , on the other hand, would indicate that the species is distributed more evenly throughout the stand as a whole.

Theoretically, $M$ should not exceed 1 , although in practice it may do so. It must be remembered that $1-M_{s p}$ is an estimate of $P_{(s p)}$ when the trees are randomly dispersed throughout the stand. An overestimate of $1-M_{s p}$ may result in values larger than 1 .

It must be noted, that $M$ can only be used in cases where the species composition of a stand is known. This is not always the case, particularly not in a third world country such as Namibia.

\section{B.5. Discussion}

When discussing diversity the scale at which such diversity is evaluated must be considered (Levin 1992). Consider the following example:

On a global or 'continental' scale the species Schinziophyton rautanenii, a dioceous tree of significant socio-economic importance to rural communities in Namibia, occurs in a belt across the southern African subregion (Peters 1987).

Within this region the species occurs in distinct patches, depending on the spatial distribution of growth factors, significantly the availability of deep aeolian sands (Helgren 1982). At a local scale, that is, within a stand, a species might show an aggregated, random or regular distribution as considered by Begon et al. (1986). Measures such as the nearest neighbour (Clark \& Evans 1954) or the Uniform Angle Index (Gadow 1999, Staupendahl 2001) can be used to quantify such dispersal patterns.

Generally, however, individual plant species do not occur in isolation, and the dispersion of a species needs to be considered in relation to others. At global level this may be done by comparing the species' regions 


\section{B. The behaviour of the species mingling index $M_{s p}$ in relation to species dominance and dispersal}

of occurrence. Where such regions overlap closer investigation may show the distribution of patches in relation to each other. Landscape metrics such as the Juxtapositioning index and other measures may be used to evaluate the adjacency of patches (McGarigal et al. 2001).

Should patches overlap, however, the mixing of species becomes relevant. The dispersal of trees within an area must be considered in a similarly hierarchical manner. For instance, the nearest neighbour index for a single species after Clark \& Evans (1954) shows that a species is dispersed non-randomly, throughout an area as a whole. The Uniform Angle Index, (Staupendahl 2001) on the other hand serves to indicate how the species is arranged within patches. Both indexes are averages for areas and patches respectively.

The mingling index considered here provides a further refinement. Ultimately this index shows a clumping of plants in relation to other plants rather than within area or patch.

\section{B.6. Conclusion}

Species diversity is an important aspect of ecosystem conservation since it has significant impact on ecosystem resilience. In order to evaluate ecosystem status or management action it is necessary to measure such diversity. The indexes used thus far are based on the contribution of a species to a stand, and none provides an indication of how diversity is dispersed.

The investigation above shows, that the mingling index is sensitive to the proportion of a species in a stand, as well as its dispersal throughout the stand. Low proportions of a given species dispersed evenly (randomly) over a stand will show a high degree of mingling. However, even a low overall presence of a species is able to result in a low degree of mingling if trees are found in comparatively small patches.

The different forms of clumping simulated above are very much a function of how a study area is defined. A small plot may contain only one patch. Larger areas may contain a number of patches each of which reflecting a specific spatial dispersal and mingling of species. 


\section{B.7. Acknowledgements}

I would like to thank a number of persons who were prepared to act as sounding boards for various ideas, and who provided valuable advice: Prof. von Gadow, Institute of Forest Management, Georg-August University Göttingen, Prof. Stoyan, Inst. für Stochastik, TU Bergakademie, Freiberg; Dr. McGarigal, Department of Natural Resources Conservation, University of Massachusetts; Dr. Fortin Department Zoology; University of Toronto; and Dr. Watts, Project leader Landscape Ecology, Woodland Ecology Branch Forest Research.

\section{B.8. References}

Begon, M. Harper, J.L. \& Townsend, C.R. 1986. Ecology; Individuals, Populations and Communities. Blackwell Scientific Publications.

Clark P.J. \& Evans, F.C. 1954. Distance to Nearest Neighbor as a Measure of Spatial Relationships in Populations. Ecology 35(4):445453.

Gadow K. v. 1999. Waldstruktur und Diversität. Alg. Forst u. J.-Ztg. 170:117-122.

Gadow K. v. \& Hui, H.Y. 2002. Characterizing forest spatial structure and diversity. In: Björk, L. (ed.): Proc. Of the SUFOR international workshop "Sustainable Forestry in Temperate Regions", in Lund, Sweden: 20-30.

Gadow K. v. \& Bredenkamp B. 1992. Forest Management. Academica, Pretoria.

Graz F.P. 1996. Management of a Pterocarpus angolensis population under the influence of fire and land use. M.Sc. thesis. University of Stellenbosch, South Africa.

Helgren, D.M. 1982. Edaphic Context of the Mongongo (Ricinodendron rautanenii) in the Northwestern Kalahari. South African Journal of Science 78:131-132.

Hong S.H., Dezonia B.E. \& Mladenoff D.J. 2000. An aggregation index (AI) to quantify spatial patterns of landscapes. Landscape Ecology 15:591-601.

Hui G.Y., Albert M. \& v. Gadow, K. v. 1998. Das Umgebungsmaß als Parameter zur Nachbildung von Bestandesstrukturen. Forstw. Cbl. 


\section{B. The behaviour of the species mingling index $M_{s p}$ in relation to species dominance and dispersal}

\section{7:258-266.}

LEVIN S.A. 1992. The Problem of Pattern and Scale in Ecology. Ecology 73(6):1943-1967.

Lewandowski A. \& Pommerening A. 1997. Zur Beschreibung der Waldstruktur - Erwartete und beobaachtete Arten-Durchmischung. Forstw. Cbl. 116:129-139.

McGarigalL K., Cushman S. A., Neel M. C., \& Ene E. 2002. FRAGSTATS: Spatial Pattern Analysis Program for Categorical Maps. Online documentation. URL: http://www.umass.edu/ landeco/research/fragstats/fragstats.html

McGurren A.E. 1988. Ecological Diversity and Its Measurement. Croom Helm. pp. 179.

Pacala S.W.P. \& Deutschman D.H. 1995. Details that matter: the spatial distribution of individual trees maintains forest ecosystem function. OIKOS 74:357-365.

Peters, C.R. 1987. Ricinodendron rautanenii (Euphorbiaceae): Zambezian Wild Food Plant for All Seasons. Economic Botany 41:494-502. Pretzsch, H. 2001: Modellierung des Waldwachstums. Parey Buchverlag Berlin.

Staupendahl K. 2001. Das flächenbezogene Winkelmass Wf -Ein Index zur quantitativen Beschreibung der horizontalen Baumverteilung. In: A. Akca et al. (HRSG): Waldinventur, Waldwachstum und Forstplanung - Moderne Technologien, Methoden und Verfahrensweisen. Festschrift K. von Gadow. Zohab-Verlag Göttingen. 101-115 Stg (4.1) Stochastig Geometry. Inst. für Stochastik, Technische Universität Bergakademie, Freiberg.

Stoyan D. \& Penttinen A. 2000. Recent Applications of Point Process Methods in Forestry Statistics. Statistical Science 15(1)61-78.

Von Breitenbach F. 1973. Pterocarpus angolensis: a Monograph. Trees in South Africa, Jnl. Of the Tree Society of South Africa Vol XXV(3). Zar J.H. 1999. Biostatistical Analysis (4th ed). Prentice Hall, London. Zenner E. 1998. Eine neue Methode zur Untersuchung der Dreidimensionalität in Waldbeständen. IN Pelz D.R., Rau O. \& Saborowski J. 11. Tagung Internationale Biometrische Gesellschaft Deutsche Region, Arbeitsgruppe ökologie, Freiburg 30. September - 2 Oktober 1998 


\section{Assessing the spatial diversity of a dry savanna woodland stand in Northern Namibia using neighbourhood-based measures}

Graz, F.P. in press. Assessing the spatial diversity of a dry savanna woodland stand in Northern Namibia using neighbourhood-based measures. Biodiversity and Conservation.

The publication was printed with the kind permission of Springer Science and Business Media, Manuscript BIOC 1233, J3AUT2 2075246

Dedicated to the late H. Roth, a student and a friend.

\section{Abstract}

The dry woodland savannas of Namibia are of significant socio-economic importance. The paper tests the suitability of a number of diversity indicators developed for species poor systems in Europe in the woodland context. The indicators that were tested included the species specific Mingling index, $M_{S p}$, the measure of surround and the Uniform Angle Index. The simple application of the methods permit relatively unschooled crews to conduct an enumeration in the field. The results show that the indicators do not only display current diversity status, but also reflect the ecological context of the individual species.

Keywords: Spatial Diversity - Mingling Index - Uniform Angle Index - woodland savanna - Spatial Structure - Ecology - Namibia 


\section{Assessing the spatial diversity of a dry savanna woodland stand in Northern Namibia using neighbourhood-based measures}

\section{C.1. Introduction and Background}

The dry woodland savannas of northern Namibia are of significant socioeconomic importance to many rural communities, providing a variety of timber and non-timber products. The woodland resources that are used range from building material and wood fuel to food, medicine and grazing (NFSP 1996). The quantities of the different products that are extracted are considerable. Ollikainen (1992) estimated for example, that firewood alone amounted to a total of 1.5 million cubic metres of wood during 1992. No quantity or value estimates of non-wood products are available for the Namibian dry woodland savannas, although these may be considerable.

The various woodland products differ in their importance to the various communities, and at different times. Although exact quantities were not indicated, Lee (1973) reported, for instance, that the intake of Schinziophyton rautanenii nuts could comprise up to $90 \%$ of the total food intake of some San communities. While this percentage will have changed in the meantime, Büschel (1999) indicated that the nuts still represent the staple diet of nomadic and sedentary San groups. The importance of the nuts increases particularly when agricultural crops are insufficient to meet normal requirements.

Other communities in the Kavango region of Namibia depend almost entirely on the production and sale of carvings for the tourism industry, although no studies seem to have been published in this regard. Some carvings are also produced in the Caprivi region, but the local population does not appear to depend as much on this form of income although no estimates are available.

The emphasis on different species for the carving industry is also shifting. In the early 1990's the industry in the Okavango region made use of Pterocarpus angolensis almost exclusively. Now, however, species like Guibourtia coleosperma, Baikiaea plurijuga and even S. rautanenii (despite its light weight) are being utilized extensively. This is primarily due to the overexploitation of $P$. angolensis.

Further woodland species, such as Burkea africana or Terminalia sericea serve mainly for poles or as firewood, although they support a caterpillar that also represents an important source of food (Leger 1997). 


\section{C.2. Spatial diversity and woodland structure.}

The word "structure" generally considers the composition of a population of trees in terms of specific characteristics. These may include tree age, size, species or sex (in the case of dioceous trees). Spatial structure, on the other hand looks at the arrangement of such characteristics in space. Spatial diversity refers to the arrangement of the characteristics in relation to each-other or in relation to a particular point on the ground.

The woodland savanna in northern Namibia is supported by coarse Aeolian sands with poor water holding capacity and nutrient status. The trees that occur here need to cope with highly variable precipitation and high evaporation rates. Frequent fires and exploitation further affect the environment. Taken in combination, trees and especially their seedling have to cope with a wide variety of conditions over a very short period of time and have adapted accordingly.

A number of the woodland species are frequently, though not exclusively, found in almost monospecific stands. This may be due to regeneration requirements, as in the case of $P$. angolensis (Graz 1996), the ability to compete, especially for water, as in the case of B. plurijuga (Mitlöhner 1997) or superior fire tolerance as in the case of B. africana (Rutherford 1981).

The monospecificity of stands of $S$. rautanenii and $T$. sericea have not been investigated. T. sericea however, is a pioneer that may quickly colonize open areas where it may actually form thickets (Schackleton 2001).

Büschel (1999) reported on the other hand that stands dominated by $S$. rautanenii were comprised of trees of different sizes and species in the Okavango region of Namibia. Similarly, Mitlöhner (1997) also described stands of mixed species, comprising of $P$. angolensis, B. africana and B. plurijuga, while observations near the study site also showed mixed stands (unpublished data).

In addition to being almost monospecific, trees within many stands often seem to be of similar size although not necessarily of similar age. Childes (1984) reported, for instance, that B. plurijuga stands were of variable age despite the equal size of the trees. Plants remain small for a number of years until environmental conditions are suitable for further development. This is probably also the case for $B$. africana and 


\section{Assessing the spatial diversity of a dry savanna woodland stand in Northern Namibia using neighbourhood-based measures}

$S$. rautanenii, although nothing seems to have been documented.

The restriction of growth described by Childes for B. plurijuga is similar to the suffrutex development stage of $P$. angolensis reported by Vermeulen (1990). During this period seedlings from a number of years may accumulate in this developmental stage and develop together to the sapling stage when environmental conditions permit. In such cases the above ground parts are not of the same age as the roots. It is unclear if the differences in the ages of the roots will be reflected in the survival rate of the above ground parts of the trees.

It is also uncertain whether or not whole stands of any of the above species will die off and be replaced by others at a different location, or whether the existing regeneration is sufficient to replace those trees that have died.

The data pertaining to the structure of stands in northern Namibia currently available is superficial, despite its significant importance for management.

Spatial diversity, or a lack of spatial diversity, has important implications. Consider for instance the effect of exploitation on an even sized, monospecific stand; selection based on a minimum diameter may result in a local clear-felling (von Breitenbach 1973, Graz 1996). The resulting vegetation structure would be increasingly prone to fire that may cause further vegetation change, as well as subsequent erosion and nutrient loss (see Graz 1996).

Causes of mortality are not necessarily only of human origin, however. The different sizes of a number of species have, for example, their own degree of fire tolerance. This means that trees up to a particular size class may be removed from a stand by a sufficiently intense fire. Wilson \& Witkowski (2003) found that the bark-thickness of B. africana increases with tree circumference between 0 and $400 \mathrm{~mm}$. The thickness of the bark is the primary protector against the affect of fire on the cambium.

Fire tolerance may be overcome if the bark of trees is breached by animals (Yeaton 1988) or growth stresses (Graz 2003).

Studies relating to spatial aspects have in the past concentrated on the dispersion of plants using measures such as the nearest neighbour of Clark \& Evans (1954) or point to plant distances after Pielou (1959). More recently the Uniform Angle Index (Gadow 1999, Staupendahl 2001, Gadow et al. 2003) has been implemented to describe complex forest 


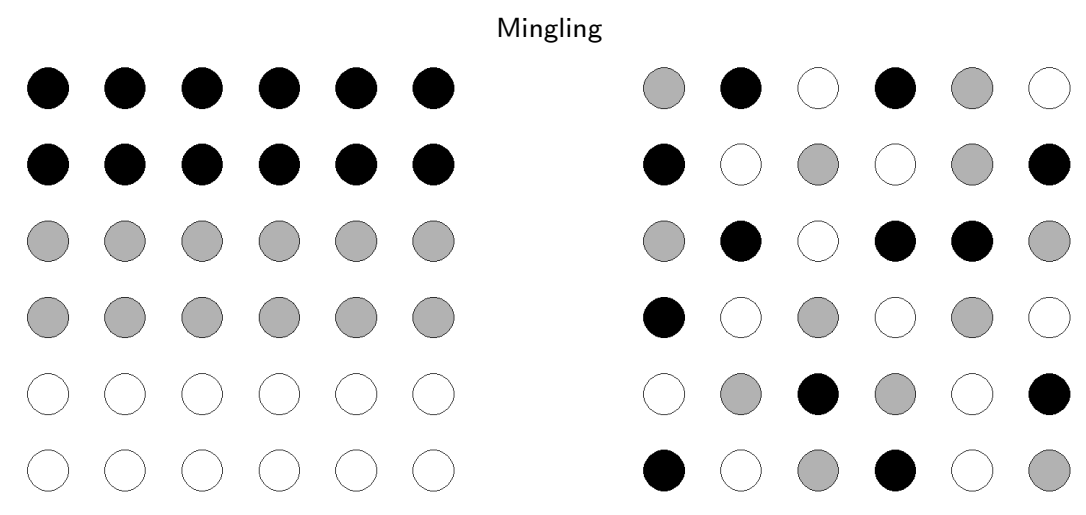

(a) Low

(b) High

Figure C.1.: The mingling of black, grey and white 'trees' within two square stands (after Gadow 1999).

structures. The aggregation of tree attributes have only been addressed more recently by other measures, such as the "measure of surround" (Hui et al. 1998) or the spatial "mingling" (Gadow, 1999).

The mingling measure is used to quantify the degree of interspersion or mingling of tree characteristics, as illustrated in Figure C.1. Trees that are surrounded by others of similar characteristic are aggregated in terms of the characteristic, implying a lower degree of mingling of this characteristic. On the other hand, trees surrounded by others of dissimilar characteristic imply a higher degree of mingling. Mingling should not only be considered in terms of categorical data, such as species or sex, or whether a tree is alive or dead, but should be expanded to include any measure with which a tree might be described, including height or diameter.

Albert \& Gadow (1998) reported on the use of these neighborhoodbased measures to assess the effect of selective thinning on the diversity of a beech stand in Germany. The authors had found the measures to be sensitive to small-scale differences and changes of woodland structure, and were able to provide more intuitively acceptable results than the segregation index of Pielou (1977, p. $227 \mathrm{ff})$. 


\section{Assessing the spatial diversity of a dry savanna woodland stand in Northern Namibia using neighbourhood-based measures}

This study aims to achieve two main objectives. The first objective is to assess the applicability of indicators that were developed and assessed in Europe to the Southern African context where little or no basic stand information is available for non-plantation areas. In addition, the study intends to generate information that will promote the understanding of the ecology of Namibia's woodland resources.

\section{C.3. Description of the Study Area}

The woodland area that was enumerated covers approximately $70 \mathrm{ha}$ and is situated between $19^{\circ} 30^{\prime} \mathrm{E}, 19^{\circ} 15^{\prime} S$ and $19^{\circ} 45^{\prime} \mathrm{E}, 19^{\circ} 30^{\prime} S$ near the Kanovlei Forestry Research Station in the western Tsumkwe district of the Otjozondjupa region, northeastern Namibia.

The area is dominated by linear fossil dunes or sandy plains on calcareous deposition, similar to those in the adjoining Kavango region described by Graz (1999). The soils are Kalahari sands, classified as unconsolidated aeolian material by Coetzee (2001), with very poor water holding capacity and nutrient status, and subsequently a very low potential for any agricultural development (Department of Water Affairs 1991)

The region is traversed by a system of omuramba (vegetated dry riverbed), with the soils classified as unconsolidated fluvial material (Coetzee 2001). These soils are shallower and have a heavier texture than the dunes (Department of Water Affairs 1971).

Precipitation is mostly in the form of thunderstorms amounting to an average rainfall of between $500 \mathrm{~mm}$ and $600 \mathrm{~mm}$ per year (Amakali 1992). However, the distribution of precipitation is highly variable and prominently positively skewed. Expected rainfall is therefore significantly lower than the long-term averages. Rain generally falls in the period September to May, with most rain occurring between December and March.

Average annual evaporation rates are between $2600 \mathrm{~mm}$ and $2800 \mathrm{~mm}$ (Crerar \& Church 1988) resulting in an overall moisture deficit.

de Pauw \& Coetzee (1999) have determined an approximate growing period of between 91 and 120 days, based on the relationship between available moisture, the amount of evapotranspiration and the average air temperature. 
Although the general vegetation is described as tree savanna and woodland by Giess (1998), there is some significant variation in species and structural composition. The Directorate of Forestry identifies a number of dissimilar patches of forest or savanna (Chakanga 1995).

While the sandy planes and dunes are dominated by Burkea africana, various species of Combretum, Pterocarpus angolensis, Schinziophyton rautanenii and Terminalia sericea. Scattered patches of Baikiaea plurijuga also occur.

The lower lying omuramba vegetation is comprised primarily of Acacia erioloba, Dichrostachys cinerea and Philenoptera nelsii.

Nuts from the $S$. rautanenii trees within the stand are harvested by local communities to augment their food supply, and by the Directorate of Forestry to obtain material for the National Tree Seed Centre and for exsitu conservation of genetic material. Additionally the stand shows signs of periodic wood harvesting of $B$. plurijuga stems, as well as for firewood.

Dry season fires are frequent (Graz 2003)

\section{C.4. Material and Methods}

\section{C.4.1. The Interspersion of Tree Attributes}

The original measure of mingling and its derivatives are based on the proportion of trees with dissimilar characteristics to those of a selected sample tree. The species mingling index $M_{i}$ for a given sample tree, $i$, using $\mathrm{n}$ neigbours is, for example, obtained through:

$$
M_{i}=\frac{1}{n} \sum_{i=1}^{n} m_{i j}
$$

Where

$$
m_{i j}= \begin{cases}1, & \text { if the tree is of another species } \\ 0, & \text { if the tree is of the same species }\end{cases}
$$

When four neighbours are used to determine $M_{i}$ the index may obtain one of five possible values: 


\section{Assessing the spatial diversity of a dry savanna woodland stand in Northern Namibia using neighbourhood-based measures}

0/4 none of the neighbours are of a different species,

$1 / 4$ one of the neighbours is of a different species,

$2 / 4$ two of the neighbours are of a different species,

$3 / 4$ three of the neighbours are of a different species; and

$4 / 4$ all of the neighbours are of a different species.

The arithmetic mean $\left(M_{S p}\right)$ of the $M_{i}$ values that were obtained for a particular species sp provides a measure of the degree of interspersion of the species in the area. $M_{S p}$ provides a value between 0 and 1 .

Values close to 0 indicate that trees of the reference species sp occur in groups therefore implying a low degree of mingling and high degree of aggregation. High values of $M_{S p}$, closer to 1 , on the other hand, imply a high degree of mingling, i.e. trees of the reference species do not occur together.

As is the case when examining the distribution of data around a mean value, additional information may be extracted from the distribution of $M_{i}$ values of individual species.

When the proportion that a species contributes to a stand is known, as assumed in the studies reported on by Lewandowski \& Pommerening (1997) and Hui et al. (1998) a theoretical distribution of $M_{i}$ values may be calculated based on the hypergeometric probability distribution. The distribution reflects the number of expected $M_{i}$ values that would be obtained if all trees were interspersed randomly.

The hypergeometric distribution is used to determine the probability, $P$, that a number of trees of a particular species may occur in a given sample of $n$ trees taken from a population of $N$ trees containing $k$ trees of the species of interest. The probability that $x$ trees in the sample will be of the species of interest is then determined after Newmark (1997) as:

$$
P=\frac{\left(\begin{array}{l}
k \\
x
\end{array}\right) \cdot\left(\begin{array}{l}
N-k \\
n-x
\end{array}\right)}{\left(\begin{array}{l}
N \\
n
\end{array}\right)} \quad \text { for } \quad x=0,1,2, \ldots n
$$

which expands to:

$$
P=\frac{\frac{k !}{x !(k-x) !} \cdot \frac{(N-k) !}{(n-x) !(N-k-(n-x)) !}}{\frac{N !}{n !(N-n) !}} \quad \text { for } \quad x=0,1,2, \ldots n
$$


The resulting probability multiplied by the total number of samples that were taken provides the expected number of $M_{i}$ values for that species. The observed and expected distributions of $M_{i}$ values may then be compared with the application of standard statistical methods to test for significance of deviations from the theoretical (random) distribution.

Although no detailed data is available for any of the woodland areas in Namibia, and the extent of the woodland areas hampers the collection of such information, the sample size provided a suitable estimate of the species composition of the stand.

The simulation study reported on by Graz (2004) has shown that the mingling index is sensitive to the species composition of a stand. In a stand of trees interspersed randomly, for example the aggregation of a species, $1-M_{S p}$, approximates the proportion that a species $S p$ contributes to the stand. This may be more intuitively understood if we consider each sample tree to provide an estimate of the proportion that its species contributes to the stand. Values of $1-M_{S p}$ which are greater than the proportion contribution therefore indicate an over-aggregation of the species, while lower values imply overdispersion within the stand. This relationship provides an important base from which the index may be interpreted.

This study investigated the interspersion of a number of tree characteristics. In addition to the mingling of species described above, the interspersion of tree dominance is quantified on the basis of diameter $\left(T_{S p}\right)$ and height $\left(H_{S p}\right)$ using the "measure of surround" described by Hui et al. (1998), and which is applied in a method analogus to that of the mingling index.

$$
T_{i}=\frac{1}{n} \sum_{i=1}^{n} t_{i j}
$$

where

$$
t_{i j}= \begin{cases}1, & \text { if the tree is thicker than the sample tree } i \\ 0, & \text { otherwise }\end{cases}
$$

The species specific mean interspersion of tree diameter, $T_{S p}$, is then the arithmetic mean of the the values of $T_{i}$ for that species.

Similarly, the interspersion of tree height, $H_{i}$, is obtained through: 


$$
H_{i}=\frac{1}{n} \sum_{i=1}^{n} h_{i j}
$$

where

$$
h_{i j}= \begin{cases}1, & \text { if the tree is higher than the sample tree } i \\ 0, & \text { otherwise }\end{cases}
$$

The species specific interspersion of tree height, $H_{S p}$, is then again determined as the mean of the values of $H_{i}$ for the species.

An equivalent measure was used to quantify the interspersion of dead trees $\left(D_{S p}\right)$ by counting the number of dead neighbours for each sample tree.

\section{C.4.2. Uniform Angle Index}

The uniform angle index (UAI) was initially described by Gadow et al. (1998) and later by Staupendahl (2001) to provide a measure of the overall contagion of trees within a forest stand.

The index is obtained by identifying the $n$ nearest neighbours of a sample tree. Starting with the closest neighbour and moving in a clockwise direction around the sample tree the angle, $a_{j}$, between two adjacent neighbours is determined in relation to the sample tree. The number of angles smaller than, or equal to, a given critical angle, $a_{0}$, are then counted, i.e.

$$
W_{i}=\frac{1}{n} \sum_{i=1}^{n} w_{i j}
$$

where

$$
t_{i j}= \begin{cases}1, & \text { if } a_{j} \leq a_{0} \\ 0, & \text { otherwise }\end{cases}
$$

The critical angle (in degrees) is determined as:

$$
a_{0}=\frac{360^{\circ}}{\text { number of neighbours }}
$$


Four neighbours would therefore be evaluated in terms of a $90^{\circ}$ critical angle $^{1}$. Since all of the indexes used to measure the interspersion of tree characteristics were based on four trees, the same neighbours could be used for the UAI.

A practical advantage of choosing $a_{0}=90^{\circ}$ is that two adjoining sides of a record book or clipboard may be used to determine whether or not an angle is greater than or less than the critical angle.

Effectively, the index describes the spatial distribution around a particular reference tree. If the species of the reference tree is noted we may obtain the mean value for either for the whole population or for a particular species species of interest.

The mean value of the index is strongly correlated with the nearest neighbour index of dispersion of Clark \& Evans (1954) that has long been used in ecological studies. Together with the number of trees in a stand, the uniform angle index may be used to estimate the distribution of distances between a tree and its neighbours (Gadow et al. 2003). This information is generally not available and comparison of observed index values are compared to the simulation results of Gadow et al. (1998) are used.

\section{C.4.3. Sampling}

The extent of the stand was recorded in the field using a Garmin Venture GPS. The track-log was stored for subsequent mapping. A regular sample grid of one geographic second was then superimposed on the stand amounting to a sample point approximately every $30 \mathrm{~m}$ at that latitude.

Sampling points were located using a standard GPS receiver. The accuracy of autonomous GPS readings was considered adequate for the purpose of the study. While a dense canopy reduces the reliability of a GPS reading within a stand (Dominy \& Duncan 2001), many of the trees in the area had already shed their leaves and canopy interference was considered negligible after initial comparison of signal strengths in wooded and in open areas.

Since the enumeration coincided with the war in Iraq it is uncertain whether GPS readings were affected by selective availability on some days. It was felt, however, that this was acceptable.

${ }^{1}$ More recent studies have shown that this statement needs to be modified; a more suitable critical angle is $72^{\circ}$ (see Gadow et al. 2003). 


\section{Assessing the spatial diversity of a dry savanna woodland stand in Northern Namibia using neighbourhood-based measures}

At each sample point the closest tree with a dbh of $5 \mathrm{~cm}$ or more was identified to serve as reference tree. Although trees had, in a few cases, snapped off below breast height, such trees were nevertheless sampled, since they play a role in the interspersion of plants.

For each sample tree the four nearest neighbouring trees with a diameter of greater than $5 \mathrm{~cm}$ were determined and compared with the reference tree in terms of species, mortality, height and diameter, and the uniform angle index was established.

Time was kept short by assigning two persons to each sampling team. While the enumerator collected the measures, a navigator moved to find the next sample point.

A total of 1121 sample points were assessed. The data was entered into a spreadsheet and the indexes were calculated for each species using cross tables.

\section{C.5. Results and Discussion}

The species-specific indexes are summarized in Table C.1. The table also shows a surrogate species of 'Dead' created to record trees that were still standing but had been burnt beyond a stage where they might be identified. Also, species of the genus Combretum and Comiphora were lumped, as individual species could not readily be identified. The row marked 'overall' provides the each index as calculated over the entire data set.

The overall shows a contagion $\left(W_{i}\right)$ greater than 0.6 , here indicating a tendency towards non-random (clumped) dispersion of trees (after Gadow et al 1998). The dispersion around trees of the individual species does not seem to diverge very much from the mean value of 0.665 , if Philenoptera nelsii and Securidaka longipedunculata are discounted because of their very low overall occurrence. This is in line with general observations in the field. The table shows that most of the species have a tendency to aggregate.

To compare the proportion of a given species within the stand and the value $1-M_{S p}$ consider table C.2. The table omits those species with very few observations (less than $5 \%$ of the total). The final column in the table reflects the parameter $M$ proposed by Graz (2004) to determine the degree of interspersion. The value of $M$ is larger than 0 and less than 
or equal to 1 . Values close to 0 indicates a very low degree of mingling, and 1 indicates a more random distribution of the species in the stand.

Table C. 2 shows that B. plurijuga has the highest degree of aggregation followed by Terminalia sericea.

More T. sericea seedlings survive in open areas, i.e. away from conspecific trees (Smith \& Grant 1986) where it has the ability to form thickets (Shakelton 2001). This was evident in the field. T. sericea would colonize gaps in the canopy, thus causing the aggregation.

The dispersion of B. plurijuga is also shown in figure C.2. The figure shows that the species occurs in a very limited area. The accompanying graph shows the relative distribution of $M_{i}$ values (bar) and the theoretical hypergeometric distribution. The graph shows a clear difference between the two, due to the clumping of the species, reflected by the low value of $M$ (Table C.2).

The cause of the aggregation of $B$. plurijuga is uncertain, since the trees had few larger neighbours as evidenced by the low value of $T_{S p}$ in table C.1. It is possible that the patch of B. plurijuga is a remnant of a larger stand that has been subject to high degrees of mortality. This possibility stems from reports by von Breitenbach (1968) who suggested that the almost pure stands in the Caprivi region developed towards mixed stands as a result of fire.

The possibility is corroborated by the high degree of mortality $\left(D_{S p}\right)$ associated with the species (see figure C.3). The dead trees within the B. plurijuga patch, shown in figure C.3, are generally large trees. This is not evident from the indexes but supports the suggestion by von Breitenbach cited above.

In contrast to $B$. plurijuga, $P$. angolensis is interspersed almost randomly according to Table C.2 and in Figure C.2. As is evident in the figure, the observed distribution of $M_{i}$ values (bars) follow the theoretical distribution much more closely than those of $B$. plurijuga. It must be noted, that $P$. angolensis occurs comparatively seldom within the B. plurijuga patch. This exclusion from the patch is more pronounced for $B$. africana. The reason or cause for this is not readily apparent. Outside this patch $B$. africana is more aggregated resulting in the lower value of $M$.

The random distribution of $P$. angolensis is probably a reflection of the regeneration requirements of the species. Vermeulen (1990) reports that $P$. angolensis is especially sensitive to competition in the seedling 


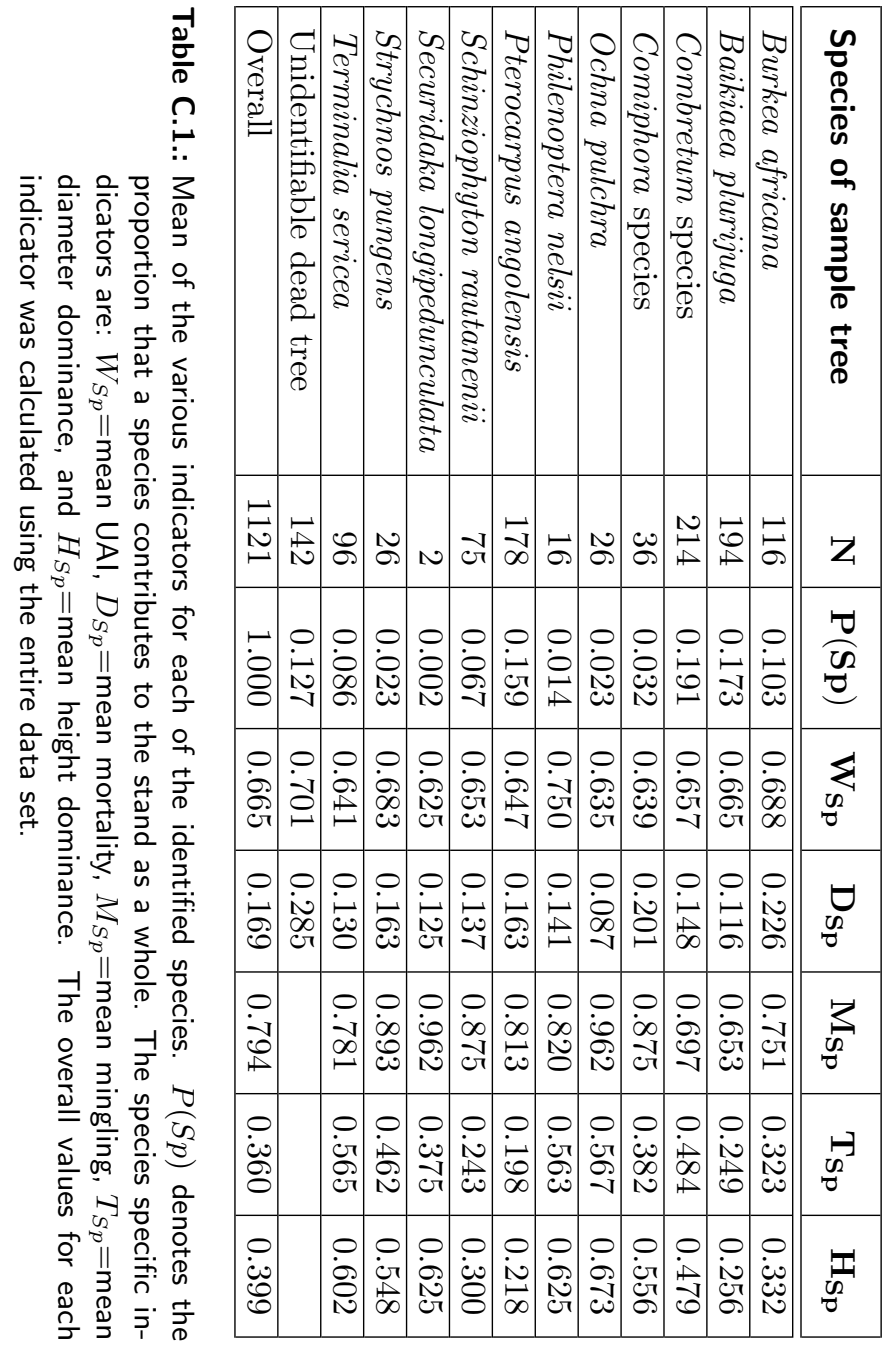




\begin{tabular}{|c|c|c|c|c|c|c|c|c|}
\hline 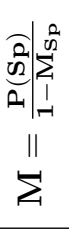 & 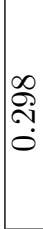 & $\begin{array}{l}0 \\
0 \\
0 \\
0 \\
0\end{array}$ & ְُ & $\begin{array}{l}\infty \\
\infty \\
\infty \\
0\end{array}$ & 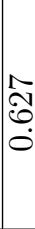 & ब्? & $\begin{array}{l}\text { J } \\
\text { J }\end{array}$ & \\
\hline$\sum_{1}^{\infty}$ & $\stackrel{N}{\stackrel{N}{*}}$ & 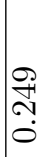 & $\begin{array}{l}\stackrel{9}{\rho} \\
\stackrel{\leftrightarrow}{0}\end{array}$ & 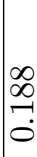 & 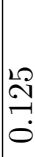 & 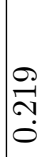 & 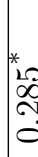 & \\
\hline$\sum_{i}^{\infty}$ & 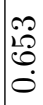 & $\stackrel{\mathscr{2}}{\mathfrak{2}}$ & $\begin{array}{l}\hat{\sigma} \\
\stackrel{0}{0} \\
\dot{0}\end{array}$ & $\begin{array}{l}\infty \\
\infty \\
\infty \\
0\end{array}$ & $\begin{array}{l}10 \\
\stackrel{1}{1} \\
\infty \\
0 \\
0\end{array}$ & $\begin{array}{l}\not{\infty} \\
\stackrel{\sim}{0} \\
\ddot{0}\end{array}$ & & \\
\hline$\frac{\widehat{\rho}}{\stackrel{2}{n}}$ & $\stackrel{\leftrightarrow}{\stackrel{\rho}{\ominus}}$ & 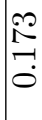 & $\stackrel{\vec{\sigma}}{\vec{\sigma}}$ & 官 & 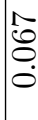 & $\begin{array}{l}\mathscr{0} \\
\infty \\
0 \\
0\end{array}$ & I & \\
\hline Z & $\stackrel{0}{\rightleftharpoons}$ & హ゙ & $\frac{\vec{J}}{\mathrm{~N}}$ & $\infty$ & 10 & 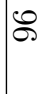 & $\stackrel{\Im}{\beth}$ & $\frac{2}{7}$ \\
\hline 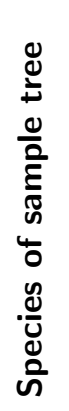 & 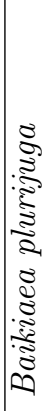 & 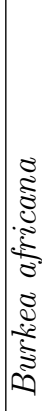 & 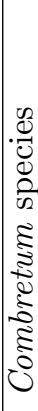 & 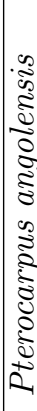 & 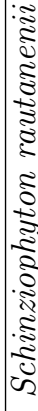 & 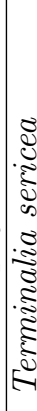 & 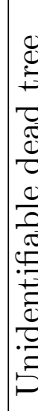 & 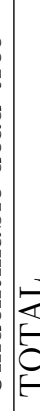 \\
\hline
\end{tabular}


C. Assessing the spatial diversity of a dry savanna woodland stand in Northern Namibia using neighbourhood-based measures
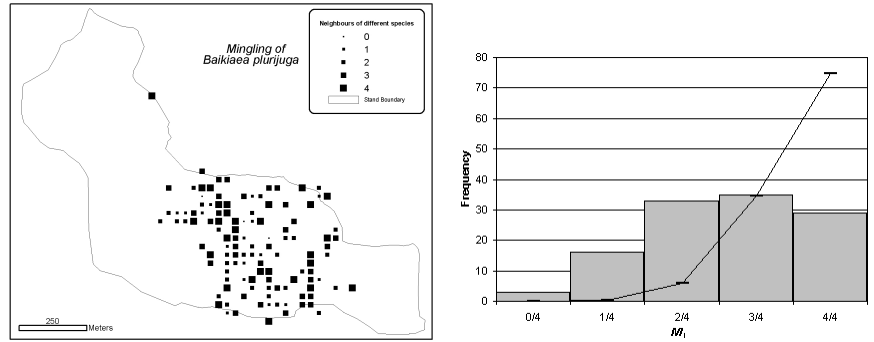

(a) $M=0.298$
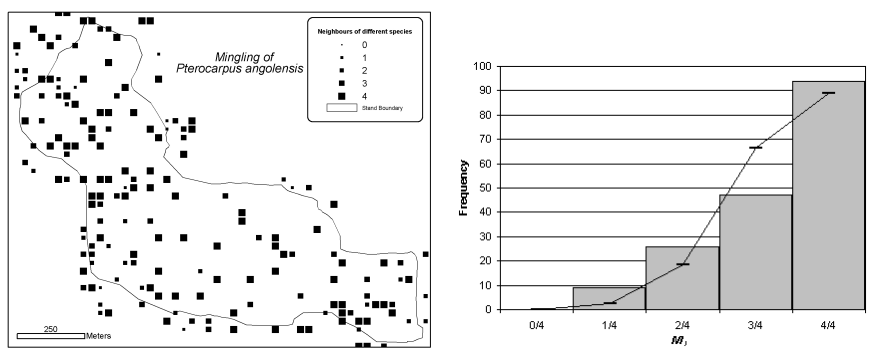

(b) $M=0.877$
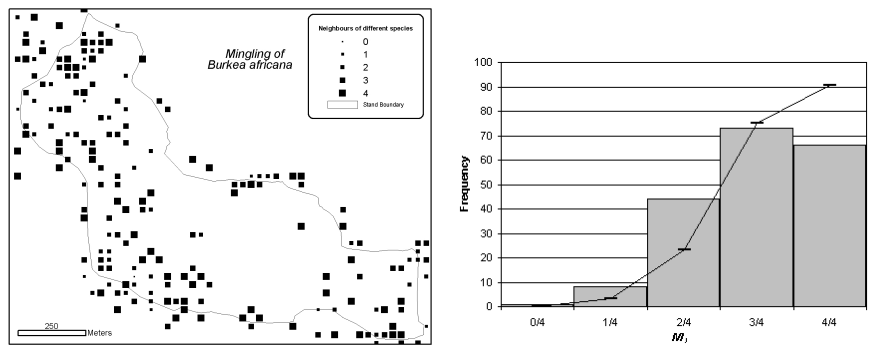

(c) $M=0.696$

Figure C.2.: The dispersion of Baikiaea plurijuga, Pterocarpus angolensis and Burkea africa, within the study area. High values of $M_{i}$ are shown in large circles and vice versa. The graphs depict the observed relative distribution of $M_{i}$ values (bars), and the theoretical hypergeometric distribution (lines) of the values that would indicate a completely random interspersion of the species. 

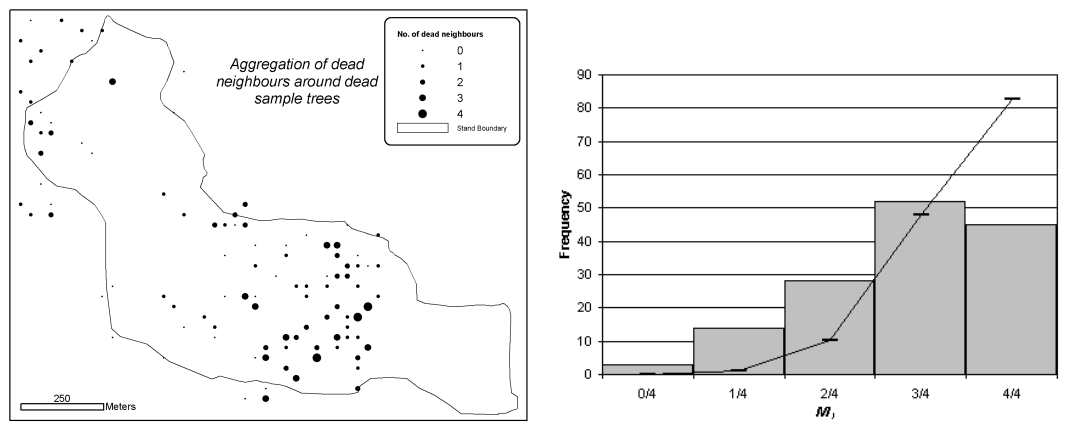

Figure C.3.: The aggregation of dead trees within the stand. The degree of interspersion is reflected by the size of the points, with a high degree of aggregation shown by larger points. $M=0.438$

and establishment phases. The species therefore often regenerates in areas that have been cleared by human or other action. Other species would then establish themselves later.

The interspersion of trees of different size is reflected in the columns $T_{S p}$ (diameter specific) and $H_{S p}$ (height specific) in Table C.1. Preliminary simulation results have shown that a random interspersion of tree sizes would result in an overall average of $T_{S p}=0.5$ and $H_{S p}=0.5$. The table shows, therefore, that size classes are not interspersed randomly.

$P$. angolensis, $S$. rautanenii and $B$. plurijuga need to be highlighted. The low values of $T_{S p}$ and $H_{S p}$ for these species imply that few neighbouring trees are larger than the reference tree. This is supported by general observations in the field. The species therefore dominate in the area in which they occur. It also reflects the regeneration requirements of $P$. angolensis noted previously, but highlights the importance of further research into the demography of the other two species.

Table C.1 also shows a similarity between the values of $T_{S p}$ and $H_{S p}$ of the individual species. Unpublished data shows a high degree of correlation between the dbh and height of $B$. africana $\left(r^{2}=0.8352\right)$, as well as for $P$. angolensis $\left(r^{2}=0.7317\right)$ for nearby stands.

Differences between the two indexes are due to the number of species found in the stand, and the differences in their respective diameter- 


\section{Assessing the spatial diversity of a dry savanna woodland stand in Northern Namibia using neighbourhood-based measures}

height relationships. A larger difference occurs for the Comiphora species, however, reflecting the squat form of the trees; a relatively thicktrunked but short tree.

\section{C.6. Conclusions}

In the past the applications of neighbourhood-based spatial measures were supported by detailed knowledge of the stands that were assessed, as noted above. This was not the case in this study, where only the extent of the stand was known. However, despite their simple application the indexes are able to provide information about the stands they describe, being able to reflect much of what is currently known about the individual tree species and their ecological circumstances.

The results have also highlighted gaps in our knowledge of the ecology of a few of the important trees, such as Schinziophyton rautanenii, Baikiaea plurijuga, and Burkea africana, as well as the various Combretum species that occur in the area. These include regeneration requirements and species succession, and highlights the need for further investigation.

The application of the measures described here has shown that they are easily applied in the field with relatively little training required, although the field crews will have to be able to identify the different tree species. This is particularly useful in view of the trend towards community based natural resource management in Namibia, where community members will have to assess their own resources. Since most of the rural community members are able to identify different plants in their vernaculars, species identification should not be a problem, despite sometimes limited literacy levels.

\section{C.7. Acknowledgement}

I would like to thank my sister Ms. H. Riehmer and Ms. R. Haipinge as well as the late Mr. H. Roth for their assistance with data collection in the field. My sincere thanks also to the Directorate of Forestry, Namibia, for allowing me to use the Kanovlei Forest Station as a base, and the Polytechnic of Namibia who funded the field work. I would particularly like to thank Prof. K. von Gadow, Inst. of Forest Management, Univ. 
of Göttingen for comments.

\section{C.8. References}

Albert M \& Gadow K v. (1998) Assessing biodiversity with new neighborhood-based parameters. Proceedings of the International Conference on Data Management and Modelling Using Remote Sensing and GIS for Tropical Forest Land Inventory. Jakarta, Indonesia, Oct. 26-29, 1998. Amakali M (1992) Updated Isohyetal Rainfall Map for Namibia. Unpublished Report. Department of Water Affairs, Namibia.

Anon (1996) Forest Cover Mapping, Northern Namibia, Phase I'. Unpublished report, Directorate of Forestry, Namibia

Biesele M, Bosquet J \& Stanford G (1979) A Kalahari food Staple: Ricinodendron rautanenii. In Goodin, J.R. and Northington, D.K (eds). Arid land plant resources. International Center for Arid and Semi-Arid Land Studies, Texas Tech Univ. Lubbock. pg 341-355.

Büschel D (1999) A study of Resource Utilization: A case from Namibia, Mpungu Constituency, Kavango District, Northern Namibia. CRIAA SA-DC Report, Windhoek, Namibia.

Botelle A (1999) Estimating Manketti Nut Yields in the forest of Western Kavango, Namibia. CRIAA SA-DC, Windhoek. Chakanga M (1995) Forest Cover Reconnaissance Mapping Project. Directorate of Forestry, Republic of Namibia, Windhoek.

Childes SL (1984) The population dynamics of some woody species in the Kalahari sand vegetation of the Hwange National Park. M.Sc. Thesis, Univ. of the Witwatersrand, South Africa.

Chimbelu EG (1983) The availability, use and Management potentials of Mungongo (Ricinodendron rautanenii, Schinz): A Case study of the Southern Shungu Region, Zambia. Ph.D. Thesis, State University of New York.

Clark PJ \& Evans FC (1954) Distance to Nearest Neighbor as a Measure of Spatial Relationships in Populations. Ecology 35(4):445-453.

Coetzee ME (2001) NAMSOTER, A SOTER Database for Namibia. Agroecological Zoning Programme, Ministry of Agriculture, Water and Rural Development, Namibia.

Crerar SE \& Church JT (1988). Evaporation Map for south West Africa 


\section{Assessing the spatial diversity of a dry savanna woodland stand in Northern Namibia using neighbourhood-based measures}

/ Namibia. Hydrological Report No. 11/1/8/1/H1, Department of Water Affairs, Namibia.

Dominy NJ \& Duncan B (2001) GPS and GIS methods in an African rain forest: applications to tropical ecology and conservation. Conservation Ecology 5(2): 6. [online] URL: http://www .consecol.org/vol5/iss2/ art6

De Pauw E \& Coetzee ME (1999) Production of an Agro-Ecological Zones Map of Namibia (first approximation), Part 2: Results. Agricola 10:8-68.

Department Of Water Affairs (1971) Consolidated Report on Reconnaissance Surveys of Soils of Northern and Central South West Africa in terms of their potential for irrigation. Report TS/30/71, Department of Water Affairs. Windhoek, Namibia.

Department Of Water Affairs (1991) Groundwater Investigation in Kavango and Bushmanland, Namibia. Unpublished Report. Department of Water Affairs, Windhoek, Namibia.

Du Plessis P (2001) Strategy and Action Plan for Promoting Indigenous Fruits in Namibia. Indigenous Fruit Task Team, Ministry of Agriculture, Water and Rural Development, Namibia.

Gadow K v., Hui GY \& Albert M (1998) Das Winkelmass - ein Strukturparameter zur Beschreibung der Individualverteilung in Waldbeständen. Centralblatt für das gesamte Forstwesen. 115(1):1-10.

Gadow K v. (1999) Waldstruktur und Diversität. Alg. Forst-u. J.-Ztg. 170:117-122.

Gadow K v., Hui GY, Chen BW, \& Albert M (2003) Beziehungen zwischen Winkelmass und Baumabständen. Forstw. Cbl. 122: 127-137.

Geldenhuys CJ (1977) The Effect of Different Regimes of Annual Burning on Two Woodland Communities in Kavango. South African Journal of Forestry 103:32-42.

Giess W (1998) A preliminary vegetation map of Namibia (3rd revised edition). Dinteria 4:1-112.

Goldammer JG (1998) Development of a National Fire Policy and Guidelines on Fire Management in Namibia. Namibia Finland Forestry Programme, Directorate of Forestry, Windhoek.

Graz FP (1996) Management of a Pterocarpus angolensis population under the influence of fire and land use. M.Sc. thesis, University of Stellenbosch, South Africa. 
Graz FP (1999) A Preliminary Terrain Feature Classification of the Okavango Region, Namibia. South African Journal of Surveying and GeoInformation 1:123-129.

Graz FP (2003) Fire damage to Schinziophyton rautanenii (Schinz) trees in North-Eastern Namibia. Dinteria 28:39-43.

Graz FP (2004) The behavior of the species mingling Index MSp in relation to species dominance and dispersal. European Journal of Forest Research 1:87-92

Graz FP (in prep.) Description and Ecology of Pterocarpus angolensis in Namibia.

Groome JS, Lees HMN \& Wigg LT (1957) A summary of Information on Pterocarpus angolensis. Forestry Abstracts 18 (2) 153-162

Helgren DM (1982) Edaphic Context of the Mongongo" (Ricinodendron rautanenii) in the Northwestern Kalahari. South African Journal of Science 78:131-132.

Hui GY, Albert M \& Gadow Kv. (1998) Das Umgebungsmaß als Parameter zur Nachbildung von Bestandesstrukturen. Forstw. Cbl. 117: 258-266.

Lee RB (1973) Mogongo: The Ethnography of a Major Wild Food Resource. Ecology of Food and Nutrition, Vol 2, 307-321.

Leger S (1997) The Hidden Gift Of Nature. DED, German Development Service. Berlin, Germany.

Lewandowski A \& Pommerening A (1997) Zur Beschreibung der Waldstruktur - Erwartete und beobaachtete Arten-Durchmischung. Forstw. Cbl. 116:129-139.

Mitlöhner R (1997) Pflanzeninterne Potentiale als Indikatoren für den tropischen Standort. Shaker Verlag.

NFSP (1996) Namibia Forestry Strategic Plan. Directorate of Forestry Windhoek, Namibia.

Newmark J (1997) Statistics and Probability in Modern Life. Sixth Edition. Sauders College Publishing. Fort Worth.

Ollikainen T (1992) Study on Wood Consumption in Namibia. Internal report, Directorate of Forestry, Windhoek.

Palmer E \& Pitman N (1972) Trees of Southern Africa. Vol. 2; Balkema, Cape Town.

Pielou EC (1977) Mathematical Ecology. John Wiley \& Sons, New York: 384 p. 


\section{Assessing the spatial diversity of a dry savanna woodland stand in Northern Namibia using neighbourhood-based measures}

Rutherford MC (1981) Survival, regeneration and leaf biomass changes in woody plants following spring burns in Burkea africana - Ochna pulchra savanna. Bothalia 13:531 552.

Shackleton CM (2001) Managing regrowth of an indigenous savanna tree species (Terminalia sericea) for fuelwood: the influence of stump dimensions and post-harvest coppice pruning. Biomass and Bioenergy 20:261-270

Smith TM \& Grant K (1986) The Role of Competition in a Burkea africana - Terminalia sericea Savanna. Biotropica 18:219-223

Staupendahl K (2001) Das flächenbezogene Winkelmass Wf -Ein Index zur quantitativen Beschreibung der horizontalen Baumverteilung. In: A. Akca et al (HRSG): Waldinventur, Waldwachstum und Forstplanung - Moderne Technologien, Methoden und Verfahrensweisen. Festschrift K. von Gadow. Zohab-Verlag Göttingen. 101-115

Vermeulen WJ (1990) A monograph on Pterocarpus angolensis. SARCCUS Standing Committee for Forestry. Pretoria, South Africa Von Breitenbach F (1968) Long-Term Plan of Forestry Development in Eastern Caprivi Zipfel. George, South Africa. Unpublished Report.

Wilson BG \& Witkowski ETF (2003) Seed banks, bark thickness and damage in age and size structure (1978-1999) of the African savanna tree Burkea africana. Plant Ecology 167:151-162.

Yeaton RI (1988) Porcupines, Fires and the Dynamics of the Tree Layer of the Burkea africana Savanna. Journal of Ecology 76:1017-1029 


\section{Determinants of vegetation patterns in the dry woodland savanna of northeastern Namibia}

Graz, F.P. submitted. Determinants of vegetation patterns in the dry woodland savanna of northeastern Namibia.

\section{Abstract}

The dry woodland savannas of north-eastern Namibia display a patchwork of vegetation structure. Differences in terms of species composition, growth forms and the population structure of individual plant species are affected by a number of factors. Determining factors such as rainfall and terrain have been identified to determine the potential for plant growth, while modifying factors, such as human impact and fire, are those that cause the current state of the vegetation. The effect of the various factors is reviewed and their potential interactions identified.

\section{D.1. Introduction}

The dry woodland savannas of north-eastern Namibia cover an area of approximately $160000 \mathrm{~km} 2$, falling into the vegetation type broadly classed as Baikiaea-vegetation by Werger and Coetzee (1978). Within the southern African subregion, the woodland savanna extends from north-eastern Namibia into southern Angola, western Botswana, northern Zimbabwe, and Zambia. A description of the vegetation in Namibia was initially compiled by Giess in 1971 and later updated (Giess 1998). 


\section{Determinants of vegetation patterns in the dry woodland savanna of northeastern Namibia}

The descriptions provided by the above authors are broad, and a high degree of spatial and structural heterogeneity exists in the vegetation. This is highlighted by studies in the Kavango region of Namibia by de Sousa Correira and Bredenkamp (1987) and Burke (2002), and in the Caprivi by von Breitenbach (1968) and Mendelsohn \& Roberts (1997). The same regions as well as the remainder of the woodland areas were covered by the extensive forest cover reconnaissance survey conducted by the Directorate of Forestry (Chakanga 1995).

The structure and state of the vegetation in general is a function of the present and past actions and interactions of an array of factors. These factors, discussed in the following sections, may be divided into two groups after Graz (1996). These are the determining factors that govern the potential vegetation composition in terms of species. The modifying factors, on the other hand, alter the environment so that it may favour one species or growth form over another, or affect individual species or growth forms directly. While the determining factors are primarily rainfall and those factors influencing the soil moisture balance, the modifying factors are primarily of anthropogenic origin, mainly in the form of resource extraction, including land clearing and grazing of domestic animals, and fire. Grazing and browsing by wildlife is generally limited in the area since game numbers have been depleted in many of the woodland areas through overutilization.

The interactions between determining and modifying factors, as well as between different modifying factors have prompted various investigations. These include ecosystem studies by Rutherford (1975), Knoop (1982), Childes (1984), Scholes \& Walker (1993) and Graz (1996), studies dealing with the influence of fire (Geldenhys 1977, Yeaton 1988, Chidomayo 1988), plant-water relations (Mitloehner 1997) and competition (Smith \& Grant 1986). Each of the studies offers further insight into the individual factors that determine and modify the vegetation.

In order to understand the current structure of the woodlands as well as their structural development it is necessary to have an understanding of the basic processes that govern the vegetation. An overview of these processes is provided in the next few sections for this purpose. 


\section{D.2. Determinants, Modifiers and Species Responses}

\section{D.2.1. Determinants}

\section{D.2.1.1. Terrain and Soil Factors}

The soils in northeastern Namibia are dominated by unconsolidated aeolian material, generally referred to as Kalahari Sand (de Pauw and Coetzee 1999). These overlay a layer of calcrete, forming a terrain of sandy plains or a system of east-west orientated linear dunes as described by Graz (1999). The calcretous soils may be exposed in the interdunal zones (locally termed 'streets'). Figure D.1 depicts the dunes as broad bands and streets containing pans and cultivated fields of the western Kavango region in Namibia.

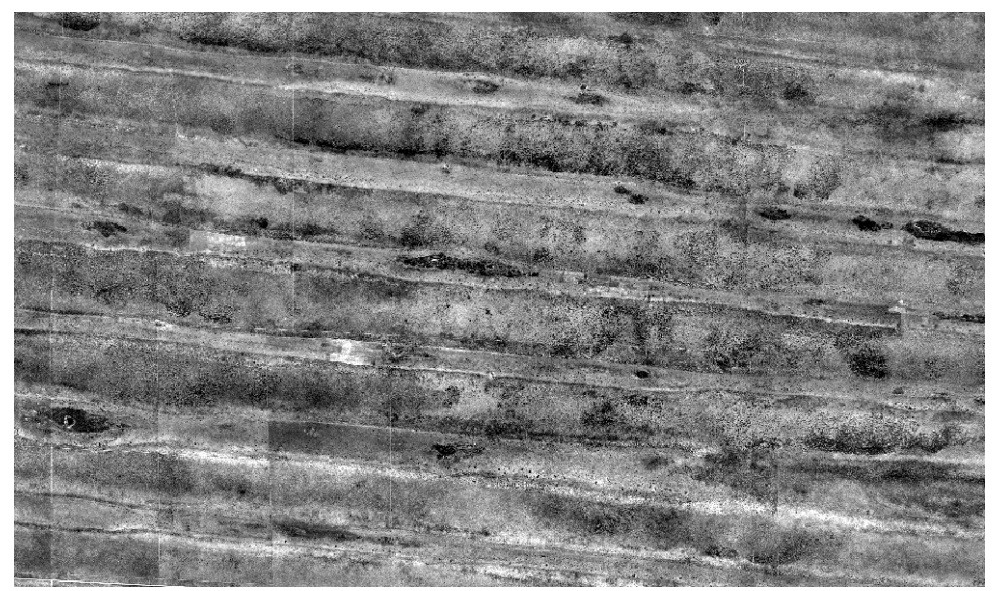

Figure D.1.: Section of an aerial photograph of the Kavango region, northern Namibia. The wide strips represent the dunes, while pans are visible as almost black patches within the streets as are cultivated fields. (DSM 1996)

The areas are traversed by rivers such as the Okavango and Kwando or by omuramba (vegetated dry river beds) of unconsolidated fluvial 


\section{Determinants of vegetation patterns in the dry woodland savanna of northeastern Namibia}

sands (de Pauw and Coetzee 1999). The omuramba soils are shallower and have a heavier texture than the dunes (Department of Water Affairs 1971).

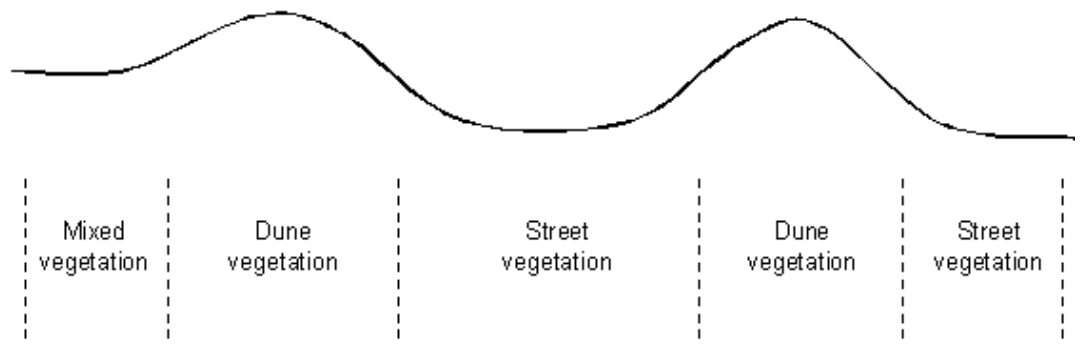

Figure D.2.: A section through the dune and street complex after Graz (1996). Mixed vegetation (referred to as 'broken dune' vegetation by Graz (1999)) is a mixture of typical dune and street vegetation, and is found on very shallow dunes.

The different soil types support different vegetation types as illustrated in figure D.2. Some tree species typical of the dune and street vegetation are given in table D.1. The species found on dunes are also those that predominate on the higher lying sandy plains, while those of the streets also dominate in the omuramba. Within the streets, pans may be surrounded by Ziziphus mucronata.

\begin{tabular}{|c|c|}
\hline Street vegetation & Dune vegetation \\
\hline \hline Acacia melifera & Pterocarpus angolensis \\
\hline Acacia erioloba & Burkea africana \\
\hline Lonchocarpus nelsii & Schinziophyton rautanenii \\
\hline Catephractes alexandri & Terminalia sericea \\
\hline Dichrostachys cinerea & Baikiaea plurijuga \\
\hline & Combretum collinum \\
\hline & Ochna pulchra \\
\hline
\end{tabular}

Table D.1.: Tree species typically found on dunes and in the streets, after de Sousa Correira \& Bredekamp (1987), Giess (1998) and Burke (2002). 
Individual studies of dune type soils by Helgren (1982), Graz (unpublished data) and Mitlöhner (1997) in different parts of the woodland savanna as well as Coetzee (1999) report sand and fine sand components of $90-96 \%$. This texture has important implications for the soil moisture balance by influencing the hydraulic conductivity and water holding capacity of the soil.

The pore spaces between the individual soil particles in sand are larger than in heavier soils it could be expected that drainage through sand is also much faster (after Foth 1990). This is true for water saturated soils as the hydraulic conductivity of soil is closely related to the moisture already present - the hydraulic conductivity decreases with decreasing soil moisture (Foth 1990, p62).

Slower infiltration of water into a dry soil may be readily seen in the field at the end of the dry season or after a few days of hot, dry weather when the soil surface is completely dry. Raindrops initially do not drain into the soil but remain on the surface. If showers are short the raindrops may evaporate before they can enter the soil to any depth, making such showers wholly ineffective. Evaporative water loss from the soil is reduced when the soil is shaded by vegetation, but in such cases more rain is intercepted by the plants themselves.

The texture also affects the amount of moisture that the soil may retain as cohesion and adhesion water. The fine sands reported by the above authors, have a grain size ranging from $0.1 \mathrm{~mm}$ to $0.25 \mathrm{~mm}$ leading a higher moisture holding capacity than more coarse sands (Foth 1990). The street soils with their heavier texture are considered drier despite their higher water holding capacity. This is primarily due to the replenishment of water in the higher soil layers through capillary movement of soil moisture when the higher soil layers has evaporated.

Although the presence of organic material in a soil might generally improve water holding capacity of such a soil, the environmental conditions present in the area are not conducive to organic matter build-up. The highly variable soil water content, particularly in the top soil, severely retards decay, while periodic fires reduce the matter that had been able to accumulate (Malaisse et al. 1975).

The soil texture and low organic matter contents result in a low nutrient status as reported by Helgren (1982), the Department of Water Affairs (1991) and Coetzee (2001). This makes particularly the dune soils little suitable for plant growth. 


\section{Determinants of vegetation patterns in the dry woodland savanna of northeastern Namibia}

\section{D.2.1.2. Precipitation}

The region is characterized by a distinct cycle of wet and dry periods. In the woodland savanna of north-eastern Namibia the wet season extends from the end of September to around mid March. The remainder of the year comprises the dry season. Significant annual variation in both the amount and timing of precipitation occur, therefore making rainfall highly unpredictable. A distinct moisture gradient has been observed over the region. Long term observations of average rainfall range from $400 \mathrm{~mm}$ in the south western parts of the woodlands to around $700 \mathrm{~mm}$ in the far eastern parts of the Caprivi strip (Amakali 1992).

The individual rainfall events frequently occur as thunderstorms (Graz 1996). These may sometimes cover extensive areas but are frequently localized. A great spatial heterogeneity therefore exists in timing and quantities of rain.

Runoff is extremely limited on the dune soils due to the high infiltration, even when the soils are very dry. Between the dunes some runoff may, however, accumulate in scattered pans. These are generally associated with other plant species.

On a local scale, the impact of rainfall is modified by interception of the existing vegetation. Although some intercepted water will evaporate from the vegetation, a proportion will reach the soil as through-fall and stem-flow. The latter, stem-flow, represents a concentrated application of water around the base of a tree. De Villiers and de Jager (1981) found that this caused the formation of a zone of increased soil moisture up to one meter in diameter around the base of the tree. This also results in wetting of the soil to considerably greater depth than rainfall on the open land, and is therefore of great importance to tree growth.

Evapotranspiration over the savanna woodland area in Namibia is estimated at between $2600 \mathrm{~mm}$ and $2800 \mathrm{~mm}$ per annum (Crerar and Church 1988) also increasing from swouth-west to north-east. Based on the resulting moisture deficit, and combined with temperature requirements for active growth, de Pauw \& Coetzee (1999) delimitated regions of growing periods ranging from 91 to 135 days in the areas in which the woodlands occur. This estimate is based on the number of days during which precipitation exceeds half the potential evapotranspiration plus the number of days to evapotranspire approximately $100 \mathrm{~mm}$ of water. 


\section{D.2.1.3. Vegetation Responses}

The responses of the vegetation and its component species to the external factors form an additional group of determinant factors. Although these adaptations may also be considered in terms modifiers it may be argued that they might fit into both categories. In the short term it may be more appropriate to consider them as determinants, as is done here.

It must be argued that current species adaptations and requirements are a form of response to the long-term environmental conditions. Below is a brief, though by no means exhaustive summary of the adaptations of woodland species.

As indicated previously, the soil moisture condition plays an important role in woodland dynamics. Different species therefore have acquired a competitive advantage when growing in a given soil type, or in the presence of other species. Some of this advantage may stem from the ability of the trees to obtain water against the soils' matrix potential (See Mitlöhner 1997).

Pterocarpus angolensis (Vermeulen 1990) and Schinziophyton rautanenii (Graz 2002) are, for example, only found on aeolian soils within the savanna woodlands, while species such as Acacia erioloba and Catophractes alexandri will seldom occur there (Burke 2002) but rather in the heavier textured dune soils.

The species $P$. angolensis is also severely affected by competition. While seedlings and suffrutex forms may occur in woodland areas the plants will not develop into trees unless competition with other plants is low. Periodic clearing of land by human or other action provides the species with suitable conditions for seedling establishment (Vermeulen 1990). This results in spatially distinct stands of relatively even sized trees as already reported by Groome et al. (1957). P. angolensis therefore generally occurs in spatially distinct size classes.

Childes (1984) showed that stems of B. plurijuga were of similar size at Hwange NP in Zimbabwe, but the roots were of different ages. Above ground plant parts were only able to establish when they were able to escape the effects of fire. Seedlings / suffrutex plant forms were therefore able to accumulate over a number of years to form a permanent trunk when the fire regime permitted.

Burkea africana, shows similarly spatially distinct size class distribu- 


\section{Determinants of vegetation patterns in the dry woodland savanna of northeastern Namibia}

tions. In this case, however, the cause of the spatial differentiation is probably different although this does not seem to have been investigated in any detail. While it is known that the species is able to regenerate freely under adult trees (Yeaton 1988), seedlings are highly susceptible to fire induced mortality (Rutherford 1981). Although no records are available in this regard, it is likely that plants of equal diameter are not necessarily of similar age.

Many of the adaptations that were documented seem to relate to coping with fire (see later). Walker et al. (1986) state that a number of woodland species exhibit cryptogeal germination (the plumule is buried in the development of the root crown below the soil surface. Buds on the root crown will therefore be protected from fire). This enables the plant to coppice from below ground if the aerial parts are removed. The authors specifically cite Burkea africana.

The suffrutex behaviour reported for $P$. angolensis by Vermeulen (1990) permits a young plant to develop a root system to a size that will support a large trunk. S. rautanenii seems to follow a similar strategy, although this has not been confirmed.

The thick bark developed by some species also provides protection against fire. Hare (1965) determined, for instance that the time required to kill the cambium of a tree was dependent on the thickness of the bark, as well as its thermal conductivity. Wilson \& Witkowski (2003) showed that bark thickness of $B$. africana increases with tree diameter. The same was noted by Vermeulen (1990) for P. angolensis. If the bark is damaged a tree will become much more susceptible to fire damage. This was reported by Yeaton (1988) for B. africana, and by Shackleton (2002) for $P$. angolensis, where porcupine, in both reports, damaged the bark near the base. Observations in the field and those reported by Graz (2003) show that growth stresses are able to cause a breach of the bark of $S$. rautanenii, but also that of $P$. angolensis. Given the spatially distinct size classes cited above, fire may repeatedly reduce the trees over larger areas back to ground level. 


\section{D.2.2. Modifiers}

\section{D.2.2.1. Direct Human Impact}

While the woodland savannas covers around $20 \%$ of Namibia's land area it supports between 50 and $60 \%$ of the country's population (Mendelsohn et al. 2002). Rural communities utilize a wide variety of resources extracted from the woodland to support their day-to-day lives.

The Namibia Forestry Strategic Plan (NFSP 1996) divides these resources into wood and non-wood products. The wood products include firewood, building and construction material, fencing material, wood for carpentry and carving. The non-wood products on the other hand, include grazing and thatching material, wildlife (where present), veld foods such as roots, fruit, nuts and honey, and traditional medicines (Leger 1997). While there is currently no information of traditional management practices regarding woody resources, periodic burning is used to enhance the quality or productivity of some non-wood forest products (Lusepani et al. 1998).

In 1992 it was estimated that a total of 1.5 million cubic meters of wood were used for firewood alone (Ollikainen 1992), most of which had originated from the woodlands. In 1996 the National Planning Commission determined a GDP (agricultural production) of $\mathrm{N} \$ 2.6$ billion, though ignoring the informal sector. During the same year the total woodland resources that were used by the informal sector amounted to an equivalent value of almost $\mathrm{N} \$ 1060$ million per annum (NFSP 1996, p. 3).

The total amounts of resources that are used annually and the number of plant species involved are quite substantial, and the selective pressure on some species may cause change in the vegetation composition in terms of species or tree-size structure. While no data is available for Namibian conditions, Columba (2003) observed in his study, that the number of tree species in a similar area declined when human influence increased. This impact was particularly evident at the edges of woodland areas. In the same area Shackleton (1993) had observed that specific size classes of trees were targeted for firewood, depending on how easily the wood could be handled.

Similar influences may be assumed to occur in Namibia. The exploitation of trees species by the carving industry, particularly $P$. angolensis, 


\section{Determinants of vegetation patterns in the dry woodland savanna of northeastern Namibia}

Guibourtia coleosperma, S. rautanenii and Combretum collinum and the specific size classes targeted by this industry as well as by builders of traditional homesteads $(10-15 \mathrm{~cm}$ dbh) are likely to impact species and size class distributions.

In north-central Namibia Erkkilä \& Siiskonen (1992) reported that firewood was hauled over a distance of up to $33 \mathrm{~km}$, as the local resources had been depleted. Due to the distances involved such haulage is primarily carried out with motor vehicles. Van Heist \& Kooiman (1992) studied the availability of fuelwood around villages in Botswana and assumed that wood was collected on foot in a radius of around $10 \mathrm{~km}$. In combination, these sources would not only indicate that the woodlands are heavily utilized around homesteads, but in a $20 \mathrm{~km}$ wide band around roads that may be travelled by motor vehicle.

The use of fire for traditional vegetation management is discussed in more detail in a separate section on fire, below.

\section{D.2.2.2. Grazing}

As indicated previously, the majority of the woodland area is unsuitable for cultivation due to the nutrient status of the soils. Land use practices have therefore concentrate on livestock farming on the dunes and sandy plains. The street and omuramba soils on the other hand, are suitable for crop farming, and large areas are cleared for agricultural use each year (Burke 2002). Areas close to roads in particular are popular due to the access that these roads provide to markets and other services.

Commercial farming practices have been implemented over the last 40 years in the northeastern parts of the Grootfontein magisterial district. The border between such commercial farms and the adjacent communal areas present a clear contrast in vegetation structure (Graz 1996). These are due to the different fire and grazing management practices in the commercial and communal areas.

The presence of Dichapetalum cymosum, a plant poisonous to cattle, in the grazing camps on the dunes requires careful cattle management. During the winter months D. cymosum represents the only green in the dune vegetation, attracting the cattle. Farmers therefore keep their cattle out of grazing camps in which this plant occurs during this time.

The different management practices implemented for dune and street vegetation has caused the development of a striking fence-line effect 
also within the farms. Acacia species and Dichrostachys cinerea may, for instance, dominate on the one side of the fence, in the streets, while broadleaved woodland trees occur on the other side. The fence-line effect is readily observed also very evident on satellite images or aerial photos as illustrated in figure D.3. The figure shows a sharp transition between the dune and street vegetation within the farming area. The transition between dune and street vegetation is not as abrupt the communal lands.

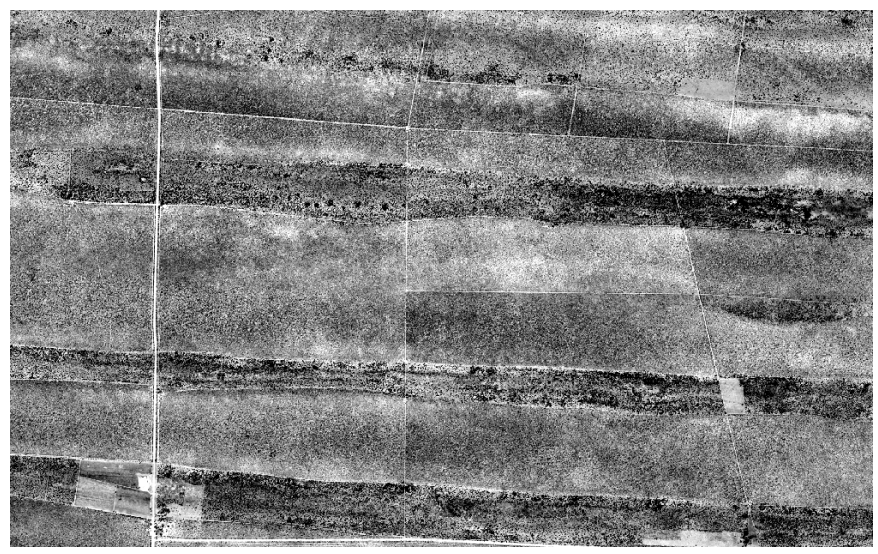

Figure D.3.: The separation of dune and street vegetation on individual farms (DSM 1996).

With the establishment of the farms permanent water points were developed. This permitted the farmers to retain their cattle on the farms throughout the year. While a system of rotational grazing rotational resting is implemented on the farms, the grazing patterns are different to those of the unmanaged wildlife populations that occurred in the area prior to the establishment of farms (see Savory \& Butterfield 1999).

Dougill et al. (1999) noted vegetation changes around boreholes in Botswana, primarily as a result of concentrated cattle grazing. This is evident in Namibia as well. Concentrations of cattle may also be found near gates or at points where salt-licks are provided in the commercial farming sector. Figure D.3 shows small white patches close to places where two or more fences meet. While these patches are comparatively small, generally only $100-200 \mathrm{~m} 2$ in extent, they represent the center of 


\section{Determinants of vegetation patterns in the dry woodland savanna of northeastern Namibia}

a zone of increased animal presence and subsequent impact. In communal areas cattle may also be concentrated around overnight enclosures or homesteads. With the establishment of new boreholes it may be observed that people will initially use boreholes primarily for the watering of cattle, but will soon settle close by, with the subsequent impact on the vegetation.

\section{D.2.2.3. Fire}

Fire has affected savanna type vegetation for thousands of years, and each year vast tracts of land are burnt in southern Africa. In 1996 and 1997 approximately $67 \%$ and $75 \%$ of land area of the Caprivi region of Namibia was burned by wild fires (Trigg 1998). Graz (2003) reported that $25 \%$ of the distribution range of S. rautanenii burnt annually or biannually in the period 1996-2001. Verlinden (in prep) shows that between $28 \%$ and $51 \%$ of the Kavango and Caprivi regions burnt annually in the period 1989 to 2001 .

In the past, fire was an important tool in traditional management of the woodland areas of Namibia, primarily to manage grazing. Traditional authorities had implemented control systems to regulate the use of fire in the past (Kotzé 1968). If a person wanted to burn to remove the grass of the previous year, shortly before the next rain season, he had to get the permission of the Chief (Wandres 1909, p. 676). Now, however, most of these systems have degenerated or been abolished altogether as the power of some traditional courts is eroded (Tuomasjukka et al. 1998).

Different growth forms and size classes of trees differ in their susceptibility to fire damage. While small shrubs may have virtually all of their above ground parts removed, larger trees are generally unaffected. If trees have sustained damage to their trunks (the bark in particular) due to animal damage (see Yeaton 1988), direct human impact (Zimmermann pers com) or due to cracking as a result of growth stresses (Graz 2003) fire will be able to penetrate the trunk of larger trees as well.

The time that trees require to regain their pre-fire state depends on the degree of damage that the trees sustained. Only when the fire tolerance of the individual trees is overcome will the plants actually die. While seedlings of species such as P. angolensis (Vermeulen 1990), S. rautanenii (Geldenhuys 1977) and Burkea africana (Rutherford 1981) 
are susceptible to fire, the plants are only top-killed and are able to grow back from the burnt stumps once they have attained a certain age. When a permanent trunk is formed, the tree becomes increasingly resistant to fire.

Repeated burning may therefore cause the formation of even sized, though not even aged cohorts of plants from the accumulated seedlings from a series of successive years. This is in accordance with the findings of Childes (1984) in the Hwange National Park, Zimbabwe. Childes compared the root collar diameter of $B$. plurijuga trees and identified significant size differences despite a fairly uniform diameter of trees.

The susceptibility of the vegetation to fire is further influenced by its own current structure. During his simulation study, Petersen (2002) determined that an area might show what he terms ecological memory of previous burns. He showed that the probability of a fire in an area would increase if the area had previously been burnt. The ecological memory concept therefore implies that the probability of occurrence of an event is affected by (similar) disturbances in the past. This happens because the event or disturbance changes the condition of the vegetation, which in turn changes the probability that a similar event or disturbance is repeated.

While his model is simple and Petersen notes that some basic assumptions may be risky, his findings are in line with observations from the field.

The concept is supported by the findings of Li et al. (1999) that an area's susceptibility to fire is determined by its condition. The condition in turn is a function of the fire history. Scholes \& Walker (1993, p.224) also note that a grass-dominated vegetation will be maintained by recurrent fires. The smaller sized grass fuels in turn increase the likelihood of fire (Heikkila et al. 1993). Similarly, Rutherford (1981) found that the number of basal shoots in an area increased with an increase in fire frequency (see below). These basal shoots are generally thin, making them more prone to damage by fire.

Such ecological memory may also be displayed in relation to other factors. Light grazing, for instance, indirectly results in the rejuvenation of grass plants, with the younger material being more palatable to grazing animals (after Wolfson 1999 and Wolfson \& Tainton 1999).

Ultimately, the effect of fire on woodland vegetation should be viewed in terms of the frequency with which fires occur, the time of burning and 


\section{Determinants of vegetation patterns in the dry woodland savanna of northeastern Namibia}

the intensity of fire. While the three aspects are necessarily dealt with in separate subsections (see below) it must borne in mind that they are very closely linked. To provide additional background to present and past burning practices, and to show that increased fire frequencies may be expected, an additional section is provided dealing with sources of fire.

Fire frequency The frequency of fire refers to the number of fires that occur over a given period of years. What should be considered important here is not so much the number of fires, but the length of the period between two consecutive burns.

The time available between two burns is the period that is available for plants to recover from the effects of a previous burn (Trollope 1982) and for young plants to outgrow a stage where they might be severely damaged or killed. The interval also represents the time available for a fuel load to accumulate in the form of leaf litter and smaller twigs. Should longer periods occur without fire then smaller and larger branches or even whole trees will be added. This significantly affects the potential damage caused by the next burn, since the time available not only affects the quantity of fuel that accumulates, but also the type of fuel.

Just as the vegetation is classified as woody or herbaceous, so we may classify the available fuel. While this may again be considered arbitrary, the two components have different combustion characteristics in view of their surface to volume ratios as well as their specific gravity. The smaller/light herbaceous fuels as well as leaf litter with a large surface area per unit volume of material are able to reach combustion temperature much faster than heavier fuels (Heikkila et al. 1993). This means that they are more easily set alight than are heavier fuels. Similarly, the smaller twigs and branches of small trees and shrubs may ignite faster than thicker fuel.

Fuel accumulation is very much determined by the growth rate of the vegetation, i.e. biomass production (although grass biomass will be affected if the area is grazed). This is in turn a function of the available soil moisture as well as the vegetation composition.

Burns are never complete. A fire may bypass smaller areas leaving the vegetation unaffected. This results in the formation of patches of vegetation that are affected by different fire frequencies and fire intensities 
(see below) in view of differences in fuel accumulation.

In summary therefore, a high fire frequency suppresses the development of seedlings and small woody plants. At the same time the development of the herbaceous cover will increase the likelihood of a fire, although the potential damage is reduced. A lower frequency on the other hand may support the development of a higher fuel load and therefore more potential for damage, but also permits the individual plants to outgrow their susceptibility.

Fire season The term fire season is somewhat misleading. Fires generally occur in the dry season, from around late April to the end of September. As the dry season progresses the fuel becomes increasingly dry, particularly the small fuels. This makes the fuel more flammable, and allows it to burn at a faster rate (a higher intensity) later in the season. It is in this context and due to the physiological status of the woodland plants that the fire season is divided into an early season, i.e. early in the dry season, and late season.

Early in the season, when fuel is still comparatively moist fires are less intense (see later), and it is possible that not all fuel will be consumed. At the same time most of the deciduous woody plants have reached (physiological) dormancy (Lawton 1978), although species such as Baikiaea plurijuga and Burkea africana may continue to grow longer into the dry season. The grasses have by that time also reached dormancy.

The dormancy of the woody plants and lower fire intensity result in less damage to woody plants than later in the season (Rutherford 1981). Furthermore, the perennial grasses that are induced to flush by the burn will not sprout as vigorously during the subsequent growing season (Tainton 1999), thus delaying the development of the herbaceous fuels.

In the long run early burning would therefore favour the woody component of the woodlands. Developing clumps of woody plants also shade out much of the herbaceous growth with the subsequently reduced fuel load and likelihood of a fire. In order to promote the formation of closed woodlands, management, burns should be carried out early in the dry season (Trapnell 1959, Geldenhuys 1977, Chidomayo 1988).

As the dry season progresses the fuel will continue to dry thus increas- 


\section{Determinants of vegetation patterns in the dry woodland savanna of northeastern Namibia}

ing its flammability and potential rate of combustion (with concomitant intensity). Fires that occur at the end of the dry season therefore have much greater potential to damage woody plants than have early season fires (Rutherford 1981). If the fuel is sufficient even the crowns of canopy trees may be damaged (Lawton 1978).

The perennial grasses are less likely to incur serious damage if they are induced to break dormancy too early; they face less herbivore pressure than earlier in the dry season and will soon get rain. Instead they may be stimulated to grow better due to removal of moribund material.

Fire intensity The intensity of a fire refers to the rate at which heat energy is released during a fire. This is much dependent on fuel moisture since the energy used by evaporation of moisture from fuel is not released as heat energy. Late season fires are therefore of higher intensity than fires burning early in the dry season. However, as the intensity of burns increases more woody plants are killed (Rutherford 1981).

Fire intensity is also significantly correlated with the rate of spread of a fire, with higher intensity fires associated with a faster rate of spread (Trollope 1981). Rate of spread is closely linked to the fuel load (herbaceous fuel permitting faster rates of spread) and wind speed.

Fuel size also plays a significant role. Smaller fuels will produce a higher fire intensity than will larger fuels (Heikkila et al. 1993) due to the former's large surface area per unit of volume, and the concomitant rate of heat release.

It must be borne in mind that the soils that support the dry savanna woodlands do not support a dense grass cover, primarily because of a shortage of water. In this case, the growth form of a plant must be considered. Leaf litter may accumulate between the shoots of bushes or the coppice from tree bases. This may be readily observed in the field but was also specifically documented by Rutherford (1981) for Grewia species at Nylsvlei in South Africa. The accumulated litter not only leads to a higher fuel load, but a fuel load that is up against the stems of plants. This is probably the reason why $P$. angolensis coppice is unable to re-establish in areas of very high fire frequency (Vermeulen 1990). 
Sources of fire In 1981, Siegfried reported that between $54 \%$ to $73 \%$ of all fires in the Etosha National Park were caused by lightning. He recognizes that this would not be the same outside the park and considers that the majority of fires outside the park are now caused by man.

Considering the ecological importance of fire it is necessary to review briefly the causes and sources of fire in the woodland areas. In order to provide some understanding why indigenous people use fire as a management tool, a brief review of the reason for burning and the ecological impact is provided.

This is particularly important since the occurrence of fire is likely to change. In his report Goldammer (1998) highlighted the decline in nomadic habits of the indigenous people. This, together with the growing population of Namibia, is causing an increase in the incidence of fire in the woodland areas. In the light of the above it would be assumed that areas close to human concentrations are most prone to fire than those further away. Preliminary comparison between the settlements in the Kavango region and the number of fires associated with the area show, however, that the reverse is the case. This probably due to the low herbaceous fuel load as a result of heavy grazing.

\section{Grazing management}

The Herero people have burned portions of the veld in the dry season in order to stimulate the grasses to flush outside the growing season. The heat of the fire breaks the dormancy of the grasses. With this, the people provided their cattle with green grass in August and September. Apart from the earlier availability of green fodder, the cattle become accustomed to the transition from dry grass to the fresh grass of the rainy season, thus avoiding stock losses associated with stomach disorders (Vedder, 1928 p. 43). Burning to stimulate an out of season flush is still advocated for game farm management today (Tainton 1999).

The early stimulation of growth causes the perennial grasses to use their root reserves. If the rains are late, the grasses die back, to resume growth once the rains come. This second growth-spurt uses further root reserves, and is less vigorous since the plants have already used up much of these reserves. Individual plants are therefore weakened, and are easily overgrazed (Tainton 1999). In the communal areas within the woodlands of Namibia, where the control over land use must still be established, the threat of overgrazing is significant.

The weakened herbaceous component is, however, also represents less 


\section{Determinants of vegetation patterns in the dry woodland savanna of northeastern Namibia}

competition for grass seedlings. Early burning would therefore be to the advantage of the woody plant component.

Hunting

While some animals may move in direct consequence to fire, the early growth of grass that is stimulated by fire has been used by the local population to attract game animals to specific areas (Vedder 1923, Vedder 1928, p. 43, Lusepani et al. 1998, Anon 1999), making them easier to find and hunt. This method is particularly effective in the dry season, but may also result in severe overutilization of the grasses.

Fire has also been used to remove undergrowth to enhance long distance visibility for the detection of game animals (Tuomasjukka et al. 1998), and also facilitates easier tracking (Lusepani et al. 1998, Büschel 1999). In recent years the long distance visibility is also said to have served poachers to detect the movement of law enforcement officers.

Other Uses

The increased visibility that is achieved when the undergrowth is removed has also been exploited by the Bushman people to facilitate collection of mangetti (S. rautanenii) nuts (Tuomasjukka et al. 1998). It has also been noted that fire stimulates the growth of other veld foods (Lusepani et al. 1998) and is used for honey hunting (Goldammer 1998).

Von Breitenbach (1968) and Gibson et al. (1981) report that fire is often used for the clearing of land for cultivation. While the resulting ash-bed effect initially high yields, production declines as the effect is lost within only a few years.

\section{D.3. Discussion and Conclusion}

The woodland vegetation in northern and north-eastern Namibia is subject to a variety of influences. These range from direct exploitation by resident communities and the effects of fire to more subtle modifications in the effect of abiotic factors caused by the existing structure and composition of the vegetation itself. The actions and interactions of the factors discussed above results in a diversity of vegetation structure in terms of species composition and the make-up of the populations of the component species.

The effects of some factors cover distinct regions with abrupt changes to adjacent areas where the same factor changes its intensity or effect, 
or does not affect the vegetation at all. The difference in soil moisture regimes between dunes and street soils and the commercial vs. communal farming areas fall in this category. The effects of fire should also be included here since the fires have definite boundaries to their effect.

Other factors display a gradual change in intensity, radiating outwards from a particular point or area. Here the gradually decreasing intensity of grazing with increasing distance from a water point or kraal, or the change in rainfall and evaporation from south west to north east are important.

A third group of factors may be identified to form an intermediate category between the two identified above. This group represents those factors that have a fairly even effect over a region around a central point or area. Included here is the collection of veld foods, wood for carving or firewood around a settlement. The effect differs from the first group in view of its dynamics. As a resource becomes scarce the collection distance is increased. Differences in relation to the second group manifest in the relatively sudden change in the intensity of the factor.

Ultimately, the combined influence of determining and modifying factors results in an irregular patchwork of vegetation structure, in terms of species composition, density, age or size class distributions and growth forms (see Chakanga 1995).

\section{D.4. Acknowledgements}

I would like to thank Prof. P. Poschlod, Univ. of Regensburg for comments on an early version of the manuscript and helping me on to the right track.

\section{D.5. References}

Amakali, M., 1992. Updated Isohyetal Rainfall Map for Namibia. Unpublished Report. Department of Water Affairs, Windhoek, Republic of Namibia.

Anon, 1999. Oshaampula Community Forest Reserve PRA Report. Directorate of Forestry, Windhoek, Republic of Namibia. 


\section{Determinants of vegetation patterns in the dry woodland savanna of northeastern Namibia}

Burke, A. 2002. Present vegetation in the Kavango Region. J. Nam. Sci. Soc. 50:133-145.

Büschel, D. 1999. A Study of Resource Utilisation: A case from Namibia, Mpungu Constituency, Kavango District, Northern Namibia. CRIAA SA-DC Report, Windhoek.

Chakanga, M. 1995. Forest Cover Reconnaissance Mapping Project. Directorate of Forestry, Windhoek, Republic of Namibia,.

Chidomayo, E.N. 1988. A re-assessment of effects of fire on miombo regeneration in the Zambian Copperbelt. Journal of Tropical Ecology 4:361-372

Childes, S.L. 1984. The population dynamics of some woody species in the Kalahari sand vegetation of the Hwange National Park. M.Sc. Thesis. University of the Witwatersrand, Johannesburg, South Africa. Coetzee, M.E. 1999. Preliminary Agroecological Zones. Agricola 1998/1999; Addendum.

Coetzee, M.E. 2001. NAMSOTER, A SOTER Database for Namibia. Agroecological Zoning Programme, Ministry of Agriculture, Water \& Rural Development, Namibia.

Columba, J.C.L. 2003. Effects of Woodland Fragmentation on Tree Diversity in the Northern Province, South Africa. M.Sc. Thesis, ITC, Enschede, The Netherlands.

Crerar, S.E. \& Church, J.T. 1988. Evaporation Map for South West Africa / Namibia. Hydrological Report No. 11/1/8/1/H1. Department of Water Affairs, Windhoek, Republic of Namibia.

De Pauw, E. \& Coetzee, M.E. 1999. Production of an Agro-Ecological Zones Map of Namibia (first approximation), Part 2: Results. Agricola 10:8-68.

De Sousa Correira, R.J. \& Bredenkamp, G.J. 1987. A reconnaissance survey of the vegetation of the Kavango, South West Africa. J. SWA.ci. Soc. 41:29-45.

De Villiers, G. du T. de Jager, J.M. 1981. Net rainfall and interception losses in a Burkea africana - Ochna pulchra tree savanna. Water S.A. 7:249-254.

Department of Water Affairs 1971. Consolidated Report on Reconnaissance Surveys of Soils of Northern and Central South West Africa in terms of their potential for irrigation. Report TS/30/71, Department of Water Affairs. Windhoek, Republic of Namibia. 
Department of Water Affairs 1991. Groundwater Investigation in Kavango and Bushmanland, Namibia. Unpublished Report. Department of Water Affairs, Windhoek, Republic of Namibia.

DSM 1996. Digitalized orthophoto maps of 1996. Directorate of Surveying and Mapping, Windhoek.

Dougill, A.J., Thomas, D.S.G. \& Heathwaite, A.L. 1999. Environmental change in the Kalahari: Integrated land degradation studies for nonequilibrium dryland environments. Annals of the Assoc. of American Geographers 89(3):420-442.

Erkkilä, A. \& Siiskonen, H. 1992. Forestry in Namibia, 1850-1990. Silva Carelica 20:1-244.

Foth, H.D. 1990. Fundamentals of Soil Science (8th ed). John Wiley \& Sons.

Geldenhuys, C.J. 1977. The Effect of Different Regimes of Annual Burning on Two Woodland Communities in Kavango. South African Forestry Journal 103:32-42

Gibson, G.D., Larson \& T.J., Mcgruk, C.R. 1981. The Kavango Peoples, Studien zur Kulturkunde 56. Franz Steiner Verlag, Wiesbaden.

Giess, W. 1998. A preliminary vegetation map of Namibia (3rd revised edition). Dinteria 4:1-112.

Goldammer, J.G. 1998. Development of a National Fire Policy and Guidelines on Fire Management in Namibia. Namibia Finland Forestry Programme, Directorate of Forestry, Windhoek.

Graz, F.P 1996. Management of a Pterocarpus angolensis population under the influence of fire and land use. M.Sc. Thesis, University of Stellenbosch. Stellenbosch, South Africa.

Graz, F.P 1999: A Preliminary Terrain Feature Classification of the Okavango Region, Namibia. South African Journal of Surveying and Geo-Information, Vol 1:123-129.

Graz, F.P 2002. Description and Ecology of Schinziphyton rautanenii (Schinz) Radcl.-Sm. In Namibia. Dinteria 27:19-35.

Graz, F.P. 2003. Fire damage to Schinziophyton rautanenii (Schinz) trees in North-Eastern Namibia. Dinteria 28:39-43.

Groome, J.S., Lees, H.M.N. \& Wigg, L.T. 1957. A summary of Information on Pterocarpus angolensis. Forestry Abstracts 18:153-162.

Hare, R.C. 1965. Contribution of bark to fire resistance of southern trees. Journal of Forestry 63(4):248-251. 


\section{Determinants of vegetation patterns in the dry woodland savanna of northeastern Namibia}

Heikkila, T.V., Gronqvist, R. \& Jurvelius, M. 1993. Handbook on Forest Fire Control: a guide for trainers. Forestry Training Programme publication 21, National Board of Education, Helsinki, Finland, ISBN 951-47-7459-0.

Helgren, D.M. 1982. Edaphic Context of the "Mongongo" (Ricinodendron rautanenii) in the Northwestern Kalahari. South African Journal of Science 78:131-132.

Knoop, W.T. 1982. Interactions of Herbaceous and Woody Vegetation in Two Savanna Communities at Nylsvley. M.Sc. Thesis. University of the Witwatersrand, South Africa.

Kotzé, J.C. 1968. Die Kuanyama van Ovamboland, Suidwes-Afrika, 'n studie van Waarde-Opvattinge. Master's Thesis, University of Stellenbosch, South Africa.

Lawton, R.M. 1978: A study of the dynamic ecology of Zambian Vegetation. Journal of Ecology 66:175-198.

Leger, S. 1997. The hidden gift of nature. DED/German Development Service. Berlin, Germany.

Li C., Corns, I.G.W. \& Yang, R.C. 1999. Fire frequency and size distribution under natural conditions: a new hypothesis. Landscape Ecology 14: $533-542$.

Lusepani, E., Tjaveondja, L. \& Tuomasjukka, T. 1998. Proceedings of the Bushmanland Forest Conservation Workshop. Namibia Finland Forestry Programme, Directorate of Forestry, Republic of Windhoek.

Malaisse, F., Freson, R., Goffinet, G. \& Malaisse-Mousset, M. 1975. Litter Fall and Litter Breakdown in Miombo. In F. Golley \& E. Medina (Eds). Tropical Ecological Systems. Trends in Terrestrial and Aquatic Research. Springer Verlag, New-York; Ecological Studies 11:137-152.

Mendelsohn, J. \& Roberts, C. 1997. An Environmental Profile and Atlas of Caprivi. Directorate of Environmental Affairs, Windhoek, Namibia. ISBN 0-86976-408-X.

Mendelsohn, J., Jarvis, A., Roberts, C. \& Robertson, T. 2002. Atlas of Namibia, A portrait of the land and its people. David Philip Publishers, Cape Town, South Africa.

Mitlöhner, R. 1997. Pflanzeninterne Potentiale als Indikatoren für den tropischen Standort. Shaker Verlag. NFSP 1996. Namibia Forestry Strategic Plan. Directorate of Forestry, Windhoek, Republic of Namibia. Ollikainen, T. 1992. Study on Wood Consumption in Namibia. Directorate of Forestry, Windhoek, Republic of Namibia. 
Peterson, G.D. 2002. Contagious Disturbance, Ecological Memory, and the Emergence of Landscape Pattern. Ecosystems 5:329-338

Rutherford, M.C. 1975. Aspects of Ecosystem Function in a Woodland Savanna in South West Africa. PhD thesis, University of Stellenbosch, South Africa. $261 \mathrm{p}$.

Rutherford, M.C. 1981. Survival, regeneration and leaf biomass changes in woody plants following spring burns in Burkea africana-Ochna pulchra Savanna. Bothalia 13(3\&4) 531-552.

Savory, A. \& Butterfield, J. 1999. Holistic Management, 2nd edition. Island Press, Washington DC.

Scholes, R.J. \& Walker, B.H. 1993. An African Savanna, Synthesis of the Nylsvley Study. Cambridge University Press, UK.

Shackleton, C.M. 1993. Demography and dynamics of the dominant woody species in a communal and protected area of the eastern Transvaal Lowveld. South African Journal of Botany 59(6):569-574.

Shackleton, C.M. 2002. Growth patterns of Pterocarpus angolensis in savannas of the South African lowveld. Forest Ecology and Management 166:85-97.

Siegfried, W.R. 1981. The incidence of veld-fire in the Etosha National Par, 1970 to 1979. Madoqua 12:225-230.

Smith, T.M. \& Grant, K. 1986. The role of Competition in the Spacing of Trees in a Burkea africana-Terminalia sericea Savanna. Biotropica 18:219-223.

Tainton, N. 1999. Veld Management in South Africa. University of Natal Press, Pietermaritzburg, South Africa.

Trapnell, C.G. 1959. Ecological results of woodland burning experiments in Northern Rhodesia. Journal of Ecology 49:129-168.

Trigg, S. 1998. Fire Scar Mapping in Northern Namibia. Unpublished report. Namibia Finland Forestry Programme. Directorate of Forestry, Windhoek, Republic of Namibia.

Trollope, W.S.W. 1981. Recommended Terms, Definitions and Units to be used in Fire Ecology in South Africa. Proc. Grassld. Soc. Sth. Afr. 16:107-109.

Trollope, W.S.W. 1982. Ecological Effects of Fire in South African Savannas. In B.J. Huntley \& B.H. Walker (eds). Ecology of Tropical Savannas, Springer Verlag Heidelberg-New York, Ecological Studies 42:292-306 


\section{Determinants of vegetation patterns in the dry woodland savanna of northeastern Namibia}

Tuomasjukka, T., Tjaveondja, L. \& Tubalele, M. 1998. Proceedings of the 'Kavango forest conservation workshop'. Namibia Finland Forestry Programme, Directorate of Forestry, Windhoek, Republic of Namibia. Van Heist, M. \& Kooiman, A. 1992. Modelling fuelwood availability with GIS: a case study in Botswana. ITC Journal 3:277-284.

Vedder, H. 1923. Die Bergdama, Teil 1. Reihe B. Völkerkunde, Kulturgeschichte und Sprachenn, Band 7. Abhandlungen aus dem Gebiet der Auslandskunde, Band 11. University of Hamburg, Germany.

Vedder, H. 1928. The Berg Damara, IN The Native Tribes of South West Africa. Cape Times Ltd. Cape Town, South Africa. Verlinden, A. in prep. Long term fire scar monitoring with remote sensing in Northern Namibia: Relations between fire frequency, rainfall, land cover, fire management and trees.

Vermeulen, W.J. 1990. A monograph on Pterocarpus angolensis. SARCCUS Standing Committee for Forestry; Pretoria, South Africa.

Von Breitenbach, F. 1968. Long-term Plan of Forestry Development in the Eastern Caprivi Zipfel. Department of Forestry, Indigenous Forest Office, Saasveld, South Africa.

Werger, M.J.A. \& Coetzee, B.J. 1978. The Sudano-Zambezian region. IN Werger M.J.A. (ed). Biogeography and Ecology of Southern Africa. Dr. W. Junk bv. Publishers, The Hague.

Walker, B.H., Stone, L., Henderson, L. \& Vernede, M. 1986. Size structure analysis of the dominant trees in a South African savanna. S. Afr. J. Botany 52(5):397-402.

Wandres, C. 1909. über das Recht der Daman und Bergdaman. Zeitschrift für Kolonialpolitik, Kolonialrecht und Kolonialwirtschaft.

Wilson, B.G. \& Witkowski E.T.F. 2003. Seed banks, bark thickness and change in age and size structure (1978-1999) of the African Savanna tree, Burkea africana. Plant Ecology 167:151-162.

Wolfson, M.M. 1999. .The response of forage plants to defoliation: Grasses. IN Tainton N. (ed) Veld Management in South Africa. University of Natal Press, Pietermaritzburg, South Africa.

Wolfson, M.M. \& Tainton, N. 1999. The morphology and physiology of major forage plants: Grasses. IN Tainton N. (ed) Veld Management in South Africa. University of Natal Press, Pietermaritzburg, South Africa. Yeaton, R.I. 1988. Porcupines, Fires and the Dynamics of the Tree Layer of the Burkea africana Savanna. Journal of Ecology 76:1017-1029 


\section{E. Application of a Stem Number Guide Curve for sustainable harvest control in the dry woodland savanna of northern Namibia}

Graz, F.P. \& von Gadow, K. submitted. Application of a Stem Number Guide Curve for sustainable harvest control in the dry woodland savanna of northern Namibia.

\section{Abstract}

The savanna woodlands of north-eastern Namibia are a significant source of essential resources for the rural population. Thus far, however, there is little or no growth data available to predict future timber supplies and current yield regulation is limited to the issuing of harvesting permits based on the assessment of available tree sizes, rather than a tree population as a whole.

This paper presents the negative exponential function for the development of a guide curve. The curve defines an optimum stand structure based on desired timber yields for specific tree sizes, the intrinsic mortality rates of individual species and the total desirable stocking of a stand. The application of the approach is assessed using the size class distributions of two prominent tree species of the Kanovlei area in north-eastern Namibia. While the function models the development of the populations of the species well, timber and non-timber trees will need to be modelled separately. 


\section{E. Application of a Stem Number Guide Curve for sustainable harvest control in the dry woodland savanna of northern Namibia}

Keywords Savanna woodlands, stem number, negative exponential function, guide curve, Pterocarpus angolensis, Burkea africana.

\section{E.1. Introduction}

The dry woodland savannas of northern-eastern Namibia represent an important resource for the local population. Not only do the woodlands provide land for grazing, food, medicine and firewood, but also form the primary source of wood for the building of traditional homes, for fencing and for the carving industry (Namibia Forestry Strategic Plan 1996).

The total amount of sawtimber harvested in 1990 amounted to around $5700 \mathrm{~m}^{3}$ to produce approximately $3100 \mathrm{~m}^{3}$ of sawn wood (Ollikainen 1992). Charcoal is not produced.

While the report by Ollikainen (1992) does not cover the consumption of wood by the carving industry, the volumes of timber used by this sector are substantial. It is doubtful that current levels of exploitation from the woodlands are sustainable, although no data is available to validate this. Casual observations in 1994 and 2004 indicate, however, that the carving industry now includes that of Pterocarpus angolensis, Guibourtia coleosperma, Schinziophyton rautanenii, Baikiaea plurijuga and some Combretum species, while in the past, $P$. angolensis had been used almost exclusively.

In the past, a number of concessions had been given for the exploitation of $P$. angolensis and B. plurijuga. Concession holders were allocated a given area in which they might cut any $P$. angolensis tree with a dbh larger than $45 \mathrm{~cm}$ or B. plurijuga larger than $32 \mathrm{~cm}$.

At present all timber-harvesting concessions have been discontinued due to a general perception of overutilization rather than specific data. Permits are, however, still issued for the small-scale exploitation of $P$. angolensis using the $45 \mathrm{~cm}$ minimum dbh limit, but restricting permits to 5 trees per applicant per year. Granting or rejecting a permit application is generally at the discretion of the inspecting officer who primarily assesses the availability of the requested trees and sizes, rather than the tree population as a whole.

Although B. africana is not harvested commercially it is frequently used for the construction of traditional houses, fencing posts or firewood, and no minimum dbh is specified. 
Currently there is little or no growth data available in Namibia on which to base a more appropriate yield regulation system (Hangula 1999). This lack of information has particularly strong implications for the more popular species, such as P. angolensis, Burkea africana and Baikiaea plurijuga.

Using published figures from other areas is not a reliable solution. Consider for example that $P$. angolensis is said to have a diameter growth of approximately $0.5 \mathrm{~mm}$ per year in Tanzania (Schwarz et al. 2002), 2.6-3.9mm per year in Zimbabwe (Stahle et al.1999) and 2.0$7.5 \mathrm{~mm}$ in South Africa (Shackleton 2002). All these areas have a higher rainfall and can therefore expect higher growth rates than in Namibia as diameter growth seems to be linked to rainfall (Stahle et al. 1999). Also, none of the authors specify stand density. This parameter is important, however, since $P$. angolensis is sensitive to competitions.

Optimally, a system is required that uses age or size structures to determine the quantity of timber that may be extracted from a given age or size class within a particular forest over a specified period of time (see Gadow \& Bredenkamp 1992).

In Namibia a yield regulation system needs to address or cope with a number of additional issues. Some of these had previously already been identified by Seydack et al (1990) for consideration in the Kneysna forests of South Africa, and include the following:

- The different woodland species have different recruitment strategies and requirements that need to be considered.

- Trees are cut to serve a variety of uses. The required diameters differ between species and uses.

- The cutting of trees may not kill the tree but reduce it to a coppicing stump that has the potential to develop into an adult tree.

- The woodlands need to maintain a continuous cover with the removed trees replaced by natural regeneration as far as possible to minimize cost of establishment.

- The system needs to be simple to implement in the field. Namibia is in the process of establishing a series of community forests that are to be managed by members of the communities. While management planning, including yield regulation, is assisted by the 


\section{E. Application of a Stem Number Guide Curve for sustainable harvest control in the dry woodland savanna of northern Namibia}

forestry authorities the implementation of management is left to the communities.

Seydack et al. (1990) and Seydack (1995) describe criteria and implementation of a mortality pre-emption approach to the calculation of harvesting levels and the selection of individual timber trees in the Knysna forests. Here, harvesting levels are established as a function of the ingrowth. While the system accommodates a number of the difficulties named above, it cannot be implemented here due to the lack of necessary data.

The above restrictions and issues may also be addressed through the application of a stem-number guide curve that specifies the distribution of trees among specific size classes for an uneven-aged forest or woodland, and based either on a prerequisite stocking or stand basal area. This distribution represents an idealized stand structure in terms of stem numbers, basal area or volume (Cancino \& Gadow 2002), and is affected by the mix of timber size classes that are ultimately desired, as well as the natural mortality of trees within the stand.

Decisions on exploitation may be made by comparing the actual number of stems within the various size classes with the ideal distribution; the trees that are in excess within the size classes may be removed (Gadow \& Puumalainen 2000). The selection of individual trees may then follow the mortality pre-emption approach similar to that described by Seydack (1995).

The most prominent approach to model stand development in the literature uses a Markow type model similar to the Gentan model described by Suzuki (1983). The model multiplies the size or age class distribution with a set of survival probabilities to establish distribution for the next time interval. The approach permits the modeller to exercise control over the development of stems from one age or size class to the next independently of all other classes.

Desmet et al. (1996) had attempted to use the stable state distribution that results from numerous iterations of such a model to guide harvesting regulation but found the model to be inadequate. Schwartz et al. (2002) had a similar lack of success with their model for a Tanzanian population. Childes (1984) investigated the application of the model using growth stages of $B$. plurijuga rather than a size class distribution, but was not able to generate satisfactory results. 
A considerable drawback of the technique is the amount of data required for the construction of the transition matrix. This is exasperated by the fact that growth rates may change due to changes in environmental conditions. Strictly speaking, therefore, a series of transition matrixes would be required to represent multiple growing conditions, and would require significantly greater amounts of data.

A further difficulty rests with the necessity to estimate fecundity within each age class. Fruit and seed production are, however, often linked to rainfall, tree size or fire history. (see Rutherford 1982, Vermeulen 1990, Shackleton 2002, Graz 2002, and Wilson \& Witkowski 2003).

This paper investigates the potential of the negative exponential function for the development of a stem number guide curve in order to determine sustainable harvesting quotas.

\section{E.2. The Inverse Exponential Function}

The inverse exponential function follows an inverse-J shape and may be used to follow the survival of trees through a series of size or age classes Cancino \& Gadow (2002). The function models a consistent decline of a large number of small diameter trees as they progress through a series of consecutive size classes. This decline is assumed to be a result of natural mortality so that an allowable cut may be determined as the number of trees in excess of the modelled class minimum. The negative exponential curve that has the general form:

$$
N_{i}=k_{0} \cdot e^{-k_{1} d_{i}}
$$

where $N_{i}$ is the number of trees in size class $i, k_{0}$ is the intercept with the y-axis, $k_{1}$ determines the rate of change, and $d_{i}$ is the diameter class midpoint of class $i$. Note that here $i$ is followed in reverse, i.e. from high value to 1 , in contrast to the more conventional approach regarding index values. This reversal simplifies the calculation of the final distribution, as will become more evident later. The distribution will therefore increase from the larger size classes towards the smaller diameters at a constant rate, $q$, that may be calculated as: 


$$
q=\frac{N_{i+1}}{N_{i}}
$$

Since $i$ is considered from largest to smallest diameter class, $N_{i+1}$ is the number of trees in the next smaller dbh class after $N_{i}$. The inverse of $q$, ie. $q^{-1}$ represents the survival of trees from one size class to the next larger one.

To illustrate this, consider the following. In a stand $75 \%$ of trees survive from a size-class to the next larger one. Therefore $q^{-1}=0.75$ and $q=1.333$. Since the value of $q$ does not change it is possible to determine a theoretical distribution of dbh values, given an initial number of trees in the largest size class. A value of $q>1$ means that stem numbers increase between successive size classes. While a value of $q=0$ implies that no change takes place.

Figure E.1 depicts the dbh-class distributions determined using two different values of $q$. The first distribution, Figure E.1a, was obtained with $q=1.2$ while the second, E.1b, uses $q=1.3$, with the other parameters unchanged. From the figure it is evident that the distribution is quite sensitive to the magnitude of $q$.

The diameter distribution is, however, not only determined by the value of $q$, but also by the number of diameter classes that comprise the distribution, which depends on the diameter class width, $h$. The relationship between $q$ and $h$ is given by:

$$
q=e^{k_{1} h}
$$

It is important to maintain this relationship in order to retain a consistent stocking rate for different diameter-class distributions obtained from different values of $q$ or $h$. (for an explicit derivation see Cancino \& Gadow 2002).

In order to determine a specific number of trees in the largest diameter class, $N_{1}$, Cancino \& Gadow (2002) identify a maximum diameter, $D$, beyond which trees would not develop. Given $N_{1}$, we may calculate the number of trees in any size class, $i$, as:

$$
N_{i}=N_{1} \cdot q^{i-1}, \quad \text { where } \quad 1 \leq i \leq(D / h)
$$

Although fractions may be inserted into equation E.4 $h$ should be 


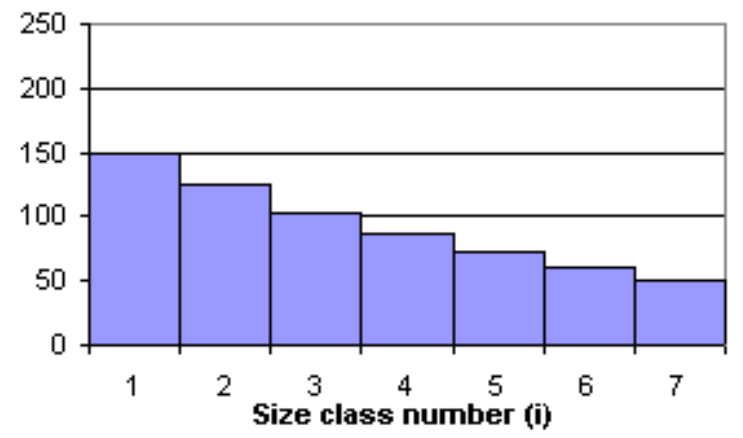

(a)

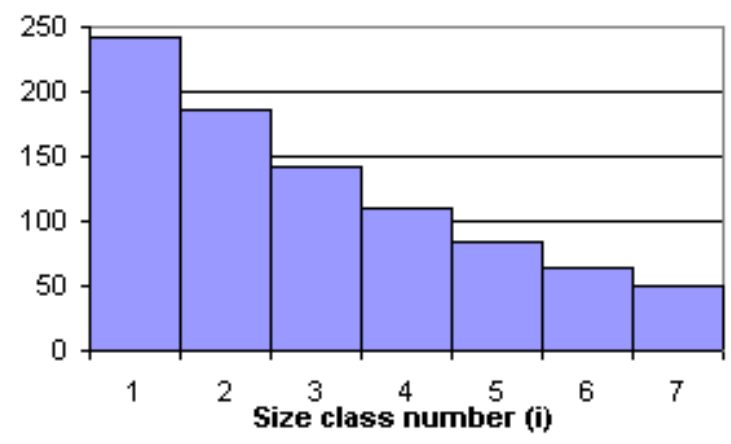

(b)

Figure E.1.: The graphs show the hypothetical dbh-class distribution of two stands, with (a) $q=1.2$; and (b) $q=1.3$ 


\section{E. Application of a Stem Number Guide Curve for sustainable harvest control in the dry woodland savanna of northern Namibia}

chosen in such a way that an integer value is obtained to ease the interpretation of the results.

The diameter class distribution obtained with equation E.4 would remain sustainable if only the excess trees in each of the diameter classes are cut, and that regeneration is consistent. The value of $q$ may be chosen at the inherent survival rate of the species, or higher.

For example, by specifying that 20 trees need to survive to the maximum diameter of $50 \mathrm{~cm}$, using a class width of $5 \mathrm{~cm}$ and a rate of change of $q=1.25$ we obtain the diameter class distribution provided in Figure E.2.

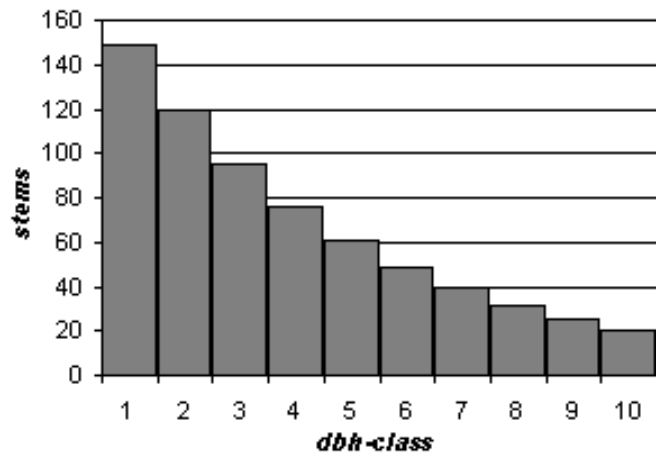

Figure E.2.: The distribution of trees in $10 \mathrm{dbh}$-classes that represent a sustainable population given the maximum diameter size, the number of diameter classes and the annual rate of reduction.

As an alternative to stipulating a final number of trees in the largest diameter class, it is possible to specify a total growing stock, $G$, or total basal area, $B$, for a specific stand.

Given values for $q$ and $G$ equation E.5 may be used to determine the trees required in diameter class 1 , while the remainder of the diameter class distribution would be calculated using equation E.4.

$$
N_{1}=\frac{G}{\sum_{i=1}^{n} q^{i-1}}
$$


Using a stand basal area, $B$, that is based on the dbh-class midpoints:

$$
B=k_{2} \sum_{i=1}^{n} N_{i} \cdot d_{i}^{2}
$$

where $k_{2}=\pi / 40000^{1}$. Replacing $N_{i}$ with equation E.4 and solving for $N_{1}$ we obtain:

$$
N_{1}=\frac{B}{k_{3}}
$$

where:

$$
k_{3}=k_{2} \sum_{i=1}^{n} q^{(i-1) \cdot d_{i}^{2}}
$$

(See Cancino \& Gadow (2002) for a full proof of their equations.)

The parameter $k_{3}$ is also affected by the number of dbh-classes and plays a key role in the calculation of the distribution. $k_{3}$ must therefore also be recalculated if $h$ is changed.

When dbh-class distributions are determined for a given stand basal area, but different values of $h$, it is important to note that different stocking rates may nevertheless be calculated. This is because the basal area is determined using the class midpoint only, disregarding the variations of diameters within each class.

Where the function is used to target larger or smaller diameters it is tempting to manipulate the value of $q$. The parameter must, however, not only be considered in terms of the mathematical ease with which the guide curve can be manipulated, but also in terms of the biological interpretation and subsequent implications. While it is always permissible to use a value of $q$ higher than that resulting from the intrinsic mortality rate of a species, the value may not be set lower since this would imply improved survival. This can, of course, not be guaranteed.

It is more appropriate to consider the manipulation of $D$ and $G$ or $B$, when calculating the guide curve. A reduction in $D$ and $B$ for example provides for a higher allowable cut in the smaller dbh-classes (given that regeneration is unchanged), as shown in Figure E.3.

When determining a relatively small maximum diameter it must be remembered that a certain number of seed trees / habitat trees must

\footnotetext{
${ }^{1} k_{2}$ converts the diameter in $\mathrm{cm}$ to an equivalent basal area in $\mathrm{m}^{2}$ per hectare.
} 


\section{E. Application of a Stem Number Guide Curve for sustainable harvest control in the dry woodland savanna of northern Namibia}

remain. The minimum number of trees needed differs between species and needs to be established in terms of seed production per tree and the viability of the seed.

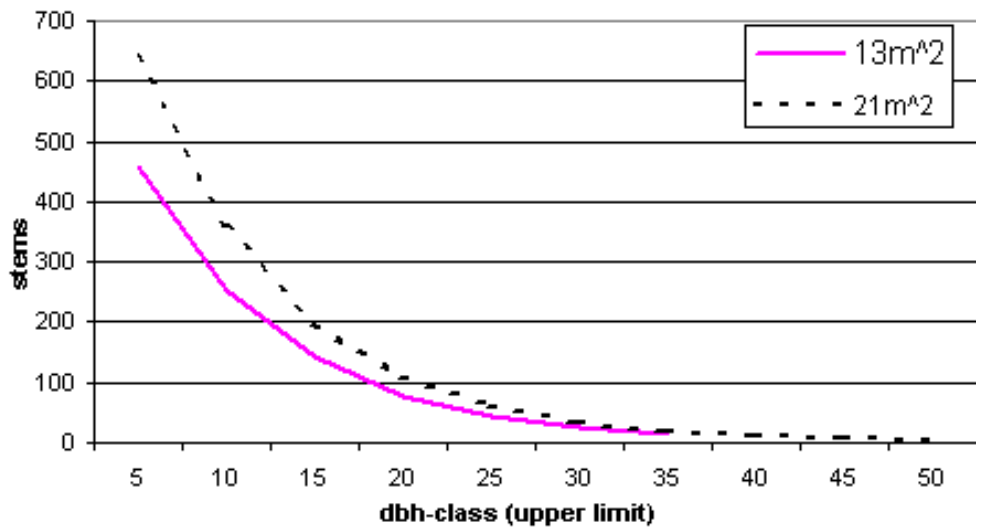

Figure E.3.: Guide curves for a tree species using $B=21 \mathrm{~m}^{2}$ with $D=50 \mathrm{~cm}$, and $B=13 \mathrm{~m}^{2}$ with $D=35 \mathrm{~cm}$. The value of $q=1.8$ remained constant. 


\section{E.3. Application and Interpretation}

Before a stem number guide curve is implemented it is necessary to determine whether or not the model adequately describes the stand structure or its development.

To do so let us consider the dbh-class distribution presented in Figure E.4. The figure depicts the diameter distribution of a savanna woodland stand of 11.8 ha in northeastern Namibia, with the line graph indicating the negative exponential curve using $N_{1}=10$ and $q=1.63$ in equation E.4.

The trees with a dbh of less than $15 \mathrm{~cm}$ are comprised to $64 \%$ of regeneration of $P$. angolensis, B. africana and $S$. rautanenii, and a further $33 \%$ of species of the genus Combretum that does not contribute to utilizable timber in this region.

Although it is clear that there is a very large difference in actual and expected stem numbers in the second and third dbh-classes, a Chi-square analysis indicates that the negative exponential curve nevertheless describes the distribution quite well $(p=0.188)$ if the two classes are not considered.

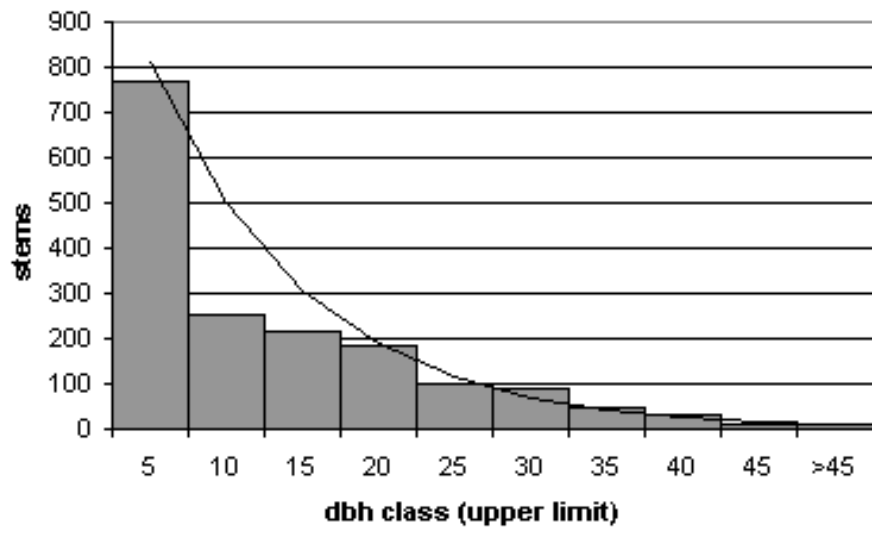

Figure E.4.: Diameter-class distribution of woody plants in a woodland stand near Kanovlei, Namibia (bars), and the hypothetical distribution with $N_{1}=10$, and $q=1.63$ 


\section{E. Application of a Stem Number Guide Curve for sustainable harvest control in the dry woodland savanna of northern Namibia}

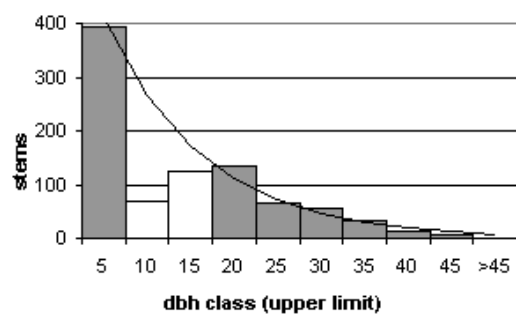

(a)

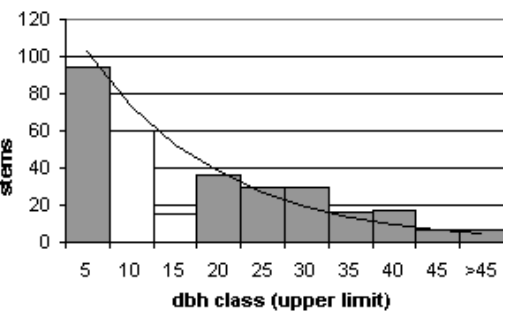

(b)

Figure E.5.: The dbh-class distributions (bars) and the best fitting negative exponential curves of (a) Burkea africana, with $q=1.55(p=0.006)$; and (b) Pterocarpus angolensis, with $q=1.31(p=0.749)$ ignoring the poor fit of classes two and three in each case.

Since not all species are used in the same way, it is necessary to consider the application of the model for individual species. Figure E.5 shows the diameter distribution of B. africana (E.5a) and P. angolensis (E.5b) within the above stand. The distribution of $P$. angolensis in Figure E.5a is very similar to that found by Schackleton (2002) at Bushbuckridge Nature Reserve in South Africa.

The figure E.6 shows that the model describes the $P$. angolensis diameter distribution quite well $(p=0.749)$, again ignoring the second and third size classes. B. africana, on the other hand, is very poorly explained $(p=0.006)$ under the same conditions. The description of the distribution of $B$. africana is significantly improved $(p=0.135)$ if only the seven size classes larger than $20 \mathrm{~cm}$ are used. Consider that a nearby community utilizes the smaller size classes for firewood and building material, as these trees are easier to handle than larger trunks. This was evident from a number of stumps observed in the field. The counts in the smaller size classes are therefore not always reliable.

\section{E.4. Implementation of the curve}

In view of the above, the inverse exponential curve can nevertheless be used to describe stand development in a way that mimics natural mor- 
tality patterns, despite the difficulties concerning individual size classes.

Since the required timber sizes for the two above species differ, they will require different curves to describe mortality rates and residual stocking. The guide curve for B. africana, for example, needs to target the smaller size classes, while that of $P$. angolensis must provide for a greater number of larger trees. This concept must be developed further, however. A number of species do not contribute to timber production bur rather serve different purposes. Trees or species may therefore be grouped as follows:

\section{Class I: Principal timber species}

The class includes all the reproductive stages of the principal timber species in the form of seedlings, suffrutex or coppice, as well as saplings, immature and mature trees. While some species considered in this class may also have medicinal uses, they are primarily timber producers.

\section{Class II: Non-timber trees}

Trees that produce edible fruit, browse for domestic stock or those which provide other products used for medicinal purposes, but are not harvested for their timber.

\section{Class III: Dead trees}

Trees that have died through fire, fungal attack or other cause and are unable to coppice.

The trees in the data set falling into class II also show the inverse$\mathrm{J}$ development curve, as shown in Figure E.6. While the contribution of the non-timber trees seems very low in this stand, unpublished data shows that their number may exceed the timber trees by far.

Despite the predictability of tree mortality itself, the number of dead trees at a given time cannot always be predetermined accurately, as these trees may quickly be reduced to ashes once they have actually fallen over. Although the mathematics themselves are comparatively simple, some difficulty may be experienced with the estimation of the required parameters. This is particularly so in the light of the absence of background information.

Perhaps the most difficult parameter to estimate is $q$. This is not only the case under Namibian conditions, but was identified by Gadow 


\section{E. Application of a Stem Number Guide Curve for sustainable harvest control in the dry woodland savanna of northern Namibia}

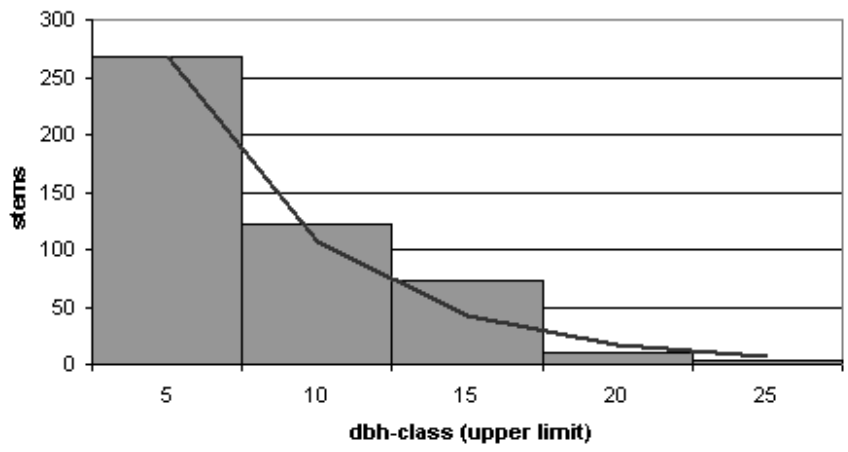

Figure E.6.: Diameter class distribution of non-timber trees in Kanovlei and the stem-number guide curve based on $q=2.5$ and $B=3$.

\& Puumalainen (2000) as a general concern; there is no hard-and-fast rule that can be applied to determine $q$. However, the two authors also show that there is a wide range of diameter distributions that are stable. It is necessary to keep in mind that mortality in the small size classes is very high, particularly as a result of fire. Although larger trees have a higher fire tolerance, they may also be damaged or killed, particularly if the bark of trees has been damaged either by animals (see Yeaton 1988, Shackleton 2002) or growth stresses (Graz 2003).

A relatively high value of $q$ may therefore have to be chosen to make allowance for the fast initial decline. It should be borne in mind that the structure of the tree population is a reflection of the historical influences that have enacted on it; $q$ is therefore reflected in the current structures evaluated above.

During the initial phases of implementation smaller and therefore a greater number of diameter classes could be used. This will provide managers with a more detailed insight into population structure and development. If diameter classes are wide problems within a class may be masked.

Various enumerations indicate that stem numbers of trees larger than $5 \mathrm{~cm}$ dbh amount to around 100 to 200 stems per hectare (Korhonen et al 1997a, Korhonen et al 1997b, unpublished data). While these 
figures may seem very low, they reflect the carrying capacity, in terms of available water and nutrients, that the area may support, and should be used as guidelines.

\section{E.5. Conclusion}

The stem number guide curve described above serves the same purpose as the normal forest concept for plantation forestry as already described by Brasnett (1954). Both approaches describe an ideal structure that managers may strive towards but would never attain.

The negative exponential function adequately describes the natural mortality patterns of the species considered here. It may therefore be used to define a dbh-class distribution that is sustainable given current mortality rates.

In the almost total absence of growth data in Namibia, the stem number guide curve provides a means of establishing periodic harvesting levels that will ensure sustainability. Implementation will require, however, that conditions are suitable for the regeneration of the individual species, and may require the maintenance of a disturbance regime.

\section{E.6. Acknowledgements}

Dr. L. Palmer, Utah Valley State College, for her advice and willingness to act as "sounding board" for the interpretation of the equations.

\section{E.7. References}

Brasnett, N.V. 1953. Planned Management of Forests. George Allen and Unwin. London.

Cancino, J. \& Gadow, K. v. 2002. Stem Number Guide Curves for Uneven-aged Forests: Development and Limitations. In: Gadow, K. v., Nagel, J. \& Saborowski, J., 2002: Continuous Cover Forestry - Assessment, Analysis, Scenarios. Kluwer Academic Publishers: 163-174.

Childes, S.L. 1984. The population dynamics of some woody species in the Kalahari sand vegetation of the Hwange National Park. M.Sc. Thesis, Univ. of the Witwatersrand, South Africa. 


\section{E. Application of a Stem Number Guide Curve for sustainable harvest control in the dry woodland savanna of northern Namibia}

Desmet, P.G., Shackleton, C.M. \& Robinson, E.R. 1996. The population dynamics and life-history attributes of a Pterocarpus angolensis DC. Population in the Northern Province, South Africa. S. Afr. J. Bot. 62(3):160-166.

Gadow, K.v. \& Bredenkamp, B. 1992. Forest Management. Academica, Pretoria, South Africa.

Gadow, K.v. \& Puumalainen, J. 2000. Scenario Planning for Sustainable Forest Management. In: Gadow, K.v., Pukkala, T. \& Tomé, M. 2000. Sustainable Forest Management. Kluwer Academic Publisher, Dordrecht: 319-356.

Graz, F.P. 1996. Management of a Pterocarpus angolensis population under the influence of fire and land use. M.Sc. Thesis, University of Stellenbosch. Stellenbosch, South Africa.

Graz, F.P. 2002. Description and Ecology of Schinziphyton rautanenii (Schinz) Radcl.-Sm. In Namibia. Dinteria 27:19-35.

Graz, F.P. 2003. Fire damage to Schinziophyton rautanenii (Schinz) trees in North-Eastern Namibia. Dinteria 28:39-43.

Hangula, R.J.K. 1999. The present status of growth and yield data in Namibia. IN Pukkala T. \& Eerikäinen (ed). Growth and Yield Modelling of Tree Plantations in South and East Africa. Proceedings of the meeting in Mombasa, Kenya 12-15 October, 1999. Tiedonantoja 97:21-30.

Korhonen, K.T., Juola, V. \& Chakanga, M. 1997a. Woody Resources of Western Tsumkwe; an inventory report. Unpublished report, Directorate of Forestry, Windhoek, Namibia.

Korhonen, K.T., Juola, V. \& Chakanga, M. 1997b. Woody Resources of East and South Tsumkwe, Otjinene and Okakarara Districts. Unpublished report, Directorate of Forestry, Windhoek, Namibia.

Namibia Forestry Strategic Plan 1996. Namibia Forestry Strategic Plan. Directorate of Forestry Windhoek, Namibia.

Ollikainen, T. 1992. Study on Wood Consumption in Namibia. Internal Report, Directorate of Forestry, Windhoek.

Rutherford, M.C. 1982. Woody Plant Biomass Distribution in Burkea africana Savannas. In Huntley B.J. \& Walker B.H. 1982. Ecology of Tropical Savannas. Ecological Studies 42. Springer Verlag.

Schwartz, M.W., Caro, T.M. \& Banda-Sakala, T. 2002. Assessing the sustaniability of harvest of Pterocarpus angolensis in Rukwa Region, Tanzania. Forest Ecology and Management 170:259-269. 
Seydack, A.H.W. 1995. An unconventional approach to timber yield regulation for multi-aged, multispecies forests. I. Fundamental considerations. Forest Ecology and Management 77:139-153.

Seydack, A.H.W., van Daalen, J.C., van Dijk, D., Reynell, D., Heyns, H., Jooste, A., Ferguson, M., Pitchford, P., Durrheim, G., \& Willems, D. 1990. Yield regulation in the Knysna Forests. South African Journal of Forestry 152:50-61.

Shackleton, C.M. 2002. Growth patterns of Pterocapurs angolensis in savannas of the South African lowveld. Forest Ecology and Management 166:85-97.

Suzuki, T. 1983. Gentan-Wahrscheinlichkeit, Vorhersagemodelle für die Entwicklung des Normalwaldes und für die Planung des Holzaufkommens. In Suzuki, T., Sloboda, B. \& Saborowski J. Beiträge zur biometrischen Modellbildung in der Forstwirtschaft. Schriften aus der Forstlichen Fakultät der Universität Göttingen 76:7-22.

Stahle, D.W., Mushove, P.T., Cleaveland, M.K., Roig, F. \& Haynes, G.A. 1999. Management implications of annual growth rings in Pterocarpus angolensis from Zimbabwe. Forest Ecology and Management 124:217-229.

Vermeulen, W.J. 1990. A monograph on Pterocarpus angolensis. SARCCUS Standing Committee for Forestry. Pretoria, South Africa.

Wilson, B.G. \& Witkowski, E.T.F. 2003. Seed banks, bark thickness and change in age and size structure (1978-1999) of the African Savanna tree, Burkea africana. Plant Ecology 167:151-162.

Yeaton, R.I. 1988. Porcupines, Fires and the Dynamics of the Tree Layer of the Burkea africana Savanna. Journal of Ecology 76:1017-1029. 

harvest control in the dry woodland savanna of northern Namibia 


\section{Bibliography}

M. Amakali. Updated Isohyetal Rainfall Map for Namibia. Department of Water Affairs, Namibia, 1992.

Anon. Consolidated Report on Reconnaissance Surveys of Soils of Northern and Central South West Africa in terms of their potential for irrigation. Technical Report TS/30/71, Department of Water Affairs, Namibia, 1971.

M. Begon, J. L. Harper, and C. R. Ecology: Individuals, Populations and Communities. Blackwell Scientific Publications, 1986.

J. Braun-Blanquet. Plant Sociology: the study of plant communities. McGraw-Hill Book Company, Inc., New York, 1932.

A. Burke. Present Vegetation in the Kavango Region. J. Nam. Sci. Soc., 50:133-145, 2002.

J. Cancino and K. von Gadow. Stem number guide curves for unevenaged forests: Development and limitations. In K. von Gadow, J. Nagel, and J. Saborowski, editors, Continuous Cover Forestry Assessment, pages 163-174. Kluwer Academic Publishers, 2002.

M. Chakanga. Forest Cover Reconnaissance Mapping Project. Directorate of Forestry, Republic of Namibia, 1995.

E. N. Chidomayo. A re-assessment of effects of fire on miombo regeneration in the Zambian Copperbelt. Journal of Tropical Ecology, 4: 361-372, 1988.

S. L. Childes. The population dynamics of some woody species in the Kalahari sand vegetation of the Hwange National Park. Univ. of the Witwatersrand, South Africa, 1984. M. Sc. Thesis. 
M. E. Coetzee. Preliminary Agroecological Zones. Agricola 1998/1999, Addendum, 1999.

M. E. Coetzee. NAMSOTER, A SOTER Database for Namibia. Agroecological Zoning Programme. Ministry of Agriculture, Water \& Rural Development, Namibia, 2001.

J. C. L. Columba. Effects of woodland fragmentation on tree diversity in the Northern Province, South Africa. Master's thesis, 2003.

S. E. Crerar and J. T. Church. Evaporation map for South West Africa/Namibia. Technical Report Hydrological Report 11/1/8/1/H1, Department of Water Affairs, Windhoek, Namibia., 1988. Hydrological Report.

E. de Pauw and M. E. Coetzee. Production of an Agroecological Zones Map of Namibia (first approximation), Part 2: Results. Agricola, 10: 8-68, 1999.

R. J. de Sousa Correira and G. J. Bredenkamp. A reconnaissance survey of the vegetation of the Kavango, South West Africa. J. SWA. Sci. Soc., 41:29-45, 1987.

G. du T. de Villiers and J. M. de Jager. Net rainfall and interception losses in a Burkea africana \& Ochna pulchra tree savanna. Water S.A., 7:249-254, 1981.

D. Edwards. A broad-scale structural classification of vegetation for practical purposes. Bothalia, 14:705-71, 1983.

H. D. Foth. Fundamentals of Soil Science. John Wiley and Sons, 8 edition, 1990.

C. J. Geldenhuys. The effect of different regimes of annual burning on two woodland communities in Kavango. South African Forestry Journal, 103:32-42, 1977a.

C. J. Geldenhuys. Management plan for Nakabunze Reserve, Eastern Caprivi. Technical Report FOR 28, Saasveld Forestry Research Centre, South Africa, 1977b. 
W. Giess. A preliminary vegetation map of Namibia (3rd revised edition). Dinteria, 4:1-112, 1998.

J. G. Goldammer. Development of a national fire policy and guidelines on fire management in Namibia. Technical report, Directorate of Forestry, Namibia, 1998. Namibia Finland Forestry Programme.

F. P. Graz. Management of a Pterocarpus angolensis population under the influence of fire and land use. University of Stellenbosch. Stellenbosch, South Africa, 1996. M. Sc. Thesis.

F. P. Graz. A preliminary terrain feature classification of the Okavango Region, Namibia. South african Journal of Surveying and GeoInformation, 1:123-129, 1999.

F. P. Graz. Fire damage to Schinziophyton rautanenii (schinz) trees in north-eastern Namibia. Dinteria, 28:39-43, 2003a.

F. P. Graz. An HTML-based concept model of the dry savanna woodland ecosystem, for teaching and learning. Conservation Ecology, 7, 2003b. URL http://www . consecol .org/vol7/iss1/art9.

F. P. Graz. The behaviour of the species mingling index $m_{s p}$ in relation to species dominance and dispersal. European Journal of Forest Research, 1:87-92, 2004a.

F. P. Graz. Description and ecology of Pterocarpus angolensis in Namibia. Dinteria, 29:27-39, 2004b.

F. P. Graz. Assessing the spatial diversity of a dry savanna woodland stand in northern Namibia using neighbourhood-based measures. Biodiversity and Conservation, in press.

F. P. Graz. Determinants of vegetation patterns in the dry woodland savanna of northeastern Namibia. submitted.

F. P. Graz and K. von Gadow. Application of a stem number guide curve for sustainable harvest control in the dry woodland savanna of northern Namibia. submitted. 
J. M. Guldin. Continuous Cover Forestry in the United States - Experience with southern pines. In K. von Gadow, J. Nagel, and J. Saborowski, editors, Proceedings of the International Conference held in Göttingen, Germany, 19-21 September 2001, 2001.

R. J. K. Hangula. The present status of growth and yield data in Namibia. In T. Pukkala and Eerikäinen, editors, Growth and yield modelling of tree plantations in South and East Africa. Proceedings of the meeting in Mombasa, Kenya 12-15 October, volume 97 of Tiedonantoja, pages 21-30, 1999.

R. C. Hare. Contribution of bark to fire resistance of southern trees. Journal of Forestry, 63:248-251, 1965.

T. V. Heikkila, R. Gronqvist, and M. Jurvelius. Handbook on Forest Fire Control: a guide for trainers. Number 21 in Forestry Training Programme publication. National Board of Education, Helsinki, Finland, 1993. ISBN 951-47-7459-0.

D. M. Helgren. Edaphic context of the Mongongo (Ricinodendron rautanenii) in the northwestern Kalahari. South African Journal of Science, 78:131-132, 1982.

W. T. Knoop. Interactions of herbaceous and woody vegetation in two savanna communities at Nylsvley. University of the Witwatersrand, South Africa, 1982. M. Sc. Thesis.

K. T. Korhonen, V. Juola, and M. Chakanga. Woody resources of east and south Tsumkwe, Otjinene and Okakarara districts. Unpublished report, Directorate of Forestry, Windhoek, Namibia, 1997a.

K. T. Korhonen, V. Juola, and M. Chakanga. Woody resources of western Tsumkwe: an inventory report. Unpublished report, Directorate of Forestry, Namibia, 1997b.

J. C. Kotze. Die Kuanyama van Ovambolan, Suidwes-Afrika, En studie van waarde-opvattinge. University of Stellenbosch, South Africa, 1968. Masters Thesis.

R. M. Lawton. A study of the dynamic ecology of Zambian vegetation. Journal of Ecology, 66:175-198, 1978. 
P. J. Le Roux. The common names and a few uses of the better known indigenous plants of South West Africa. Bulletin, Department of Forestry, South Africa, 1971.

S.A. Levin. The problem of pattern and scale in ecology. Ecology, 73: 1943-1967, 1992.

A. Lewandowski and A. Pommerening. Zur Beschreibung der Waldstruktur - erwartete und beobachtete Arten-Durchmischung. Forstw. Cbl., 116:129-139, 1997.

C. Li, I. G. W. Corns, and R. C. Yang. Fire frequency and size distribution under natural conditions: a new hypothesis. Landscape Ecology, 14:533-542, 1999.

A.E. Magurran. Ecological diversity and its measurement. Croom Helm, 1988.

F. Malaisse, R. Freson, G. Goffinet, and M. Malaisse-Mousset. Litter fall and litter breakdown in miombo. In F. Golley and E. Medina, editors, Tropical Ecological Systems. Trends in terrestrial and aquatic research, volume 11 of Ecological Studies, pages 137-152. Springer Verlag, 1975.

K. McGarigall, S. A. Cushman, M. C. Neel, and E. Ene. FRAGSTATS: Spatial pattern analysis program for categorical maps. Online, 2002. URL http://www . umass .edu/landeco/research/fragstats/ fragstats.html.

J. Mendelsohn, A. Jarvis, C. Roberts, and T. Robertson. Atlas of Namibia. A portrait of the land and its people. David Philip Publishers, Cape Town, South Africa, 2002.

R. Mitlöhner. Pflanzeninterne Potentiale als Indikatoren für den tropischen Standort. Shaker Verlag, 1997. Habilitationsschrift.

J. Newmark. Statistics and Probability in Modern Life. Sauders College Publishing, Fort Worth, 6 edition, 1997.

NFSP. Namibia Forestry Strategic Plan. Technical report, Directorate of Forestry, Namibia, 1996. 
C. R. Peters. Ricinodendron rautanenii (Euphorbiaceae): Zambezian wild food plant for all seasons. Economic Botany, 41:494-502, 1987.

G. D. Peterson. Contagious disturbance, ecological memory, and the emergence of landscape pattern. Ecosystems, 5:329-338, 2002.

H. Pretzsch. Modellierung des Waldwachstums. Parey Buchverlag, Berlin, 2001.

D. M. Roche. Biodiversity its measurement and metaphysics. University of Sydney, Australia, 2001. M.Sc. Thesis.

M. C. Rutherford. Survival, regeneration and leaf biomass changes in woody plants following spring burns in Burkea africana-Ochna pulchra savanna. Bothalia, 13:531-552, 1981.

A. Savory and J. Butterfield. Holistic Management. Island Press, Washington DC, 2 edition, 1999.

R. J. Scholes and B. H. Walker. An African savanna: Synthesis of the Nylsvley study. Cambridge University Press, 1993. M.Sc. Thesis.

M. W. Schwartz, T. M. Caro, and T. Banda-Sakala. Assessing the sustaniability of harvest of pterocarpus angolensis in rukwa region, tanzania. Forest Ecology and Management, 170:259-269, 2002.

A. H. W. Seydack. Continuous Cover Forestry Systems in tropical and subtropical forests: Current state and future perspectives. In K. von Gadow, J. Nagel, and J. Saborowski, editors, Proceedings of the International Conference held in Göttingen, Germany, 19-21 September 2001, 2001.

C. M. Shackleton. Demography and dynamics of the dominant woody species in a communal and protected area of the eastern Transvaal Lowveld. South African Journal of Botany, 59:569-574, 1993.

C. M. Shackleton. Growth patterns of Pterocarpus angolensis in savannas of the South African Lowveld. Forest Ecology and Management, 166:85-97, 2002.

W. R. Siegfried. The incidence of veld-fire in the Etosha National Park, 1970 to 1979. Madoqua, 12:225-230, 1981. 
D. W. Stahle, P. T. Mushove, M. K. Cleaveland, F. Roig, and G. A. Haynes. Management implications of annual growth rings in Pterocarpus angolensis from Zimbabwe. Forest Ecology and Management, 124:217-229, 1999.

T. Suzuki. Gentan-Wahrscheinlichkeit, Vorhersagemodelle fr die Entwicklung des Normalwaldes und für die Planung des Holzaufkommens. In T. Suzuki, B. Sloboda, and J. Saborowski, editors, Beiträge zur biometrischen Modellbildung in der Forstwirtschaft. Schriften aus der Forstlichen Fakultät der Universität Göttingen, volume 76, pages 7-22, 1983.

N. Tainton. Veld management in South Africa. University of Natal Press, Pietermaritzburg, 1999.

W. R. Teague and D. M. Killilea. The effect of ringbarking Brachystegia spiciformis Benth., Julbernardia globiflora (Benth.) troupin and Terminalia sericea Burch ex DC. trees at different heights with or without the addition of a Picloram/2,4- D mixture to the ring. J. Grassl. Soc. South Afr., 7:157-165, 1990.

C. G. Trapnell. Ecological results of woodland burning experiments in Northern Rhodesia. Journal of Ecology, 49:129-168, 1959.

S. Trigg. Fire scar mapping in northern Namibia. Unpublished report, Directorate of Forestry, Namibia, 1998. Namibia Finland Forestry Programme.

W. S. W. Trollope. Ecological effects of fire in South African savannas. In B.J. Huntley and B. H. Walker, editors, Ecology of Tropical Savannas, volume 42 of Ecological Studies, pages 292-306. Springer Verlag, 1982.

T. Tuomasjukka, L. Tjaveondja, and M. Tubalele. Proceedings of the Kavango forest conservation workshop. Technical report, Directorate of Forestry, Namibia, 1998. Namibia Finland Forestry Programme.

M.G. Turner, R. H. Gardner, and R. V. O'Neill. Landscape ecology in theory and practice. Springer Verlag, New York, 2001.

C.J. van Daalen. Germination of pterocarpus angolensis seed. South African Journal of Forestry, 158:33-36, 1991. 
N. van Rooyen. Flowering plants of the Kalahari dunes. Ecotrust, 2001. ISBN 0-620-27376-3.

W. J. Vermeulen. A monograph on Pterocarpus angolensis. Technical report, SARCCUS Standing Committee for Forestry, 1990.

F. von Breitenbach. Long-term plan of forestry development in the Eastern Caprivi Zipfel. Technical report, Department of Forestry, South Africa, 1968. Indigenous Forest Office.

K. von Gadow. Harvest scheduling in commercial timber plantations. In Research Contributions to Plantation Forestry, Festschrift in honour of Prof. A. van Laar. University of Stellenbosch, 1988.

K. von Gadow. Waldstruktur und diversität. Alg. Forst u. J.-Ztg., 170: 117-122, 1999.

K. von Gadow and B. Breedenkamp. Forest Management. Academica, South Africa, 1992. ISBN 0868744476.

K. von Gadow and H. Y. Hui. Characterizing forest spatial structure and diversity. In L. Björk, editor, Proc. of the SUFOR international workshop: Sustainable forestry in temperate regions, pages 20-30, 2002. Lund, Sweden.

B. H. Walker, L. Stone, L. Henderson, and M. Vernede. Size structure analysis of the dominant trees in a South African savanna. S. Afr. J. Botany, 52:397-402, 1986.

B.H. Walker and I. Noi-Meir. Aspects of the stability and resilience of savanna ecosystems. In B. J. Huntley and B. H. Walker, editors, Ecology of Tropical Savannas, volume 42 of Ecological Studies. Springer Verlag, 1982.

H. Walter. Natural savannas. In J. H. Burnett, editor, Ecology of tropical and subtropical vegetation. Oliver and Boyd, Edinburgh, 1971.

C. Wandres. über das recht der Daman und Bergdaman. Zeitschrift für Kolonialpolitik, Kolonialrecht und Kolonialwirtschaft, 1909. 
M. J. A. Werger and B. J. Coetzee. The Sudano-Zambezian region. In M. J. A. Werger, editor, Biogeography and Ecology of Southern Africa. Dr. W. Junk bv. Publishers, The Hague, 1978.

B. G. Wilson and E. T. F. Witkowski. Seed banks, bark thickness and change in age and size structure (1978-1999) of the African savanna tree, Burkea africana. Plant Ecology, 167:151-162, 2003.

M. M. Wolfson. The response of forage plants to defoliation: grasses. In N. Tainton, editor, Veld management in South Africa. University of Natal Press, Pietermaritzburg, South Africa, 1999.

M. M. Wolfson and N. Tainton. The morphology and physiology of major forage plants: grasses. In N. Tainton, editor, Veld management in South Africa. University of Natal Press, Pietermaritzburg, South Africa, 1999.

R. I. Yeaton. Porcupines, fires and theddynamics of the tree layer of the Burkea africana savanna. Journal of Ecology, 76:1017-1029, 1988.

J. H. Zar. Biostatistical Analysis. Prentice Hall, 1999.

E. Zenner. Eine neue Methode zur Untersuchung der Dreidimensionalität in waldbeständen. In D. R. Pelz, O. Rau, and J. Saborowski, editors, 11. Tagung Internationale Biometrische Gesellschaft Deutsche Region, Arbeitsgruppe ökologie, 1998. 


\section{Acknowledgements}

I would very much like to thank the persons listed below for their support.

First and foremost to my wife and children who had to give a lot of time, but who nevertheless gave me their support; especially when work and studies built up pressure. Also to my parents, brother and sisters for their patience.

To Prof. K. von Gadow, on whose help and support I could always rely, and who helped me stay on track.

Dr. G. Schäfer who was prepared to read the same chapters repeatedly and who provided much valuable input into style and expression.

Mr. J. Fendler who helped with the typesetting of this dissertation.

To my employer, the Polytechnic of Namibia who gave me some time to work on my studies even during office hours. I would particularly like to thank the librarians Mrs. J. Grobler, Mrs. E. Visagie und Mrs. J. Heikens for their assistance in obtaining the necessary background material.

Finally to all my friends, colleagues and acquaintances who provided much spoken and unspoken support. 
Acknowledgements

152 


\section{Eidesstattliche Erklärung}

Hiermit erkläre ich an Eides statt, dass ich die vorliegende Dissertation selbständig verfasst und keine anderen als die angegebenen Hilfsmittel und Quellen verwendet habe.

Ich habe mich noch keinem anderen Promotionsverfahren unterzogen und die Dissertation nicht in der gleichen oder anderen Fassung einer anderen Fakultät oder einem Prüfungsausschuss an einer anderen Hochschule zur Überprfung vorgelegt.

Die Promotionsordnung der Fakultät für Forstwissenschaften und Waldökologie der Georg-August-Universität Göttingen habe ich zur Kenntnis genommen.

Windhuk, Oktober 2004

Friedrich Patrick Graz 
Eidesstattliche Erklärung

154 


\section{Lebenslauf}

\section{Biografische Zusammenfassung}

Name:

Geburtsdatum:

Geburtsort:

Staatsangehörigkeit:

Alter:
Friedrich Patrick GRAZ

19. Mai 1966

Northeim

Deutsch

38

\section{Schulbildung}

1974-1976 Grundschule Westerhold, Ostfriesland, Deutschland.

1976-1978 Bonaero Park Pimary School, Bonaero Park, Südafrika.

1978-1980 Deutsche Schule Pretoria, Südafrika.

1980-1983 Sir Pierre v. Ryneveld High School, Kempton Park, Südafrika. 


\section{Akademische Ausbildung}

1984-1988 B.Sc. Forestry (Forest Management \& Nature Conservation), University of Stellenbosch, Südafrika.

1989-1989 Hons. B.Sc. Forestry (Forest Management), University of Stellenbosch, Südafrika, bei Prof. K. v. Gadow. Thema: The timber resources of South Africa.

1994-1996 M.Sc. Nature Conservation, University of Stellenbosch, Südafrika, bei Dr. H. J. v. Hensbergen. Thema: The Management of a Pterocarpus angolensis population under the influence of fire and Land Use.

2001-2004 Dissertation, an der Fakultät für Forstwissenschaften und Waldökologie, der Georg-August-Universität Göttingen, unter der Betreuung von Prof. K. v. Gadow. Thema: Structure and diversity of the dry woodland savanna of northern Namibia.

\section{Beruflicher Werdegang}

1990-1995 Directorate of Forestry, Namibia: Forestry Technician, Utilisation Officer, Entsendet zum National Remote Sensing Centre, Namibia.

1995-1998 Mondi Forest (North), South Africa: Integrated Forestry Data-Base Officer.

1998-2004 Polytechnic of Namibia: Lektor. 


\section{Publikationen}

GRAZ F.P. 1992. Forestry Germplasm in Namibia. Dinteria 23, Windhoek, Namibia

GRAZ F.P. 1999. A Preliminary Terrain Feature Classification of the Okavango Region, Namibia. South African Journal of Surveying and Geo-Information 1:123-129

GRAZ F.P. 2001. Three cotyledons on Schinziophyton rautanenii seedlings. S. Afr. J. Bot. 67:70-71

ZIMMERMANN, I., GRAZ, F.P., BERRY, M., IMASIKU, N., MUROUA, D. SIBALATANI, M. \& SIKOPO, C. 2001. Quantified range condition assessment of open Camelthorn savanna along a degradation gradient. African Journal of Range and Forage Science. $18: 1-6$

GRAZ, F.P. 2002. Description and Ecology of Schinziphyton rautanenii (Schinz) Radcl.-Sm. In Namibia. Dinteria 27:19-35

GRAZ F.P. 2003. Fire damage to Schinziophyton rautanenii (Schinz) trees in North-Eastern Namibia. Dinteria 28:39-43

GRAZ F.P. 2003. The growth of Schinziophyton rautanenii seedlings under different shade conditions. Dinteria 28:44-46

GRAZ F. P. 2003. An HTML-based concept model of the dry savanna woodland ecosystem, for teaching and learning. Conservation Ecology 7(1): 9. [online] URL: http://www.consecol.org/vol7/iss1/art9

GRAZ F.P. 2004. The behaviour of the species mingling index Msp in relation to species dominance and dispersal. European Journal of Forest Research 123:87-92

GRAZ F.P. 2004. Application of a Total Station in savannah vegetation Surveys. Dinteria 29:41-53 
GRAZ F.P. 2004. Description and Ecology of Pterocarpus angolensis in Namibia. Dinteria 29:27-39

GRAZ F.P. in press. Assessing the spatial diversity of a dry savanna woodland stand in Northern Namibia using neighbourhood-based measures. Biodiversity and Conservation

GRAZ F.P. \& von Gadow, K. submitted. Implementing stem number guide curves in the dry woodland savanna of northern Namibia

GRAZ F.P. submitted. Determinants of vegetation patterns in the dry woodland savanna of northeastern Namibia 